\title{
Máster de Investigación
}

\section{en Traducción e Interpretación}

Estudio descriptivo de la traducción para el doblaje del slang en el largometraje Jackie Brown

(Quentin Tarantino, 1997)

Curso: 2010/2011

Asignatura: SAT 013 - Trabajo de fin de máster

Autora: Ana Tamayo Masero

DNI: $16083460-\mathrm{C}$

Director: Frederic Chaume Varela 
La fotografía es verdad. Y el cine es una verdad 24 veces por segundo. Jean Luc Goddard (1930 - ), director de cine. 


\section{$\underline{\text { ÍNDICE }}$}

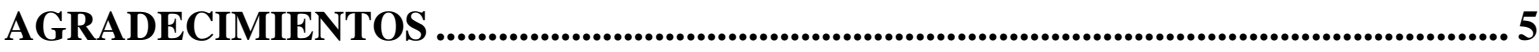

MOTIVACIÓN PERSONAL Y OBJETIVOS DEL ESTUDIO........................................ 5

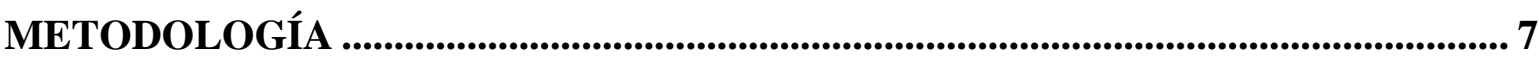

ESTRUCTURA DEL TRABAJO _................................................................................ 7

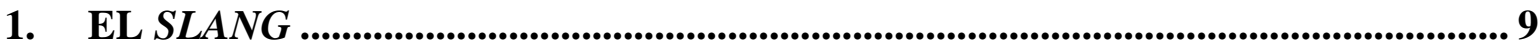

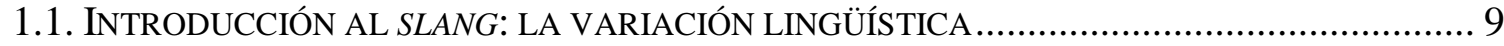

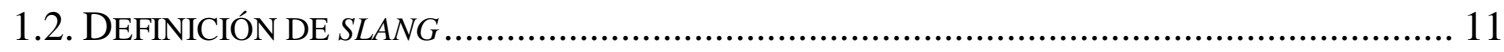

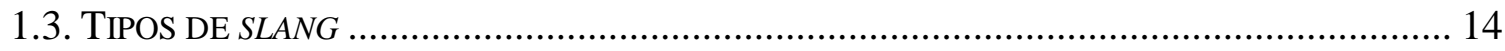

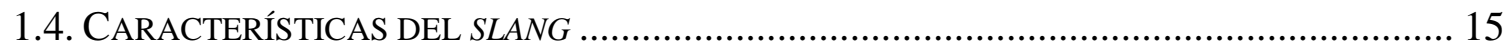

2. EL SLANG EN LOS ESTUDIOS DE TRADUCCIÓN.............................................. 19

2.1. EL SLANG DESDE LAS PERSPECTIVAS PRESCRIPTIVISTA Y DESCRIPTIVISTA .................. 19

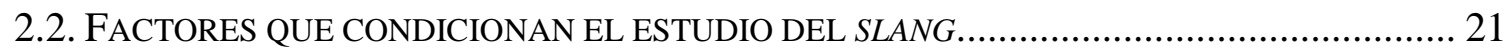

2.3. TÉCNICAS Y ESTRATEGIAS PARA LA SUPERACIÓN DE RESTRICCIONES ......................... 22

2.4. CONCLUSIONES Y REFLEXIONES DEL ESTUDIO DEL SLANG EN TRADUCCIÓN................. 24

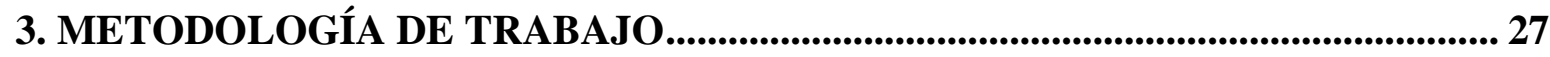

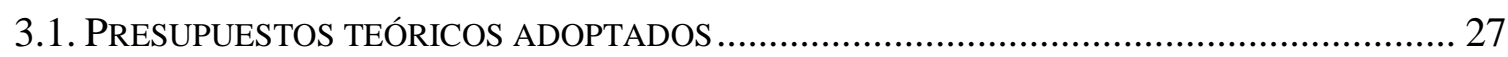

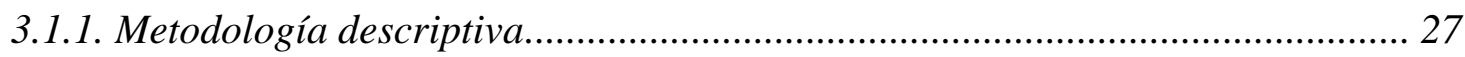

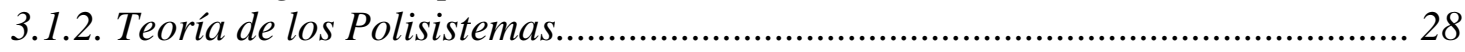

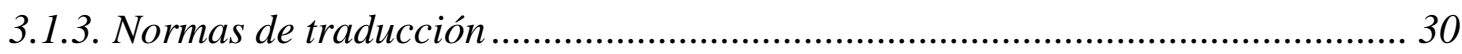

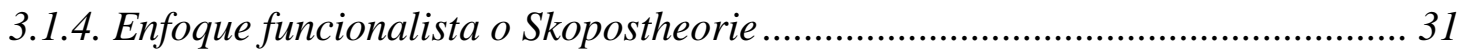

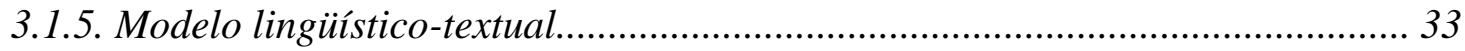

3.1.6. Modelo discursivista (análisis del discurso) o pragmático ................................. 34

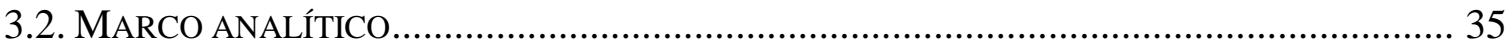

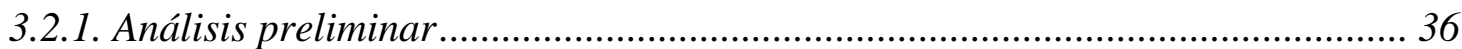

3.2.2. Análisis cuantitativo y cualitativo de los datos recopilados ................................ 37

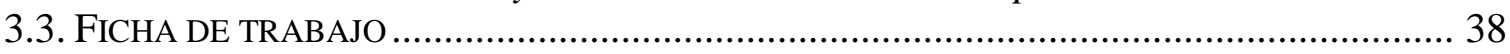

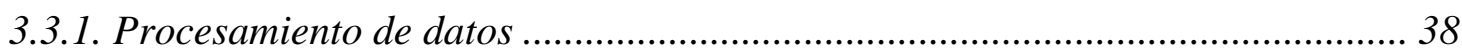

4. JUSTIFICACIÓN DEL CORPUS............................................................................ 41

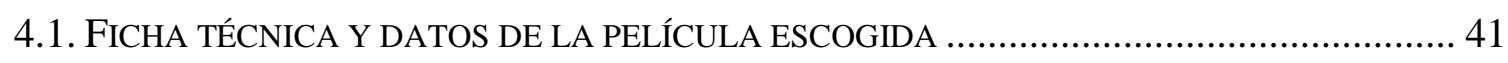

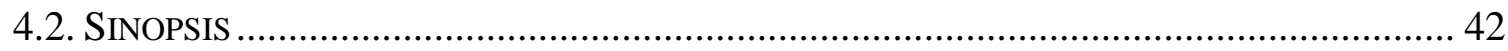

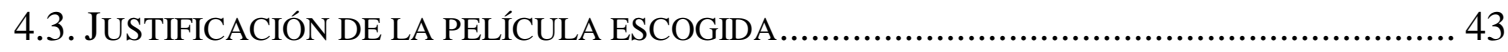

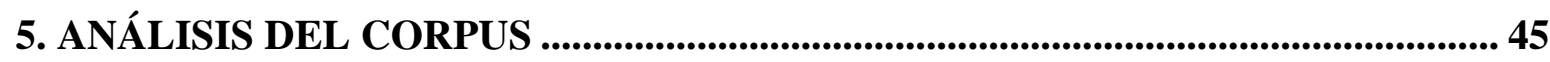

5.1. RECOPILACIÓN DE MUESTRAS Y DATOS PARA EL ANÁLISIS ….................................... 45

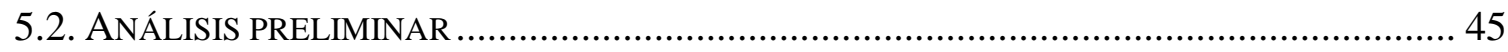


5.3. ANÁLISIS CUANTITATIVO Y CUALITATIVO DE LOS DATOS RECOPILADOS ..................... 47

5.3.1. Muestras en las que el TM presenta homofuncionalidad ............................... 47

5.3.2. Muestras en las que el TM presenta pérdida de carga pragmática................. 51

5.3.3. Muestras en las que el TM presenta carga pragmática añadida....................... 56

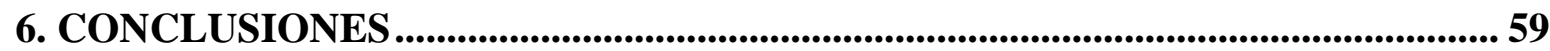

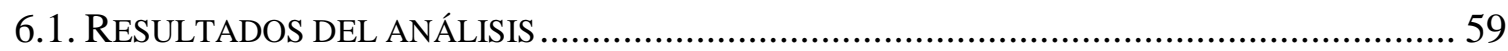

6.2. CONCLUSIONES GENERALES SOBRE LA TRADUCCIÓN DEL SLANG EN EL CORPUS ...........60

6.3. GRADO DE CUMPLIMIENTO DE LOS OBJETIVOS Y VALIDACIÓN DE HIPÓTESIS .................60

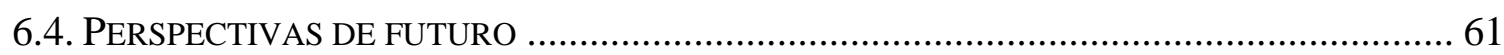

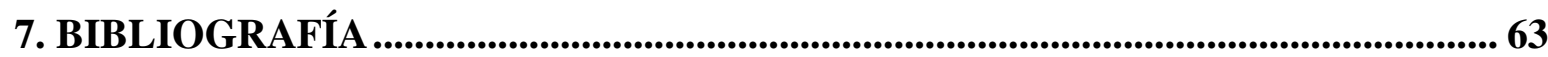

ANEXO 1: MUESTRAS DE SLANG ORIGINAL Y TRADUCIDO DE JACKIE

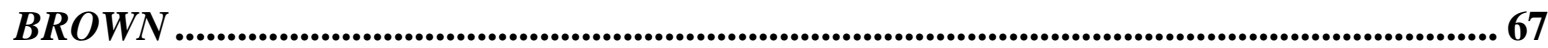

ANEXO 2: RECOPILACIÓN DE DATOS PARA SU ANÁLISIS ............................. 95

ANEXO 4: CD-ROM CON LAS VERSIONES ORIGINAL Y TRADUCIDA DEL LARGOMETRAJE Y EL TRABAJO PRESENTADO EN FORMATO DIGITAL 173

\section{$\underline{\text { ÍNDICE DE TABLAS }}$}

TABLA 1. DEFINICIONES EN ESPAÑOL DEL TÉRMINO ARGOT ........................... 12

TABLA 2. DEFINICIONES EN INGLÉS DEL TÉRMINO SLANG .............................. 13

TABLA 3. FUNCIONES Y CARACTERÍSTICAS DEL SLANG .................................. 18

TABLA 4. FICHA TÉCNICA DEL FILME JACKIE BROWN (FUENTE: THE

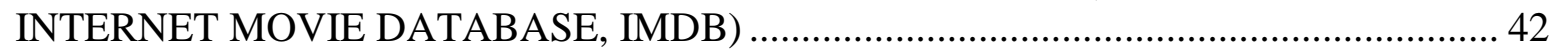

TABLA 5. MUESTRAS DE SLANG ORIGINAL Y TRADUCIDO DE JACKIE BROWN

TABLA 6. DATOS EXTRAÍDOS DE LAS MUESTRAS EN LAS QUE EL TM PRESENTA HOMOFUNCIONALIDAD

TABLA 7. DATOS EXTRAÍDOS DE LAS MUESTRAS EN LAS QUE EL TM PRESENTA PÉRDIDA DE CARGA PRAGMÁTICA. 166

TABLA 8. DATOS EXTRAÍDOS DE LAS MUESTRAS EN LAS QUE EL TM PRESENTA CARGA PRAGMÁTICA AÑADIDA 
Estudio descriptivo de la traducción para el doblaje del slang en el largometraje Jackie Brown (Quentin Tarantino, 1997)

\section{$\underline{\text { Agradecimientos }}$}

Antes de presentar mi trabajo final, me gustaría mostrar mi agradecimiento a aquellos que han hecho posible que se lleve este trabajo a cabo. Me siento enormemente agradecida a la coordinación del Máster en Investigación y Traducción, llevada a cabo por Josep Marco Borillo y Frederic Chaume Varela. Si no hubiera sido por este máster y, sobre todo, por la buena administración de las plataformas web y por el apoyo incondicional de sus coordinadores nunca me hubiera imaginado poder entrar en un mundo tan apasonante como la Traductología.

Especialmente agradecida me siento hacia Frederic Chaume, director de este TFM, que ha sabido mantenerme en calma cuando me he sentido agobiada y quien me ha permitido aprender y desarrollarme por mí misma pero siempre mostrándome su apoyo y ayuda profesional.

A todos los profesores del máster, en especial a María Calzada Pérez, quien desde que comenzara mi Licenciatura en 2004 no ha dejado de ser mi inspiración en el mundo de la traducción y la traductología. Por las horas extras que invertía en chatear con nosotros durante el máster, por saber calmar nuestros nervios, por escucharnos y, además, entendernos y, sobre todo, por hacerme sentir que en Traductología todo es tan fácil como apasionante si se enfoca adecuadamente.

A Carlos, por saber darme la alegría que a veces me falta para poder seguir adelante.

Last but not least, a mi familia, que no siempre entiende lo que hago pero siempre entiende que lo haga.

\section{Motivación personal y objetivos del estudio}

Desde que empezara la Licenciatura en Traducción e Interpretación en 2004, la traducción audiovisual (TAV) ha sido mi rama predilecta tanto en traducción como en traductología. Además, las nuevas tecnologías han permitido que el mundo se encamine hacia un punto en donde los recursos multimedia lo son todo. La cuestión de la importancia del mundo audiovisual, pues, va más allá de la traducción y la traductología.

Aún recuerdo el día que decidí que quería dedicarme a la TAV. Fue en una conferencia de Nino Matas (traductor audiovisual de, entre otros filmes, Harry Potter y El 
Estudio descriptivo de la traducción para el doblaje del slang en el largometraje Jackie Brown (Quentin Tarantino, 1997)

señor de los anillos) en el que presentó la TAV como un trabajo excitante, estimulante y, sobre todo, duro e inestable. Recuerdo que dijo algo como «si de verdad os gusta el cine, no os dediquéis a esto». Bien, pues yo soy una amante de las series (más que del cine, debo confesar) y ahora comprendo a qué se refería Nino Matas cuando me resulta prácticamente imposible ver una película, o una serie, sin preguntarme cómo se habrá traducido este gesto tan característico de esta cultura, o esta otra escena en la que hay un primer plano de la boca de tal actriz. Es ese punto desafiante lo que realmente me llena de la TAV: la necesidad de reinventar soluciones, de analizar hasta el último gesto, de entrar dentro de cada personaje y de cada idiolecto. Y ese es precisamente uno de los aspectos que más me apasiona de esta rama, el idiolecto, el slang, el argot, el acento, el deje... en definitiva, la manera de hablar que tiene cada personaje y el modo en el que se asocia a ciertas culturas, países, actitudes, grupos sociales, calidad de vida o valores. Por supuesto, existen otras elementos (como el vestuario, los escenarios, los gestos, etc.) en un texto audiovisual que pueden ser asociados a todas estas cuestiones, pero no todos son alterables por el traductor, que sólo podrá manipular el código lingüístico. Es una cuestión interesantísima la de cómo manipular el código lingüístico a la hora de traducir para conservar las características propias de cada personaje sin que resulte ajeno para el espectador meta, cómo encontrar el punto medio entre convencionalidad y naturalidad, en qué momento se pueden transgredir las normas de traducción... Todo esto es, para mí, un reto tras otro, cada desafío más interesante que el anterior.

Sin embargo, mi experiencia como traductora audiovisual no es mucha. Centro toda esa pasión que siento por la TAV en estudiarla, más que en ejercerla. Porque sólo mediante estudios descriptivos que den cuenta de todos los aspectos relacionados con esta profesión podremos llegar realmente a comprenderla y a ejercerla con seguridad y profesionalidad.

Con el propósito de seguir desarrollándome en los estudios de la TAV y en las implicaciones de las decisiones traductológicas en torno a la manera de hablar (a la variación lingüística) presentamos aquí un estudio descriptivo de la traducción del slang en un largometraje. El objeto de estudio será una película dirigida por Quentin Tarantino, a saber, Jackie Brown (la justificación de la elección del objeto de estudio puede verse en el apartado 4. (Justificación del curpus)

Los objetivos específicos de este trabajo podrían resumirse de la siguiente manera:

Describir el tipo de slang que aparece en el largometraje. 
Estudio descriptivo de la traducción para el doblaje del slang en el largometraje Jackie Brown (Quentin Tarantino, 1997)

Estudiar de qué manera un tipo de slang es asociable a ciertas técnicas de traducción general o técnicas de traducción de la variación lingüística.

$>$ Describir la función que cumple el slang en la película original y analizar si la versión doblada es homofuncional.

Teorizar sobre qué ventajas o desventajas puede tener la jerarquización de ciertas prioridades o el uso de ciertas técnicas de traducción.

\section{Metodología}

La metodología llevada a cabo para la realización de este estudio es la de los Estudios Descriptivos de Traducción, en tanto que pretendemos, mediante un estudio observacional exploratorio, buscar normas de traducción que den cuenta de cómo se lleva a cabo la práctica traductora en este campo. Dentro de este marco metodológico prodeceremos a extraer segmentos de slang del TM y buscaremos su segmento reemplazado en el TO. Esto nos servirá para poder caracterizar el slang utilizado y extraer técnicas de traducción general y de variación lingüística para comprobar si la carga pragmática de los segmentos del TO se ha mantenido, aumentado o perdido. De esta manera podremos inferir normas y recurrencias en la traducción.

\section{$\underline{\text { Estructura del trabajo }}$}

En el capítulo 1 realizamos una breve introducción a la variación lingüística y al concepto de slang como un tipo de variación lingüística que caracteriza ciertas clases o grupos sociales. Analizamos las posibles definiciones del término slang y presentamos la taxonomía que seguiremos para su caracterización. En el capítulo 2 nos adentramos en los Estudios de Traducción y en cómo estos han tratado la cuestión del slang. El capítulo 3 está dedicado a la metodología de trabajo que se usará para el estudio. En este apartado presentamos los presupuestos teóricos que conforman el modelo de análisis integrador que se usará para el trabajo, así como el marco analítico para el mismo y la ficha de trabajo que servirá para extraer datos de las muestras. En el capítulo 4 presentamos el corpus del trabajo y justificamos su elección. En el capítulo 5 nos adentramos en el análisis del corpus 
Estudio descriptivo de la traducción para el doblaje del slang en el largometraje Jackie Brown (Quentin Tarantino, 1997)

y llevamos a cabo un análisis preliminar del largmetraje para después analizar los datos extraídos de las muestras. En el capítulo 6 presentamos las conclusiones que se derivan del análisis de los datos y las conclusiones generales que deducimos para la traducción del slang, así como el grado de cumplimiento de los objetivos marcados para este trabajo. En este apartado también presetaremos las perspectivas de futuro que supone la realización de este estudio. Las muestras extraídas del corpus y los datos de las muestras para su análisis se presentan en el Anexo 1 y Anexo 2 respectivamente. 
Estudio descriptivo de la traducción para el doblaje del slang en el largometraje Jackie Brown (Quentin Tarantino, 1997)

\section{El slang}

El uso y la creación del slang han sido ampliamente estudiados tanto desde el punto de vista de la lingüística como de la traducción. Este resulta ser un ámbito de estudio candente, en tanto que el uso y la creación del slang deben su origen a, y están estrechamente vinculados con, la sociedad y sus individuos. Además, se trata de un ámbito de estudio muy complejo y, en muchas ocasiones, el acercamiento a dicho fenómeno es bastante subjetivo. Antes de entrar en las cuestiones metodológicas que sientan las bases de este trabajo, creemos oportuno hacer una introducción sobre el fenómeno del slang (Capítulo 1) y sobre cómo se ha estudiado desde el punto de vista de la traductología (Capítulo 2).

\subsection{Introducción al slang: la variación lingüística}

El término slang está asociado a ciertos estereotipos, clases o grupos sociales o, incluso, a razas o edades. Para empezar - y para comprender por qué tenemos que partir del concepto de variación lingüística - tomemos como referencia las siguientes palabras de Mayoral:

La comunicación de la variación se realiza mediante la transmisión de estereotipos, estereotipos que en una medida apreciable pero variable están basados en convenciones sociales [...]. Los estereotipos están basados en buena parte en el conocimiento folclórico o popular y no en el conocimiento científico. Para una comunicación eficaz, es necesario utilizar el estereotipo que el destinatario pueda interpretar en el sentido deseado (2000:7).

Para poder entender a qué nos referimos cuando hablamos de slang, tenemos que partir, como sugiere la cita de Mayoral, del concepto de variación lingüística. Tomando como base la tesis doctoral presentada por el autor (Mayoral, 1997) podríamos definir la variación lingüística como la expresión de mensajes con un contenido semántico potencialmente similar en los que la producción del discurso resulta diferente. Como apunta dicho autor «la idoneidad [del uso de una u otra variación lingüística o de la lengua estándar] se deberá referir a la situación comunicativa y a las exigencias de eficacia en la comunicación» (Mayoral, 1997:105). Parece, pues, que la idoneidad del uso del slang no 
Estudio descriptivo de la traducción para el doblaje del slang en el largometraje Jackie Brown (Quentin Tarantino, 1997)

tendrá sólo que ver con el grupo social, la raza o la edad a la que se atribuye uno u otro tipo de slang, sino también - y sobre todo- a la situación comunicativa en la que realice el intercambio.

En este sentido, la Lingüística Funcional Sistémica, con referentes e impulsores como Firth, Halliday y Crystal y Davy, da cuenta de cómo se usa el lenguaje y apunta que la lengua tiene una función social, por lo que aspectos como la cultura o la sociedad resultan ser estratos explicativos del mismo.

Antes que Mayoral, en los Estudios de Traducción, autores como Catford (1965), House (1977), Hatim y Mason (1990, 1997) o Bell (1991) desarrollaron este concepto partiendo de la teoría clásica de la variación lingüística, desarrollada en el seno de la Lingüística Funcional Sistémica y tomando como base algunos conceptos e ideas de Firth y Halliday. Todos estos autores, de una u otra manera, establecen una distinción dicotómica de las variedades lingüísticas que pueden existir en una lengua según el usuario o según el uso que se haga de la misma.

Catford (1965) habla de variedades permanentes (que corresponderían a las variedades según el usuario) y variedades pasajeras (que corresponderían a las variedades según el uso de la lengua, esto es, según el registro, el modo y el estilo en el que se encuentra la situación comunicativa). House (1977), si bien se refiere también a esta distinción dicotómica, habla de dimensiones de uso y de usuario. Hatim y Mason (1990, 1997) comparten la visión de estos autores, «e incluyen el análisis del registro como una parte de su modelo del contexto, dentro de lo que ellos denominan dimensión comunicativa» (Marco, 2002:2). Bell (1991), por su parte, hace esta misma distinción entre uso y usuario, pero se centra en el análisis de las variaciones que surgen del uso de la lengua, «tratando de señalar vínculos entre cada variable y algunas de sus manifestaciones lingüísticas prototípicas» (Marco, 2002:2).

Hatim y Mason (1990, 1997) sintetizan esta propuesta dicotómica de la teoría clásica de la variación lingüística. Basándose en conceptos ya desarrollados en la Lingüística Funcional Sistémica, las autoras apuntan que el cambio del registro, esto es, la variación lingüística según el uso, puede estudiarse según el campo (lenguaje especializado, de transición o no especializado), el modo (forma en la que se desarrolla el acto comunicativo, puede ser escrito, oral o complejo) o el tenor del discurso. Este último aspecto, el tenor, o en palabras de Mayoral la «variedad según la actitud» (1990:36), es de especial interés para abordar el concepto de slang. El cambio en el tenor es un reflejo de la 
Estudio descriptivo de la traducción para el doblaje del slang en el largometraje Jackie Brown (Quentin Tarantino, 1997)

relación que existe entre los interlocutores y varía desde muy formal a muy informal. No existe un consenso entre los estudiosos de la lingüística por lo que respecta a cuántos grados de formalidad pueden diferenciarse en la categoría del tenor del discurso. Lo que sí podemos asegurar es que los grados del tenor se mueven en un continuo en el que se sitúa la formalidad del intercambio comunicativo, continuo en el que las fronteras entre uno y otro grado no están del todo delimitadas. En un intercambio muy informal es donde podríamos encontrarnos con el uso del slang; de hecho, Newmark (1988:14) propone el slang como uno de los ocho grados del tenor.

El dialecto correspondería al otro polo dicotómico, esto es, a la variación lingüística según el usuario. Fernández y Samaniego (2002) sintetizan las propuestas de varios autores y, a partir de Hatim y Mason (1990) hablan de dialecto geográfico, social, estándar, temporal e idiolecto.

Hemos de abordar el slang, pues, dentro de esta caracterización de la variación lingüística, como un tipo de variación que podrá ser distinta según el registro o el dialecto de los interlocutores. Así, y tomando la propuesta dicotómica como base teórica, podremos identificar distintos tipos de slang, según la región, el estatus social, el sexo, la edad, la relación entre los interlocutores, etc. Debemos entender el concepto de slang como una noción transversal dentro de esta teoría de la variación lingüística, pero de una manera flexible, es decir, habrá rasgos del slang que se correspondan con el uso de la lengua y sus registros y otros que se correspondan con el usuario de una lengua y sus dialectos. Los límites en el análisis de la lengua (y más aún en el modo oral, donde más a menudo suele darse el uso del slang) no siempre están claros y debemos entender el slang como un tipo de variación lingüística en constante movimiento y cambio.

\subsection{Definición de slang}

La traducción sancionada al español del concepto slang es el término argot, ya que es con este término con el que se ha estudiado el concepto en los Estudios de Traducción (véase Calvo Ferrer, 2010 o Mayoral Asensio, 1997). Veamos algunas definiciones en español del término argot: 
Estudio descriptivo de la traducción para el doblaje del slang en el largometraje Jackie Brown (Quentin Tarantino, 1997)

\begin{tabular}{|c|c|}
\hline Diccionario & Definición \\
\hline Real Academia Española & $\begin{array}{l}\text { 1. lenguaje especial entre personas de un mismo oficio o } \\
\text { actividad. } \\
\text { 2. jerga, jerigonza. }\end{array}$ \\
\hline $\begin{array}{c}\text { Diccionario de uso del } \\
\text { español de María Moliner }{ }^{I}\end{array}$ & $\begin{array}{l}\text { 1. conjunto de expresiones que emplean en lenguaje informal } \\
\text { las personas de una misma clase o de una misma profesión; } \\
\text { como los estudiantes o los toreros. Argot. Caló, cheli, coa, } \\
\text { cocoliche, germanía, jacaranda, jerigonza, lunfardo, marga, } \\
\text { márrega, replana. } \\
\text { 2. lenguaje difícil de entender. Jerigonza. }\end{array}$ \\
\hline
\end{tabular}

Tabla 1. definiciones en español del término argot

Veamos, ahora, algunas definiciones de diccionarios en inglés del término slang:

Diccionario

Merriam-Webster

Cambridge Advanced

Learner's Dictionary

Dictionary of American

English

Oxford Advanced

Learner's Dictionary

\section{Definición}

1. language peculiar to a particular group: as a: argot b: jargon.

2. an informal nonstandard vocabulary composed typically of coinages, arbitrarily changed words, and extravagant, forced, or facetious figures of speech.

very informal language that is usually spoken rather than written, used especially by particular groups of people.

a very informal language that is used esp. in speech by particular groups of people and which sometimes includes words that are not polite.

very informal words and expressions that are more common in spoken language, especially used by a particular group of people, for example, children, criminals, soldiers, etc.

\footnotetext{
${ }^{1}$ El diccionario de uso del español de María Moliner redirige la búsqueda del término argot a jerga
} 
Estudio descriptivo de la traducción para el doblaje del slang en el largometraje Jackie Brown (Quentin Tarantino, 1997)

Longman's Dictionary of very informal, sometimes offensive, language that is used Contemporary English especially by people who belong to a particular group, such as young people or criminals.

Tabla 2. definiciones en inglés del término slang

Se observa, pues, que todos los diccionarios apuntan que se trata de un lenguaje informal (con excepción de la RAE, que lo define como «especial») y que es un lenguaje utilizado por un grupo concreto de personas. Sin embargo, como bien observa Eriksen (2010:10-12), eso es todo lo que las definiciones en torno a este término tienen en común y esto muestra que las definiciones de los diccionarios son, en cierta medida, incompatibles las unas con las otras (Eriksen, 2010:10). El autor va más allá y señala que las definiciones de los diccionarios «can give you a general outline of what slang is and in which cases it is used, but the inconsistency between the individual definitions rule out dictionaries as the approach to defining what the function of slang is» (Eriksen, 2010:12). Eriksen propone el acercamiento a definiciones elaboradas por investigadores del campo, ya que estas suelen contener el aspecto sociológico que los diccionarios ignoran. En este sentido, Connie Eble define el slang como «an ever changing set of colloquial words and phrases that speakers use to establish or reinforce social identity or cohesiveness in society at large» (1996:11). Parece pues, acertado, como apunta Eriksen, dejar de lado, en cierta medida, las definiciones de los diccionarios y acercarse al concepto caracterizándolo y definiéndolo desde una perspectiva sociológica a la vez que lingüística, ya que la esencia del slang no consiste sólo en el uso y creación de ciertas palabras o frases, sino, más bien, en el impacto que su uso puede tener en la sociedad y en las relaciones interpersonales. En este trabajo adoptaremos esta definición del término slang propuesta por Eble como punto de partida y así será como entenderemos dicho término a lo largo del mismo, de ahí que hayamos descartado utilizar el término argot que, a partir de las definiciones revisadas, parece que refleja más la parte léxica y gramatical que la social. 
Estudio descriptivo de la traducción para el doblaje del slang en el largometraje Jackie Brown (Quentin Tarantino, 1997)

\subsection{Tipos de slang}

Willis (1964) propone dos tipos distintos de slang, a saber, el slang que proporciona nuevos significados a palabras de la lengua estándar y el slang que inventa nuevas palabras o estructuras que sólo tienen una pequeña conexión con palabras y estructuras establecidas en la lengua estándar. Graha (2010:21) menciona a Feldman y Sourdot para mostrar otra caracterización del slang. Estos autores han categorizado los tipos de slang según su evolución. Feldman distingue entre evolución semántica del slang (modificación o juego con el significado de las palabras) y evolución formal del slang (creación y modificación de palabras). Sourdot, por su parte, modifica la clasificación de Feldman para ofrecer una taxonomía más completa y exhaustiva y distingue entre:

\section{Procedimientos sintácticos}

2. Procedimientos léxicos

$>$ Semánticos: metáfora, metonimia, polisemia y sinonimia

$>$ Formales: composición léxica, derivación, apócope, aféresis, duplicación de sílabas, inversión, abreviación y asimilación.

Estas clasificaciones no resultan totalmente adecuadas para el análisis del slang desde un punto de vista traductológico, ya que se basan en un enfoque puramente lingüístico que obvia por completo el contexto situacional y comunicativo en el que se da el slang. Para este trabajo, sería más útil tomar como base preliminar una taxonomía como la que presenta Mayoral (1990:36) que resulta, en cierta manera, simple, pero adecuada a las necesidades del traductor a la hora de enfrentarse a su tarea. En su propuesta, Mayoral distingue entre variedades según el medio, la actitud, el origen geográfico o étnico, el individuo, el sexo, la edad, el tiempo, la posición socioeconómica o cultural, la profesión, el tema y el género o tipo de texto. Al analizar el tipo de slang según esta taxonomía de Mayoral, el traductor podrá observar las características del original para buscar un tipo de slang en la lengua y cultura meta que se adecue a la funcionalidad que le confieren dichas características al slang original y al discurso en general. Esta clasificación de Mayoral tiene en cuenta el contexto comunicativo del que carecían las clasificaciones anteriores. Sin embargo, creo que ambas taxonomías pueden resultar complementarias. El análisis lingüístico y de evolución presentado más arriba, siempre que esté precedido por un 
Estudio descriptivo de la traducción para el doblaje del slang en el largometraje Jackie Brown (Quentin Tarantino, 1997)

análisis del contexto social y comunicativo en el que se da el discurso, puede resultar útil para estudiar el slang.

No obstante, la clasificación en tipos de slang servirá para caracterizarlo, para entenderlo y para analizarlo, pero no siempre para traducirlo. La traducción del slang es una tarea muy compleja que no puede limitarse a la idea equivalencista de traducir un tipo de slang por otro. Los factores que inciden en la funcionalidad del texto y, por consiguiente, en la traducción del mismo, son demasiado complejos (aún más cuando tratamos con textos audiovisuales) como para asegurar que un tipo de slang en particular se traducirá por otro tipo de slang en particular.

\subsection{Características del slang}

Dejando aparte la falta de consenso en las definiciones y caracterizaciones de los diferentes tipos del slang, resulta evidente que el uso y la creación de slang es un claro «reflejo del carácter cambiante y dinámico del lenguaje» (Calvo Ferrer, 2010:4, la negrita es mía). Calvo Ferrer, en consonancia con la definición de Eble (1996:11) vista más arriba, apunta que el slang no es sólo un tipo de lenguaje o una variación lingüística del mismo, sino que también es un fenómeno social «que permite crear estrechos vínculos lingüísticos entre sus integrantes y posibilita una mayor cohesión e identidad frente a otros grupos externos» (2010:4). Este aspecto sociológico del término nos hace pensar que lo que diferencia al lenguaje estándar del slang no han de ser obligatoriamente las palabras escogidas para expresarse, sino el efecto que se pretende conseguir con el uso de esas palabras (Eriksen, 2010:13). Es, pues, este carácter sociológico lo que hace que el slang resulte siempre cambiante, efímero, imperdurable. En relación a este carácter efímero, Mayoral (1997) apunta que no todas las comunidades y su slang cambian de igual manera y al mismo ritmo. En ocasiones, señala el autor, se han venido generalizando las conclusiones obtenidas para las variaciones lingüísticas del inglés a otros idiomas y culturas. Este autor concluye que los cambios en la variación lingüística se deberían revisar para cada comunidad de forma independiente y, sobre todo, con mucha frecuencia, dado el carácter cambiante que señalábamos más arriba.

El hecho que apuntábamos más arriba de que el tenor del discurso se sitúe en un continuo en el que las fronteras entre lo muy formal, lo formal, lo estándar, lo informal y lo 
Estudio descriptivo de la traducción para el doblaje del slang en el largometraje Jackie Brown (Quentin Tarantino, 1997)

muy informal resultan difusas, hace que identificar el slang no siempre resulte fácil. En este sentido, Eriksen (2010:12-13) cita a Dumas y Lighter y propone cuatro criterios para identificar el slang como tal (Dumas y Lighter, 1978:14-16 en Eble, 1996:11-12):

1. Its presence will markedly lower, at least for the moment, the dignity of formal or serious speech or writing.

2. Its use implies the user's familiarity either with the referent or with that less statusful or less responsible class of people who have such familiarity and use the term.

3. It is a tabooed term in ordinary discourse with persons of higher social status or greater responsibility.

4. It is used in place of the well-known conventional synonym, especially in order (a) to protect the user from the discomfort caused by the conventional item or (b) to protect the user from the discomfort or annoyance of further elaboration.

Dumas y Lighter proponen que, cuando el discurso cumple al menos dos de estas cuatro características, nos encontramos ante la presencia de slang (Eriksen, 2010:13).

Por otro lado, Adams caracteriza el slang como «casual, racy, vivid, irreverent, and playful elements [that] rebels against the standard (whether mildy, wildly or in between)» (2009:9, la negrita es mía). Es más, este autor propone que el slang «can be mild and casual in its appearance just as it can be racy and irreverent» (Eriksen, 2010:14). Se trata, pues, de una cuestión de registro y de usuario. No podemos asumir que todos los tipos de slang tienen las mismas características y funciones. Si bien los cuatro criterios mencionados por Dumas y Lighter nos pueden dar una idea general de qué características definen lo que es y lo que no es el slang, cada situación comunicativa (dependiendo del idiolecto, de la relación entre los interlocutores, del modo de transmisión, etc.) definirá las características y funciones concretas del slang utilizado para dicho acto de comunicación. Esto nos lleva a deducir que algo común a todos los tipos de slang ha de ser el conocimiento compartido por parte de los interlocutores del contexto comunicativo en el que se sucede el discurso. Los interlocutores han de saber y estar de acuerdo, de una u otra manera, en el tipo de contexto que envuelve su acto comunicativo. Así, el tipo de slang utilizado se adecuará al contexto y situación comunicativa y se cumplirán las expectativas comunicativas de los interlocutores, dando lugar a una comunicación exitosa. 
Estudio descriptivo de la traducción para el doblaje del slang en el largometraje Jackie Brown (Quentin Tarantino, 1997)

Además del conocimiento compartido del contexto comunicativo, existen otros dos aspectos que, a nuestro parecer, caracterizan todos los tipos de slang y que surgen de los motivos que llevan a su aparición. Son los aspectos de unidad y distinción: unidad respecto al grupo con el que el emisor quiere identificarse y distinción respecto de los demás grupos sociales.

Para concluir con la caracterización del slang, podemos tomar como referencia la enumeración sintetizada de Eriksen (2010:25-26). Este autor apunta que lo que mejor caracteriza y define el slang es que se usa para:

$>$ Establish group relations and identity

$>$ Separate one group of people from another

$>$ Rebel against standard language through the use of words and expressions that are not defined in standard language

$>$ Lead a conversation towards informality

$>$ Suggest 'insider-knowledge' with the people to whom you are speaking

$>$ Show the speaker's attitude through the use of words and expressions that differ from standard Language

Según lo explicado hasta el momento, podríamos resumir y sintetizar las características y funciones del slang de la siguiente manera:

Funciones

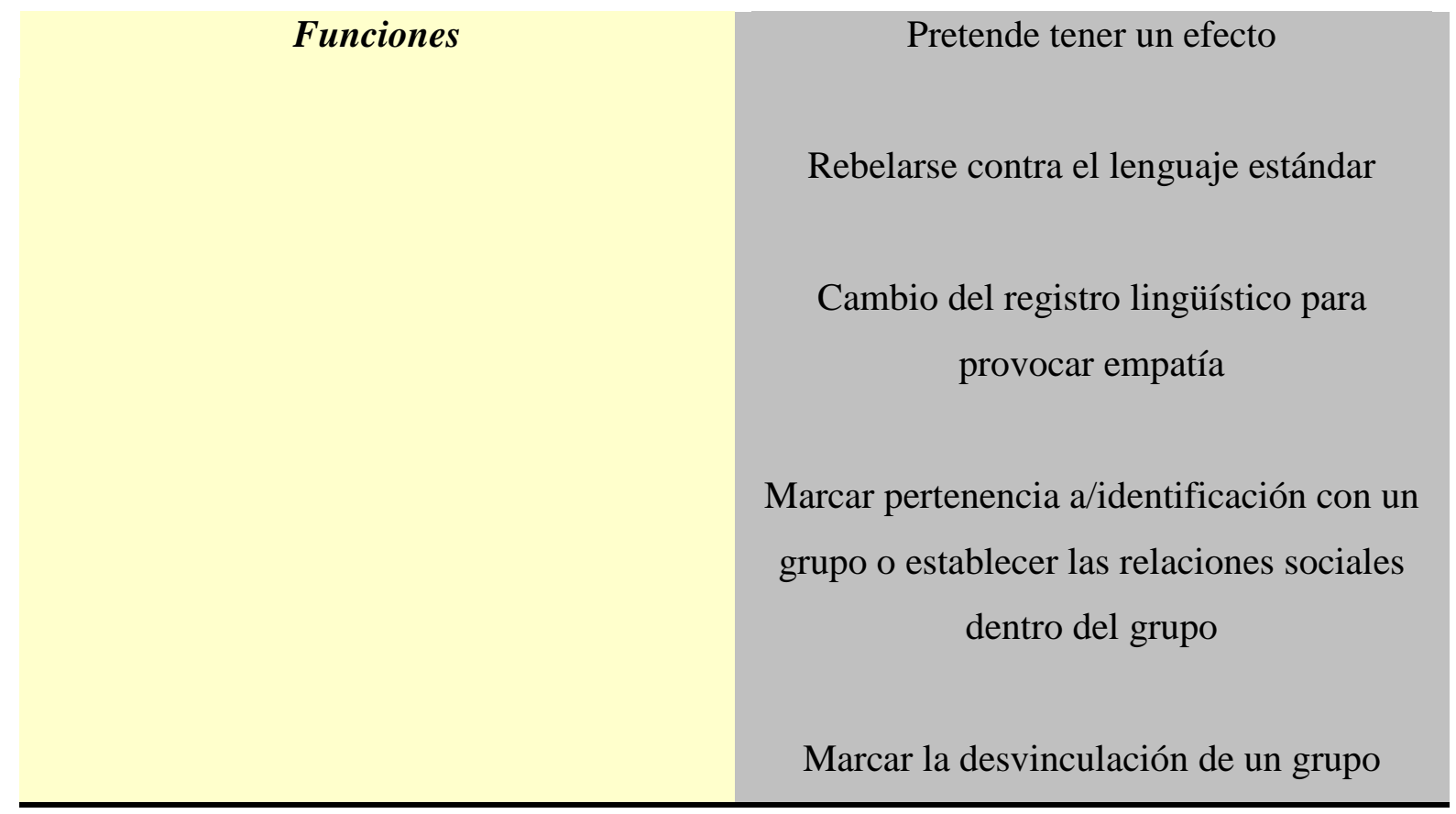


Estudio descriptivo de la traducción para el doblaje del slang en el largometraje Jackie Brown (Quentin Tarantino, 1997)

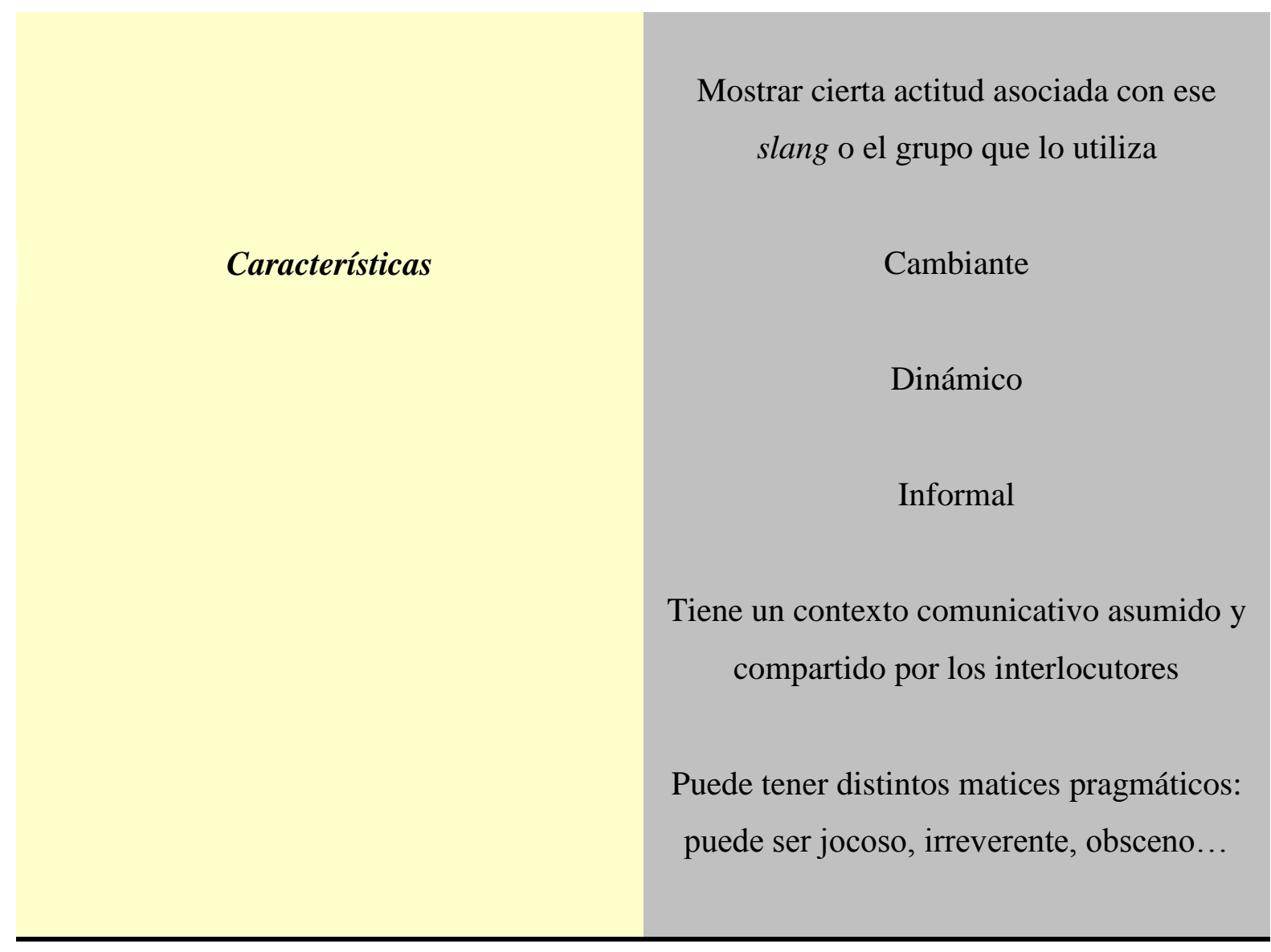

Tabla 3. Funciones y características del slang 
Estudio descriptivo de la traducción para el doblaje del slang en el largometraje Jackie Brown (Quentin Tarantino, 1997)

\section{El slang en los Estudios de Traducción}

El análisis y la investigación del slang resultan interesantes para los Estudios de Traducción en tanto que el slang muestra, y es producto de, un marcado carácter cultural que puede afectar a la manera en la que los receptores reciben el mensaje y, sobre todo, puede causar un problema de traducción, como reflejan varios autores (véase Calvo Ferrer, 2010 o Eriksen, 2010).

Eriksen señala una de las cuestiones más importantes a la hora de plantearse el estudio del slang en Traducción cuando formula las siguientes preguntas:

Slang seems to be connected to the culture in which it is created, so how are slang words and expressions transferred into another language and culture and does the transfer affect the possibility to maintain the use of slang in the translation? (2010:6).

\subsection{El slang desde las perspectivas prescriptivista y descriptivista}

Hasta mediados de la década de los 70, la tarea traductora se entendía exclusivamente como una operación lingüística. Esto, junto al hecho de que en la época imperasen las teorías lingüísticas de tipo formalista, hizo que la traducción se abordara, durante décadas, con un enfoque prescriptivista. Las teorías y estudios desarrollados bajo la noción prescriptivista que dominaba la disciplina se basaban en la argumentación de que traducir es sustituir unos elementos lingüísticos por otros, argumento mediante el cual sólo se consideraban correctas las traducciones que, por ser una mera trasladación lingüística, no presentaban distanciamiento respecto al texto original. La perspectiva tradicional lingüística de marcado carácter prescriptivista apuntaba que «el estudio del argot se realizaría a través de la creación de listados unívocos de términos equivalentes entre distintos idiomas» (Calvo Ferrer, 2010:15). Sin embargo, como bien apunta Calvo Ferrer «resulta complicado imaginar una serie de términos argóticos monosémicos y sin más de una colocación que cuenten con tan sólo un equivalente en la lengua de llegada» (2010:7), por lo que la perspectiva puramente lingüística y prescriptivista fue dejando paso a otros enfoques más acordes con la realidad del fenómeno traductor. 
Estudio descriptivo de la traducción para el doblaje del slang en el largometraje Jackie Brown (Quentin Tarantino, 1997)

En 1976, un grupo de estudiosos de la traducción concluyó que los estudios de la disciplina se centraban demasiado en el texto origen, y a partir de la conferencia internacional celebrada en Lovaina, distintos traductólogos revindicaron la necesidad de que la teoría y la práctica traductora se centraran más en la cultura y texto metas. Las distintas propuestas tratadas en estas conferencias, y en las publicaciones a las que dieron lugar, confluyeron en la creación del llamado marco descriptivista que ha dominado la disciplina hasta la actualidad. El paradigma descriptivista confluyó enseguida con una teoría literaria emergente en la época, la llamada Teoría de los Polisistemas (desarrollada más abajo), en la que, entre muchos otros aspectos, «se abordaría el estudio del argot dentro del polisistema de llegada, con el objeto de esclarecer las relaciones entre el componente argótico traducido y las formas argóticas ya existentes dentro de la cultura receptora de la traducción» (Calvo Ferrer, 2010:15). Es más, «la traducción del componente argótico se estudiaría en el marco de la mencionada relación existente dentro de un mismo polisistema, con el objeto de averiguar las normas y condicionantes que gobiernan tanto la producción como la recepción de la misma» (Calvo Ferrer, 2010:15). El método deductivo sobre el que se asienta la Teoría de los Polisistemas hace que esta no pretenda dar a conocer equivalencias perfectas de términos argóticos, sino más bien pretenda «deducir las normas y condicionantes operativos dentro del contexto sociocultural en que se ha originado la traducción» (Calvo Ferrer, 2010:17).

Autores como Catford, House, Hatim y Mason o Bell o bien se basaban en una visión prescriptivista de la traducción, o bien se centraban en el análisis del texto origen y no del texto meta, como no podía ser de otra manera dada la juventud de la disciplina de la época. Otros autores como Mayoral (1999) y Muñoz (1995) tienen una visión distinta de la caracterización de la variación lingüística a la propuesta dicotómica presentada más arriba. Muñoz, como Mayoral, se basa en la teoría del skopos (desarrollada más abajo) para argumentar su posición. En este sentido apunta que «lo que importa es que los lectores [espectadores, en nuestro caso] reconozcan en los rasgos representativos escogidos unos determinados estereotipos sociales y culturales» (Marco, 2002:8), no la sistematización concreta de cada variación lingüística. A diferencia de la propuesta basada en la lingüística sistémica presentada más arriba, autores con una visión basada en planteamientos cognitivistas de la traducción, como Mayoral o Muñoz, opinan que traducir no es analizar, sino comunicar, algo muy acorde con las tendencias actuales en los Estudios de Traducción. 
Estudio descriptivo de la traducción para el doblaje del slang en el largometraje Jackie Brown (Quentin Tarantino, 1997)

\subsection{Factores que condicionan el estudio del slang}

Las restricciones —entendidas como los obstáculos que impone el texto origen mediante sus códigos y sus canales para su traducción - a la hora de analizar el slang desde un punto de vista traductológico son varias. Para empezar, Eriksen (2010) apunta que al tratarse de un fenómeno del lenguaje coloquial, los géneros en los que se puede estudiar son limitados. En este sentido, los textos audiovisuales (las películas y las series, sobre todo) proporcionan, a menudo, contextos comunicativos en los que el discurso se desarrolla en un ambiente informal que da lugar al uso de slang. Las series y películas resultan, pues, una de las mejores fuentes para el análisis de la traducción del slang. Además, como ya hemos visto en el apartado 1.4. Características del slang), el slang se caracteriza por ser, aparte de un tipo de variación lingüística, un fenómeno social que ayuda a crear vínculos entre los integrantes de un grupo y a distinguir ese grupo social de otros. En este sentido, «translating slang seems to be a task that faces many challenges because of the implication of the use of slang that is to be considered in the translation process» (Eriksen, 2010:32). Por otro lado, la naturaleza coloquial y espontánea que se le atribuye a este tipo de variación lingüística hace que surja un problema importante a la hora de traducir. Calvo Ferrer (2010:4-5) lo explica de la siguiente manera:

Por lo general, en cada idioma existe una serie de términos argóticos cuyo significado es conocido por un número limitado de hablantes. Incluso cuando su uso se haya circunscrito a tal grupo de hablantes, suele existir un término equivalente en la lengua de llegada cuando existe también un grupo paralelo a aquél en el que se originó el término. Todo grupo social que alcance nuestra imaginación, bien sea de futbolistas, jubilados o adolescentes, posee, en mayor o menor grado, su propia terminología. Si tal grupo existe en la cultura receptora del texto meta, con mucha probabilidad existirá una terminología paralela y el problema traductor será sensiblemente menor. Siguiendo con el ejemplo, los futbolistas británicos y los españoles harán en gran medida uso de terminología similar, puesto que sus actividades deportivas son similares. Será, por tanto, tarea del traductor, establecer las identidades idiomáticas que le permitan establecer los paralelismos adecuados. [...] El principal problema se presenta cuando el término argótico encierra conceptos desconocidos o 
Estudio descriptivo de la traducción para el doblaje del slang en el largometraje Jackie Brown (Quentin Tarantino, 1997)

novedosos en la cultura meta, o bien define las actividades de un grupo social que no encuentran equivalente en la misma.

\subsection{Técnicas y estrategias para la superación de restricciones}

Las escuelas lingüísticas que dominaron la escena de la investigación en Traductología hasta mediados de la década de los 70 del siglo pasado consideraban ciertos rasgos de las lenguas como intraducibles. La hipótesis de Sapir-Whorf (también conocida como el principio de relatividad lingüística) se fundamenta en que el conocimiento y la interpretación de la realidad tienen su base, entre otras cosas, en la lengua materna. Siguiendo esta hipótesis, cada lengua interpreta y estructura la realidad a su manera, manera que no es intercambiable con la forma en la que otras lenguas estructuran la realidad. Autores como García Yebra (1994) no tienen una visión tan extremista de la posibilidad (o no) de que los textos sean traducidos, pero sí que apuntan, basándose en la hipótesis SapirWhorf, que no existe una traducción perfecta, sino que sólo se puede aspirar a que excelentes traductores tengan el propósito de traducir lo mejor posible. Uno de los aspectos que se puede ser tema de debate en cuanto a su (in)traducibilidad es la traducción del slang, vistos los problemas mencionados más arriba.

Sin embargo, según la disciplina y su investigación fueron avanzando surgieron propuestas de técnicas y estrategias asociadas a la traducción de la variación lingüística. Newmark (1988), por ejemplo, señala que no es imposible traducir el dialecto y sugiere que existen diversos procedimientos que el traductor puede adoptar para enfrentarse a la traducción del dialecto, a saber, mostrar un uso argótico de la lengua, enfatizar los contrastes de clase social o indicar rasgos culturales locales (Mayoral, 1997:58). Newmark, además, apunta a conceptos e ideas que aún están vigentes en la práctica traductora de la variación lingüística, como son la imposibilidad de generalizar en torno a las restricciones traductológicas que presenta el slang o la necesidad de encontrar la equivalencia funcional del texto (Mayoral, 1997:58).

Para la superación de estas restricciones, Marco (2002) propone una serie de soluciones en pares dicotómicos que muestran las opciones del traductor para la traducción de la variación lingüística. Su visión descriptivista permite valorar las ventajas e inconvenientes de una u otra opción traductológica. Esta propuesta se podría sintetizar de la siguiente manera: 
Estudio descriptivo de la traducción para el doblaje del slang en el largometraje Jackie Brown (Quentin Tarantino, 1997)

a) traducción con marcas/sin marcas: Una traducción sin marcas eliminaría la variación lingüística y optaría por una solución en el registro estándar, mientras que la traducción con marcas intentaría (de una manera total o parcial) reproducir la «riqueza dialectal del original» (Marco, 2002:9).

Una traducción con marcas conlleva riesgos, en tanto que el traductor no estará pisando en terreno seguro, por el contrario, una traducción sin marcas le permite al traductor llevar a cabo su tarea por un terreno seguro en el que se basa en uso estándar de la lengua meta. Sin embargo, en un intento de llevar a cabo su tarea con seguridad, el traductor, en su traducción sin marcas, puede simplificar demasiado el texto y, de alguna manera, alterar el significado original.

b) traducción con transgresión/sin transgresión: Está relacionada con la distinción anterior en tanto que una traducción con marcas de variación lingüística puede incluir una transgresión de las normas lingüísticas (uso incorrecto de formas verbales, mala ortografía, omisión de sufijos...). En la traducción sin transgresión no cabrían las incorrecciones lingüísticas, sino que se optaría por una solución muy informal u oral de la lengua, pero, en definitiva, correcta lingüísticamente.

Si el traductor opta por una traducción sin transgresión de la norma lingüística, esta opción no siempre dará como resultado que el TO y el TM sean homofuncionales (Marco, 2002:10), en tanto que se perderá un rasgo importante del TO. Transgredir la norma, por otro lado, podría resultar dañino para las lenguas que no están perfectamente asentadas o para los estudiantes de la lengua meta. Además, en periodo de formación o no, al lector puede resultarle, cuanto menos, rara la transgresión de la norma, seguramente, como apunta Marco, por la poca tradición de esta solución ante los problemas de variación linguiística.

c) naturalidad/convencionalidad: $\mathrm{Si}$ el traductor decide marcar la variación lingüística, la solución de la naturalidad sería, por decirlo de alguna manera, sustituir los rasgos de la variación lingüística en la lengua origen por otros rasgos existentes en la lengua meta, de modo que esta operación «remita al lector [espectador, en nuestro caso] a [...] los prototipos dialectales vigentes en su cultura» (Marco, 2002:10). Por otro lado, la solución de la convencionalidad consistiría en «crear una configuración artificial de rasgos 
Estudio descriptivo de la traducción para el doblaje del slang en el largometraje Jackie Brown (Quentin Tarantino, 1997)

de diversa índole» (Marco, 2002:10) no identificables con ningún prototipo dialectal en la lengua meta.

Optar por una variación lingüística no identificable con ningún prototipo en la cultura meta puede resultar peligroso por lo artificial que le puede parecer al espectador. Por otro lado, optar por la solución de la naturalidad puede, entre otras cosas, ofender a la comunidad que se asocie con dicha variación lingüística.

\subsection{Conclusiones y reflexiones del estudio del slang en Traducción}

Si algo se puede sacar en claro de la evolución de los Estudios de Traducción respecto a la variación lingüística y, más concretamente, respecto a la traducción del slang, es que los modelos prescriptivistas y puramente lingüísticos, por sí solos, poco pueden hacer para ayudar al traductor en su tarea. El análisis de la traducción del slang se ha de realizar de manera descriptiva, de modo que la descripción de lo que realmente ocurre en una realidad y tiempo determinado ayude al investigador a comprender de manera exhaustiva qué es lo que se lleva a cabo en el mundo profesional y por qué.

Por otro lado, cabe destacar que cada traducción se inscribe en una situación distinta y la toma de decisiones respecto a la traducción depende de las características de dicha situación, en las que uno de los elementos clave es el perfil del destinatario. En este sentido, y desde nuestro punto de vista, la intraducibilidad de lenguas, textos o variaciones lingüísticas no existe. Cada texto presenta un discurso inscrito en un contexto específico. Este discurso, o el contexto en el que está inscrito, pueden resultar más o menos ajenos a la cultura meta, tendrán más o menos problemas traductológicos que harán que el proceso traductor sea más o menos complicado. No existirá, pues, en la mayoría de los casos, una equivalencia perfecta. Sin embargo, no se puede afirmar que el discurso o el contexto en el que se inscribe sean intraducibles. Todo puede expresarse utilizando los medios que ofrece otra lengua y su cultura, si bien es cierto que, en algunas ocasiones, el traductor no podrá evitar que el texto meta presente algunas pérdidas (pragmáticas, humorísticas, semánticas...) respecto al texto original. El contexto del que hablamos ofrecerá al traductor distintas posibilidades a la hora de enfrentarse a las restricciones. La traducción será, pues, una constante toma de decisiones marcada por las características de la situación comunicativa. Los Estudios Descriptivos de Traducción, en este sentido, sólo pueden 
Estudio descriptivo de la traducción para el doblaje del slang en el largometraje Jackie Brown (Quentin Tarantino, 1997)

presentar las soluciones que se observan en la práctica y analizar sus posibles ventajas y desventajas en las diferentes situaciones comunicativas, así como preguntarse por su etiología. No hay, pues, traducciones que estén bien y traducciones que estén mal de manera absoluta, sino soluciones a diferentes restricciones que presentan unas $\mathrm{u}$ otras ventajas o desventajas y que son fruto de una u otra ideología.

Para la toma de decisiones, el traductor deberá, antes de enfrentarse al aspecto lingüístico de su tarea, reflexionar sobre quién recibirá el texto y qué se pretende con el texto. Vemos, pues, una necesidad de compaginar el enfoque descriptivista con el funcionalista (desarrollado más abajo) cuando pasamos de la reflexión a la acción y nos enfrentamos ante un problema de traducción, a fin de tener una visión más amplia de la tarea traductora.

Para sistematizar y dar coherencia a la toma de decisiones, es conveniente que el traductor tenga en consideración una serie de prioridades globales (que conciernen al texto como conjunto) y locales (que conciernen a segmentos concretos del texto) (Zabalbeascoa, 1996). Cuando el traductor se enfrenta a restricciones en su texto, es muy recomendable asignar una jerarquía de prioridades al segmento y al texto completo, esto es, tener en mente qué resulta imprescindible trasladar al TM. En el aspecto lingüístico se tomarán como prioridades locales aspectos como la función del slang en el texto en cuestión o la caracterización de los personajes mediante el slang. En este sentido, para una toma de decisiones coherentes, el traductor deberá atender a sus prioridades globales, que suelen ser aquellas a las que (casi) todo texto atiende y que siempre hay que tener en mente, a saber, mantener la cohesión y coherencia del texto, llegar al receptor meta de la misma manera que el autor del texto llega al receptor origen, tener en mente la funcionalidad del texto... En todo texto, sobre todo en el texto audiovisual, habrá signos o códigos que restrinjan nuestras posibilidades a la hora de traducir. Establecer una jerarquía de las necesidades nos ayuda a visualizar qué es lo que no se puede perder de vista y cuáles son los aspectos de los que se puede, en mayor o menor medida, prescindir si hubiera algo que nos obligase a prescindir de alguna prioridad (Zabalbeascoa, 1996). 
Estudio descriptivo de la traducción para el doblaje del slang en el largometraje Jackie Brown (Quentin Tarantino, 1997) 
Estudio descriptivo de la traducción para el doblaje del slang en el largometraje Jackie Brown (Quentin Tarantino, 1997)

\section{Metodología de trabajo}

\subsection{Presupuestos teóricos adoptados}

En cuanto a la fundamentación teórica y metodológica general para el planteamiento de este trabajo, vemos necesario adoptar un enfoque integrador que abogue por la interdisciplinariedad de la investigación y sea capaz de describir la tarea traductora. En este sentido, hay varios modelos de análisis traductológico que nos gustaría destacar, dado que es necesaria una visión amplia de todos los enfoques desarrollados en la disciplina para poder llevar a cabo un estudio sobre una tarea tan compleja como la de la traducción del slang. Así, el modelo propuesto beberá de cada uno de los paradigmas resumidos a continuación.

\subsubsection{Metodología descriptiva}

Los enfoques prescriptivos han dominado los Estudios de Traducción durante décadas. Estos enfoques a menudo criticaban las traducciones y proponían mejoras, sin atender a que las traducciones son en sí productos que se insertan en una cultura y sociedad determinadas, generando reacciones como productos en sí mismos, no como traducciones.

Che Suh (2002) apunta que la aparición de la Escuela de la Manipulación (también conocida como la Teoría de los Polisistemas) ha conllevado el desarrollo de un enfoque que difiere del tradicional enfoque lingüístico, a saber, un enfoque orientado a la descripción histórica. Dentro de esta metodología descriptiva tienen cabida enfoques como el funcionalista, o la misma Teoría de los Polisistemas (desarrollados más abajo) que, en vez de proporcionar teorías estáticas de lo que está bien o mal traducido, dan cuenta de lo que ocurre en la realidad de la tarea traductora $\mathrm{y}$, mediante la deducción, concluyen en observaciones teóricas de la realidad. 
Estudio descriptivo de la traducción para el doblaje del slang en el largometraje Jackie Brown (Quentin Tarantino, 1997)

\subsubsection{Teoría de los Polisistemas}

La teoría polisistémica apareció a finales de los 60 y principios de los 70 del siglo pasado como un nuevo enfoque para abordar los estudios de traducción. Como apunta Bassnett, lo que la teoría polisistémica ofrecía era lo siguiente:

the reintroduction of questions of ideology into the study and practice of translation, by examining the processes of textual transfer across cultural boundaries and studying the ways in which text and their translators were accepted or marginalised by different literary systems (1998:106).

Se trata, pues, de una manera de abordar una rama interdisciplinaria. La traducción, entendida como el sistema (literario) de los textos traducidos en una cultura, está influenciada por muchos sistemas diferentes que hay que tener en cuenta, en este sentido, la Teoría de los Polisistemas hace hincapié en los procesos culturales que determinan las decisiones del traductor (Bassnett, 1998:108). Esto, obviamente, trajo innumerables críticas al respecto. Se acusó a esta teoría de centrarse demasiado en la cultura meta, en la ideología y en los textos literarios (no olvidemos que en este momento histórico los Estudios Literarios estaban en auge y centrar la atención del investigador en la traducción literaria y no en otros campos era una manera de otorgar mayor estatus a los estudios de traducción).

Este enfoque también explica, en cierta manera, la relevancia de estudiar el texto traducido. Even-Zohar, una de las personas más influyentes en el desarrollo de la Teoría de los Polisistemas, apunta que la historia de la literatura siempre se ha centrado en las obras escritas en versión original y sólo se han mencionado las obras traducidas cuando no había más remedio (1999:223). Esto da como resultado que no exista una visión amplia de la influencia de la literatura traducida (o adaptada) en el conjunto de la literatura.

La razón principal que menciona el autor para mostrar la importancia de estudiar la literatura traducida es que considera «la literatura traducida no solo como un sistema integrante de cualquier polisistema literario, sino como uno de los más activos en su seno» (Even-Zohar, 1999:224). Así, las obras traducidas no sólo tienen relación e influencia en el (poli)sistema literario, sino también entre sí, en tanto que las une el criterio de selección de 
Estudio descriptivo de la traducción para el doblaje del slang en el largometraje Jackie Brown (Quentin Tarantino, 1997)

la cultura receptora y el modo en que adoptan normas del sistema receptor y otros cosistemas locales (Even-Zohar, 1999:224).

Even-Zohar habla de tres casos que pueden hacer que las obras traducidas ocupen una posición central en el polisistema receptor, esto es, que participe «activamente en la configuración del centro del polisistema»(Even-Zohar, 1999:225), a saber, cuando una literatura es joven, cuando una literatura es periférica o débil (o ambas) o cuando existe un «punto de inflexión, crisis o vacíos literarios» (Even-Zohar, 1999:225).

En estos casos que apunta el autor, la literatura del propio polisistema no se ha desarrollado por completo por su juventud o por la influencia de otros polisistemas más fuertes. Las obras traducidas tendrán, en estos casos, más fuerza, más estatus y más influencia en el polisistema receptor y ocuparán lo que Even-Zohar llama «posición central» dentro del polisistema haciendo que las obras propias del polisitema pasen a una «posición periférica».

Si la literatura traducida ocupa una posición central (como ocurre con muchos géneros del cine y la televisión) será esta la que exporte ideas y modelos a la literatura local, que dependerá «estrictamente de la importación» (Even-Zohar, 1999:227), esto es, las traducciones o adaptaciones «participan en el proceso de creación de modelos nuevos» (Even-Zohar, 1999:230). El traductor o adaptador tendrá que tener presente los modelos extranjeros que se infiltran en la cultura del sistema y, por lo tanto, en la literatura local periférica. En este caso, el traductor podrá «ir más allá de las opciones que le ofrece su repertorio local establecido»y «transgredir las convenciones locales» (Even-Zohar, 1999:230). Esto mismo es aplicable a los textos audiovisuales, en tanto que si el director o el género cinematográfico de una película, por ejemplo, ocupan una posición central en el sistema, esta película podrá transgredir las convenciones de su género para reinventarse, para romper con lo establecido y para servir de modelo a aquellos géneros o directores que ocupan una posición periférica.

La importancia de estudiar la literatura traducida y la posición que esta ocupa en el polisistema en el que se inserta se relaciona con nuestro estudio en tanto que si el sistema audiovisual meta no hace uso del slang, o bien será difícil encontrar este registro o las mismas relaciones interpersonales en las traducciones o se hará un uso diferente de dicho registro. Por otro lado, si las películas traducidas (en general, o de un director en concreto, o de un género espcífico, etc.) ocupan una posición central en el sistema meta y hacen uso 
Estudio descriptivo de la traducción para el doblaje del slang en el largometraje Jackie Brown (Quentin Tarantino, 1997)

del slang, el sistema meta de producción propia tomará modelos de las películas traducidas y se observará el uso del slang.

\subsubsection{Normas de traducción}

Otro aspecto relacionado con la teoría del polisistema es el papel que juegan las normas de traducción en cualquier proceso de traslación de una obra de un sistema a otro. A este respecto, Toury analiza los conceptos de regla, norma e idiosincrasia. Los tres conceptos se refieren a pautas o medidas tomadas por el traductor que influyen en las decisiones de traducción. En palabras del autor:

en lo que se refiere a su potencia, las constricciones socio-culturales se han descrito a lo largo de una escala definida por dos extremos: por un lado, las reglas generales y relativamente absolutas, por otro, las puras idiosincrasias. Entre estos dos extremos se extiende un vasto espacio intermedio ocupado por actores intersubjetivos comúnmente denominados normas (Toury, 1999:234).

Así, en el extremo de las pautas que debe o puede seguir el traductor se sitúan las reglas (digamos, por ejemplo, que el autor ha de seguir las reglas gramaticales que dicta la lengua de destino). En el otro extremo están las idiosincrasias, entendidas como los «rasgos, temperamento, carácter, etc., distintivos y propios de un individuo o de una colectividad» (RAE, online), esto es, las pautas subjetivas que toma el traductor, por sus propias características personales. Todo lo que se sitúa en medio son normas, algunas más fuertes o acusadas y otras más débiles o menos recurrentes. Las normas serían pues, las tendencias que, si bien no están estrictamente reglamentadas son aceptadas, en mayor o menor medida, por la sociedad o por el colectivo de traductores.

El que una pauta se defina como regla, norma o idiosincrasia no es algo estrictamente fijo, sino que esta pauta puede pasar de una categoría a otra. Estos cambios en las categorías «muchas veces tienen que ver con los cambios de estatus en una sociedad» (Toury, 1999:235). Las normas son, pues, inestables y cambiantes «por su naturaleza misma» (Toury, 1999:245). De hecho, la actividad traductora contribuye a este cambio, en tanto que la aparición constante de una determinada norma puede hacer que se convierta en regla, por ejemplo. 
Estudio descriptivo de la traducción para el doblaje del slang en el largometraje Jackie Brown (Quentin Tarantino, 1997)

Las normas, sin embargo, puesto que operan «en todas las etapas de la actividad traductora» (Toury, 1999:240, la negrita es mía), «constituyen el concepto clave y el elemento focalizador en cualquier intento de explicar actividades de relevancia social» (Toury, 1999:236). Son, también, observables en la traducción, y es necesario un análisis del producto para ver qué normas operan en la tarea traductora.

En este sentido, hay que entender que lo que antes se consideraba una norma perfectamente establecida en la sociedad podría considerarse hoy en día como un recurso sintomático cuya «presencia es característica de reducidos segmentos» (Toury, 1999:253). Un ejemplo es la traducción del humor en las series de los 90. Los traductores de series como El príncipe de Bel-Air (Andy Borowitz y Susan Borowitz, 1990-1996) o Sabrina, cosas de brujas (Nell Scovell, 1993-2003) no dudaban en la década de los 90 en domesticar el humor a la hora de traducir. Así, podíamos ver alusiones al humorista Chiquito de la Calzada, o a los cantantes el Fary o Manolo Escobar.

\subsubsection{Enfoque funcionalista o Skopostheorie}

Atendiendo a las palabras de Vermeer, se podría decir que la traducción es una acción y toda acción, por definición, tiene un propósito (Vermeer, 2000:221). Este propósito es lo que Vermeer denomina skopos. Llegado el momento de dedicarse a la tarea traductora, el traductor ha de tener en cuenta el objetivo del TO y el del TM que pretende redactar. Estos propósitos pueden ser el mismo o diferir; en palabras del autor: «what the skopos states is that one must translate, consciously and consistently, in accordance with some principle respecting the target text. The theory does not state what the principle is: this must be decided separately in each specific case» (Vermeer, 2000:228). Esto es, el traductor ha de ser consciente de que el TO tiene algún tipo de propósito y que el TM también debe tener algún tipo de propósito que puede (pero no tiene por qué) coincidir con el del TO.

El modelo funcionalista, que parte de la teoría del skopos originada en Alemania, se basa en la idea de que todo texto tiene una función comunicativa. En este sentido, la traducción deberá llevarse a cabo teniendo siempre presente la función que ese nuevo texto ha de cumplir en la cultura receptora. Tomando en cuenta la función que este nuevo texto cumplirá en una nueva sociedad, se tomarán unas u otras decisiones traductológicas. 
Estudio descriptivo de la traducción para el doblaje del slang en el largometraje Jackie Brown (Quentin Tarantino, 1997)

Calzada apunta que «sus defensores [los de la Skopostheorie] abogan por una metodología sistemática sostenida sobre la finalidad del texto meta, que el alumno ha de aprender a deducir del encargo traductor» (2007:174), además, «[El funcionalismo] defiende planteamientos teóricos que surgen directamente de la práctica traductora y pone en primer plano aspectos profesionales y pragmáticos que son insoslayables en nuestro campo» (Calzada 2007:83).

En torno a cómo mantener constantemente presente la función que ha de cumplir el TM en su cultura, Zabalbeascoa (1996) señala que todo texto tiene unos impedimentos u obstáculos (aquí llamados restricciones) que son los que plantean problemas a la hora de traducir (restricciones profesionales, formales, técnicas, socioculturales...). Para poder resolver estos problemas ocasionados por las restricciones hay que confeccionar, señala Zabalbeascoa, una lista jerárquica de prioridades. Hay dos tipos de objetivos o prioridades: las globales y las locales. Aquellas son los objetivos principales del texto, esto es, entre otras cosas, qué función se quiere que cumpla el texto en la cultura meta. Estas prioridades globales van de la mano de la funcionalidad del texto y nunca han de perderse de vista. Las prioridades locales son los objetivos específicos de un segmento del texto en particular, por ejemplo, que la variación lingüística diferencie la clase social de dos personajes en una película. En estos casos, las prioridades locales suelen situarse en un nivel más alto (momentáneamente) en la jerarquía de prioridades. Una vez superadas las restricciones de este segmento en concreto, se volverá a tener en mente las prioridades globales para seguir traduciendo.

Como enfoque y modelo, la Skopostheorie aporta una visión amplia de cómo funciona la tarea traductora. Sin embargo, una visión demasiado funcionalista de la traducción puede, en alguna ocasión, descuidar los procedimientos, estrategias o técnicas traductológicas en sí, algo para lo que el enfoque lingüístico-textual es muy adecuado. Es vital, pues, tener presente cuál es la función comunicativa que pretende cumplir un texto en una sociedad, pero la complementación de este método con otros que tengan más en cuenta el proceso y el acto de traducir a un nivel más microtextual podría ser de gran ayuda. 
Estudio descriptivo de la traducción para el doblaje del slang en el largometraje Jackie Brown (Quentin Tarantino, 1997)

\subsubsection{Modelo lingüístico-textual}

En las primeras décadas del desarrollo de los Estudios de traducción (de los años 50 a los 70 del siglo $\mathrm{xx}$ ) el enfoque lingüístico con base prescriptiva dominaba la investigación en la disciplina. Cuando a mediados de los 70 se creó el Grupo de Lovaina y nació la escuela de la manipulación y la Teoría de los Polisistemas, sus promotores se mostraron totalmente en contra del enfoque lingüístico que «había demostrado ser una herramienta insuficiente» para el análisis y la tarea de la traducción (Marco, 2001:130). Marco apunta que, debido a que en las anteriores tres décadas se había prestado demasiada atención a la linguiística, había una necesidad de restaurar el equilibrio entre esta y otras disciplinas y los estudiosos que abogaban por la teoría del polisistema priorizaron los estudios literarios frente a los demás enfoques. No obstante, cabe recordar que:

a pesar del rechazo que provocaban las aproximaciones lingüísticas a la traducción entre los miembros de la escuela de la manipulación, muchos de ellos eran plenamente conscientes de que cualquier intento de describir traducciones debía pasar por el uso de un modelo de análisis que contuviera ingredientes textuales y contextuales (Marco, 2001:135).

Marco señala que si dejamos por un momento de pensar en el matiz formalista del enfoque lingüístico y «prestamos más atención a la función de los enunciados y de los textos, a su valor comunicativo, a su desarrollo en un contexto, etc., seguramente la herramienta será mucho más útil de lo que pensábamos»(2001:132). Este cambio en la visión del enfoque lingüístico surgió dentro de la disciplina y ha hecho desaparecer muchos de los recelos que había contra él. Este enfoque, además, ha pasado a entenderse como un modelo lingüístico de orientación textual que puede ser compatible con otros enfoques, como la teoría del polisistema o el funcionalismo alemán.

Hoy en día, gracias a este giro en la visión del enfoque lingüístico, los estudios dentro de este modelo han cambiado su forma de afrontar la investigación y «buena parte de los esfuerzos de los lingüistas se centran hoy en día en la constitución y funcionamiento de los textos» (Marco, 2001:133). El autor hace hincapié en que hoy en día es posible tener en cuenta los modelos descriptivos sin dejar de lado el enfoque lingüístico, siempre que sea de orientación textual. Por ejemplo, en el caso del objeto de estudio que aquí nos ocupa, es necesario analizar el fenómeno del slang considerando sus rasgos lingüísticos, pero sin 
Estudio descriptivo de la traducción para el doblaje del slang en el largometraje Jackie Brown (Quentin Tarantino, 1997)

quedarse en ellos o en las posibles equivalencias de los mismos en la lengua meta, sino trascendiéndolos y buscando explicaciones comunicativas, pragmáticas o incluso semióticas que den cuenta del uso de esos rasgos lingüísticos, y por tanto de su función en el texto origen.

\subsubsection{Modelo discursivista (análisis del discurso) o pragmático}

El modelo discursivista tiene su base en la pragmática, entendida como el estudio de las relaciones del lenguaje. Parafraseando a Martínez Sierra (2008), la pragmática estudia los actos interpersonales y sociales cuando se usa el lenguaje, las relaciones entre la lengua y el contexto y los sistemas de conocimiento compartido que hacen posible la comunicación.

Para que exista una comunicación exitosa tiene que existir, según este enfoque, un entorno cognitivo, esto es, un conjunto de supuestos que, junto a los supuestos ya existentes del mundo confeccionan lo que los seguidores de este modelo denominan efecto contextual. El hecho de derivar este efecto es lo que hace que la comunicación sea un éxito. Las conclusiones que se extraen del conocimiento previo y del input hacen que el receptor experimente un cambio significativo en su conocimiento del mundo, algo que enlaza con lo que veíamos en el punto 1.4. Características del slang), cuando hablábamos de las características del slang. En otras palabras, el procesamiento de la información del input, junto con el procesamiento de la información del mundo compartida por el emisor y el receptor, tiene como recompensa que el receptor experimente un mayor conocimiento del mundo (conocimiento más amplio de otros grupos sociales, por ejemplo) o algún tipo de placer (la risa que produce un chiste, por ejemplo).

Ya hemos comentado la necesidad de que el emisor y el receptor compartan algún tipo de información que facilite la comunicación. Siguiendo esta premisa, cualquier texto audiovisual se elabora teniendo como referente a un receptor (espectador) modelo o ideal. Cuando el traductor se enfrenta a este texto, el receptor ya no es el mismo, no es, pues, el receptor ideal. En este caso, habrá un mayor esfuerzo de procesamiento de la información para que la comunicación sea exitosa. Este mayor esfuerzo, sin embargo, no supondrá un mayor efecto cognitivo, esto es, no necesariamente se conocerá o identificará mejor al grupo social asociado con un determinado slang, sobre todo, si se trata de culturas muy 
Estudio descriptivo de la traducción para el doblaje del slang en el largometraje Jackie Brown (Quentin Tarantino, 1997)

diferentes entre sí. Por eso, cuantos más supuestos comunes tengan el receptor meta y el origen más probabilidades habrá de que la información tenga un grado de relevancia parecido y una recompensa pragmática parecida.

Este enfoque, según lo explicado más arriba, es una manera de exponer una teoría de la comunicación humana. Estamos de acuerdo con que la traducción es, sin duda alguna, un acto de comunicación en sí. Pero en el acto de traducir están implicados muchos más factores que en un acto de comunicación común (por ejemplo, hablar por teléfono), por lo que, en cierta medida, esta teoría se queda corta para abarcar todo lo que la tarea traductora supone. Si bien consideramos que no es un modelo adecuado para afrontar la tarea traductora como concepto amplio, entendemos que puede ser un modelo perfectamente válido para una investigación concreta, como esta, que se centre en la importancia de comunicar y que pueda, en cierta medida, obviar otros aspectos de la traducción. En este sentido, consideramos que este enfoque es crucial para abordar un estudio sobre el slang, ya que la recompensa pragmática que su uso supone en el receptor es un elemento clave para que el acto comunicativo se desarrolle con éxito, sobre todo cuando se trata de textos audiovisuales. En general, una disciplina tan interdisciplinaria necesita de un enfoque más heterogéneo que sepa valorar la magnitud de la complejidad de la traducción. En este sentido, este modelo puede resultar reduccionista, en tanto que se centra demasiado en cómo el receptor recibe la información y poco en cómo se produce o en cómo pretende producir esa información el emisor (Martínez Sierra, 2008). Es, pues, un enfoque más, perfectamente válido de forma parcial que ha de complementarse con los demás enfoques presentados hasta el momento.

\subsection{Marco analítico}

El marco analítico, esto es, el conjunto de principios y criterios que se usarán para la recopilación, análisis y evaluación de los datos tiene en cuenta los principios básicos señalados en el apartado anterior en torno a los diferentes enfoques o modelos de análisis en traducción. Será necesario un modelo que integre todos enfoques presentados para poder abordar el estudio de la forma más objetiva y exhaustiva posible.

En este sentido, el estudio tendrá una base lingüístico-textual, puesto que se pretenden analizar las técnicas adoptadas por el traductor en segmentos que presentan 
Estudio descriptivo de la traducción para el doblaje del slang en el largometraje Jackie Brown (Quentin Tarantino, 1997)

restricciones y prioridades relacionadas con una cierta variación lingüística. Se analizarán a un nivel microtextual los cambios que se suceden en estos segmentos para así poder extrapolar que, en general, se usa una u otra técnica en la traducción de la variación lingüística para un texto determinado. A parte del análisis de las técnicas a nivel microtextual, también se analizarán las técnicas para la traducción de la variación lingüística en el nivel textual. Para ello, nos basaremos en la propuesta de Marco (2002) presentada en el apartado 2.3. Técnicas y estrategias para la superación de restricciones). Veremos, además, si ciertas técnicas de traducción en general, o de la traducción de la variación lingüística, pueden asociarse a ciertas normas de traducción. No obstante, también hará falta un análisis de la posición de la película original y la traducida dentro del polisistema en el que se inserta, para ver si ciertas estrategias de importación o exportación de modelos e ideas están justificadas. Por otro lado, no se puede olvidar la funcionalidad que cumple el texto en general y la funcionalidad específica de cada segmento, en nuestro caso, la funcionalidad específica de cada segmento que contenga slang.

\subsubsection{Análisis preliminar}

Antes de presentar la ficha de trabajo para analizar nuestro corpus, habremos de llevar a cabo un análisis preliminar de la película que será objeto de nuestro estudio. Puesto que se trata de un pequeño trabajo de investigación, tomaremos una única película como objeto de estudio. Antes de analizar el slang de nuestra película, será necesario un análisis previo de la misma después de una primera visualización del largometraje. Presentaremos un análisis de la posición que ocupa en el polisistema la película traducida y la original, su género y la modalidad (doblaje) que analizaremos. Además, veremos cuál es la función global de la película y tras ver los resultados del análisis del slang, podremos intuir cuál es el método (interpretativo-comunicativo, literal, libre o filológico) que se ha adoptado para abordar la traducción - a falta de comprobar si el mismo método se emplea en el resto de problemas de traducción que presenta el filme- según la taxonomía de Hurtado (2001:252-253). 
Estudio descriptivo de la traducción para el doblaje del slang en el largometraje Jackie Brown (Quentin Tarantino, 1997)

\subsubsection{Análisis cuantitativo y cualitativo de los datos recopilados}

Después del análisis preliminar y de la recopilación de datos en una ficha que sigue el esquema presentado en el apartado 3.3. Ficha de trabajo), se llevará a cabo un análisis cuantitativo y cualitativo de los datos recopilados.

Hurtado (2001) observa la necesidad de que las técnicas de traducción se entiendan de forma dinámica y funcional, ya que la validez de una u otra técnica estará sujeta al contexto de la traducción que, a su vez, vendrá definido, entre otras cosas, por el género, tipo, modalidad, finalidad y método de traducción. En su clasificación propone 18 técnicas de traducción distintas que afectan al resultado de la traducción y cuya entidad emerge en comparación con el original. Todas las técnicas, según la autora, tienen que ver con las microunidades textuales, tienen un carácter discursivo y contextual y son funcionales. Martí Ferriol (2010) hace una revisión de la taxonomía de Hurtado y presenta una clasificación de 20 técnicas basada en la de esta autora y adaptada a las particularidades de la traducción audiovisual.

Esta clasificación adaptada por Martí Ferriol nos será de ayuda para el análisis cualitativo de los datos, en tanto que podremos ver qué tipo de asociaciones existen entre técnicas lingüístico-textuales (las de Martí Ferriol), técnicas de la traducción de la variación linguiística (las de Marco), normas de traducción, restricciones adicionales y tipo y particularidades del slang. A este respecto, me parece oportuno destacar la idea de Newmark (1988) de que el uso de una técnica no es rígido ni tiene fronteras perfectamente delimitadas y que puede darse la posibilidad de que se usen varias técnicas en un mismo segmento. Por otro lado, habría que apuntar que es posible que, si bien algunas técnicas se llevan a cabo de forma consciente (por ejemplo, la compresión en la elaboración de subtítulos, la ampliación o la omisión) existan otras que, cuando se adquiere experiencia, se lleven a cabo de forma inconsciente (como la modulación, el préstamo naturalizado o el equivalente acuñado).

Con este análisis cualitativo también se pretende llegar a conclusiones sobre normas de traducción, así como sobre las técnicas de traducción y la homofuncionalidad (o no) de los segmentos que presentan slang en la película (y, por tanto, de la película en sí). Esto nos permitirá evaluar las posibles ventajas y desventajas de las decisiones tomadas por el autor y vincular dichas decisiones con la posición dentro del polisistema de la película, con la 
Estudio descriptivo de la traducción para el doblaje del slang en el largometraje Jackie Brown (Quentin Tarantino, 1997)

modalidad de traducción, con el género fílmico o con las particularidades del slang de cada segmento.

Este análisis también nos ayudará a derivar conclusiones cuantitativas respecto a la frecuencia del uso de las diferentes técnicas y normas y la frecuencia de la homofuncionalidad de las muestras analizadas.

\subsection{Ficha de trabajo}

\subsubsection{Procesamiento de datos}

La recopilación y procesamiento de los datos tras varios visionados y el análisis preliminar de la película, se llevarán a cabo mediante un análisis comparativo de la versión original y la traducida. Para ello, es imprescindible un visionado exhaustivo y simultáneo de las dos versiones. En nuestro caso, el visionado exhaustivo se limitará a los segmentos en los que aparezca slang, y dejaremos de lado los demás aspectos susceptibles al análisis del largometraje para trabajos posteriores.

Los datos recopilados mediante este visionado se almacenarán en una tabla para su posterior análisis cuantitativo y cualitativo. Los apartados de la hoja de almacenamiento son los siguientes:

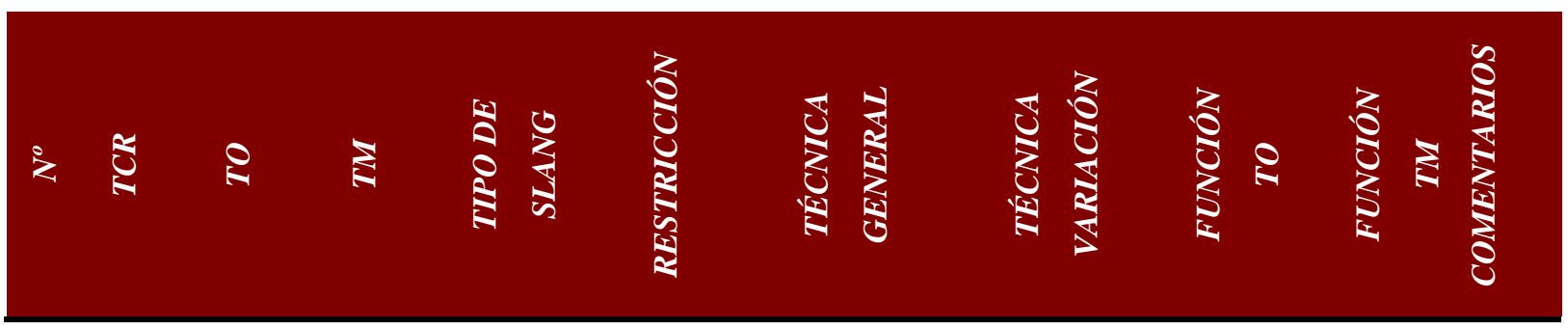

$\underline{\text { NÚMERO }} \rightarrow$ corresponde al número de la muestra en orden cronológico y permitirá que las muestras se almacenen como corpus lingüístico que sirva para posteriores estudios.

$\underline{\mathrm{TCR}} \rightarrow$ corresponde al tiempo en el que comienza la muestra con el formato hh:mm:ss. Permitirá localizar las muestras más fácilmente en la película. 
Estudio descriptivo de la traducción para el doblaje del slang en el largometraje Jackie Brown (Quentin Tarantino, 1997)

$\underline{\mathrm{TO}} \rightarrow$ texto original (en inglés) de la muestra escogida.

$\underline{\mathrm{TM}} \rightarrow$ texto traducido para doblaje (en español) de la muestra escogida.

$\underline{\text { TIPO DE } S L A N G} \rightarrow$ para clasificar la muestra, tomaremos la taxonomía presentada por Graha (2010:21) y la complementaremos con la clasificación de Mayoral (1990:36). (Véase 1.3. Tipos de slang). Este apartado toma conceptos e ideas de los enfoques lingüístico-textual y funcional y discursivista.

$\underline{\text { RESTRICCIÓN }} \rightarrow$ tomaremos la clasificación presentada por Martí Ferriol (2010:83-86). Con esta taxonomía como base, cabe comentar que todos los segmentos con slang, presentarán, por definición, una restricción lingüística. En este sentido, lo que nos interesa es analizar si esta restricción lingüística se ve agravada por otros tipos de restricciones en la clasificación de Martí Ferriol, a saber, restricciones profesionales, formales, semióticas (o icónicas) o socioculturales (2010:85).

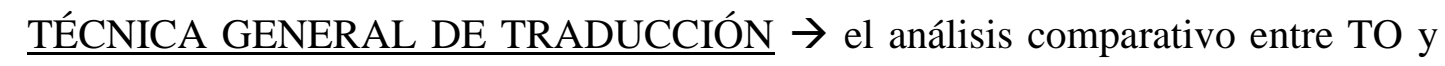
TM permitirá analizar a un nivel microtextual la técnica general adoptada para la traducción. Para ello utilizaremos la propuesta de Martí Ferriol (2010:92-94) (Véase 3.2.2. Análisis cuantitativo y cualitativo de los datos recopilados), que resulta ser una adaptación a la traducción audiovisual de las 18 técnicas propuestas por Hurtado (2001). La taxonomía adaptada de Martí Ferriol incluye un total de 20 técnicas, a saber, préstamo, claco, traducción palabra por palabra, traducción no por uno, traducción literal, equivalente acuñado, omisión, reducción, compresión, particularización, generalización, transposición, descripción, ampliación, modulación, variación, substitución, adaptación y creación discursiva. Este apartado toma conceptos e ideas de la metodología descriptivista de corpus.

\section{TÉCNICA DE TRADUCCIÓN DE LA VARIACIÓN LINGÜÍSTICA} tomaremos la clasificación de Marco (2002) (Véase 2.3. Técnicas y estrategias para la superación de restricciones) para analizar la técnica específica de la traducción de la variación lingüística a un nivel más amplio que el microtextual que permita 
Estudio descriptivo de la traducción para el doblaje del slang en el largometraje Jackie Brown (Quentin Tarantino, 1997)

vislumbrar la funcionalidad del segmento. Este apartado toma conceptos e ideas de los enfoques funcional y polisistémico.

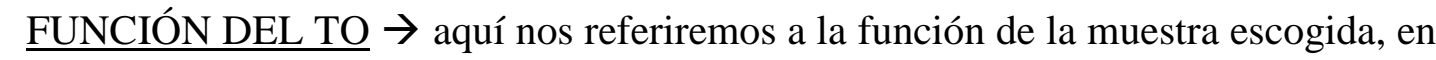
tanto que la función global del texto se habrá analizado en el análisis preliminar. (Véase Tabla 3). Este apartado se basa en el enfoque funcional.

$\underline{\text { FUNCIÓN DEL TM }} \rightarrow$ veremos la función de la traducción de la muestra escogida y analizaremos si existe una homofuncionalidad con el texto origen. (Véase Tabla 3). Este apartado se basa en el enfoque funcional.

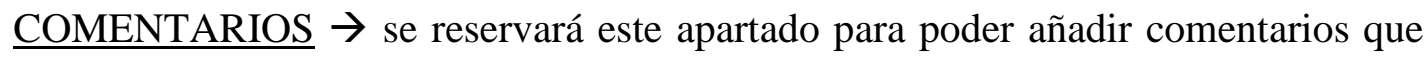
se hayan considerado relevantes durante la recopilación de datos y que puedan ayudar al posterior análisis cualitativo de los mismos.

Por cuestiones prácticas y de presentación, dividiremos la ficha de análisis en cuatro tablas. La primera tabla (Tabla 5) contendrá únicamente las muestras recogidas, esto es, se limitará a los cuatro primeros apartados de la hoja de almacenamiento presentada más arriba. En el resto de tablas (Tabla 6, Tabla 7 y Tabla 8), mantendremos el número de la muestra para poder localizarla con más facilidad y nos centraremos en los siete últimos apartados de la hoja de almacenamiento que componen el análisis de las muestras. La Tabla 6 corresponderá a las muestras en las que el TO y TM presentan una homofuncionalidad. La Tabla 7 corresponderá a las muestras en las que se observa una pérdida de carga pragmática en el TM. La Tabla 8 corresponderá a las muestras en las que el TM presenta una carga pragmática añadida respecto al TO. 
Estudio descriptivo de la traducción para el doblaje del slang en el largometraje Jackie Brown (Quentin Tarantino, 1997)

\section{Justificación del corpus}

Dado el alcance de este estudio, el análisis del slang y su traducción en largometrajes se llevará a cabo solamente en una película. Los resultados del análisis nos servirán, sin embargo, como una muestra que nos permita elaborar hipótesis para trabajos de mayor envergadura. En el futuro, sería interesante analizar un corpus más extenso de películas de este mismo director o de este mismo género, para poder extraer conclusiones más significativas y ser capaces de enunciar normas de traducción.

\subsection{Ficha técnica y datos de la película escogida}

La película escogida para tal efecto es Jackie Brown, dirigida y escrita por Quentin Taratino en 1997. El director se basó en la novela Rum Punch, de Elmore Leonard publicada en 1995, de la que extrajo la mayoría de los diálogos.

A continuación, presentamos una ficha técnica del largometraje:

\section{Título original}

Título de la versión en español

Director

País

Añ o

Género

Duración

Guión

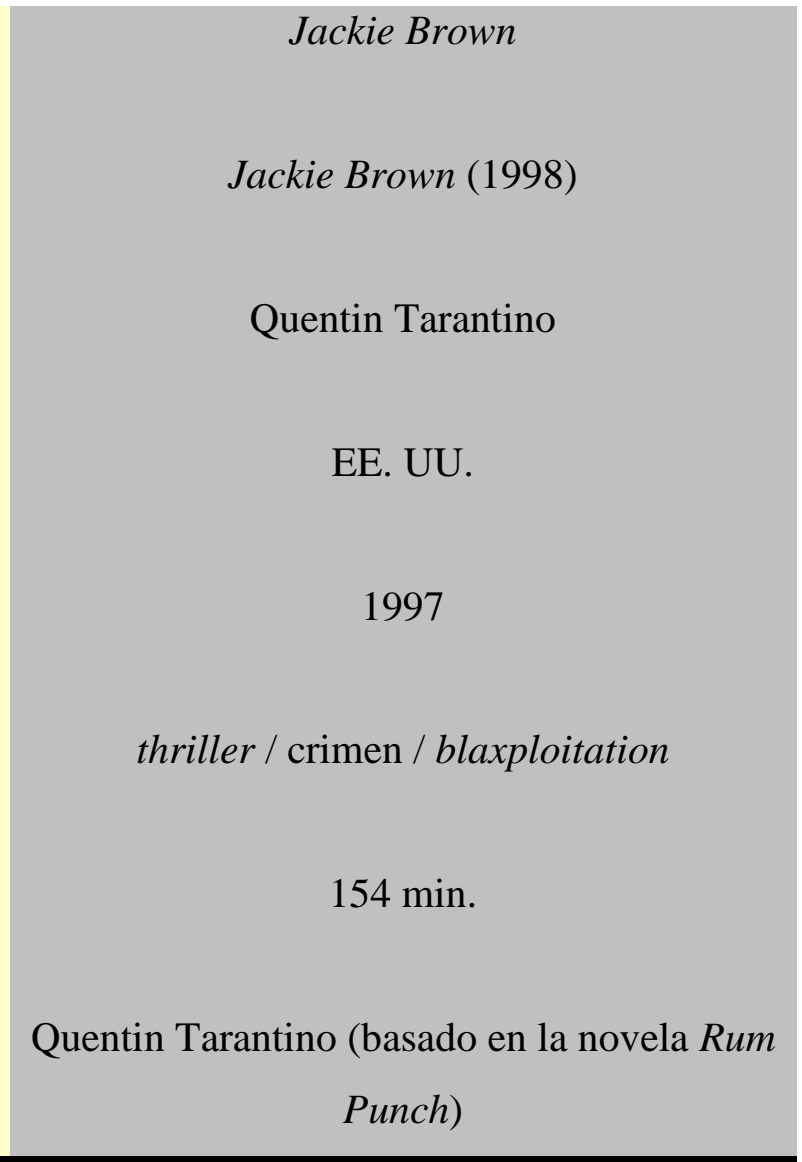


Estudio descriptivo de la traducción para el doblaje del slang en el largometraje Jackie Brown (Quentin Tarantino, 1997)

Producción

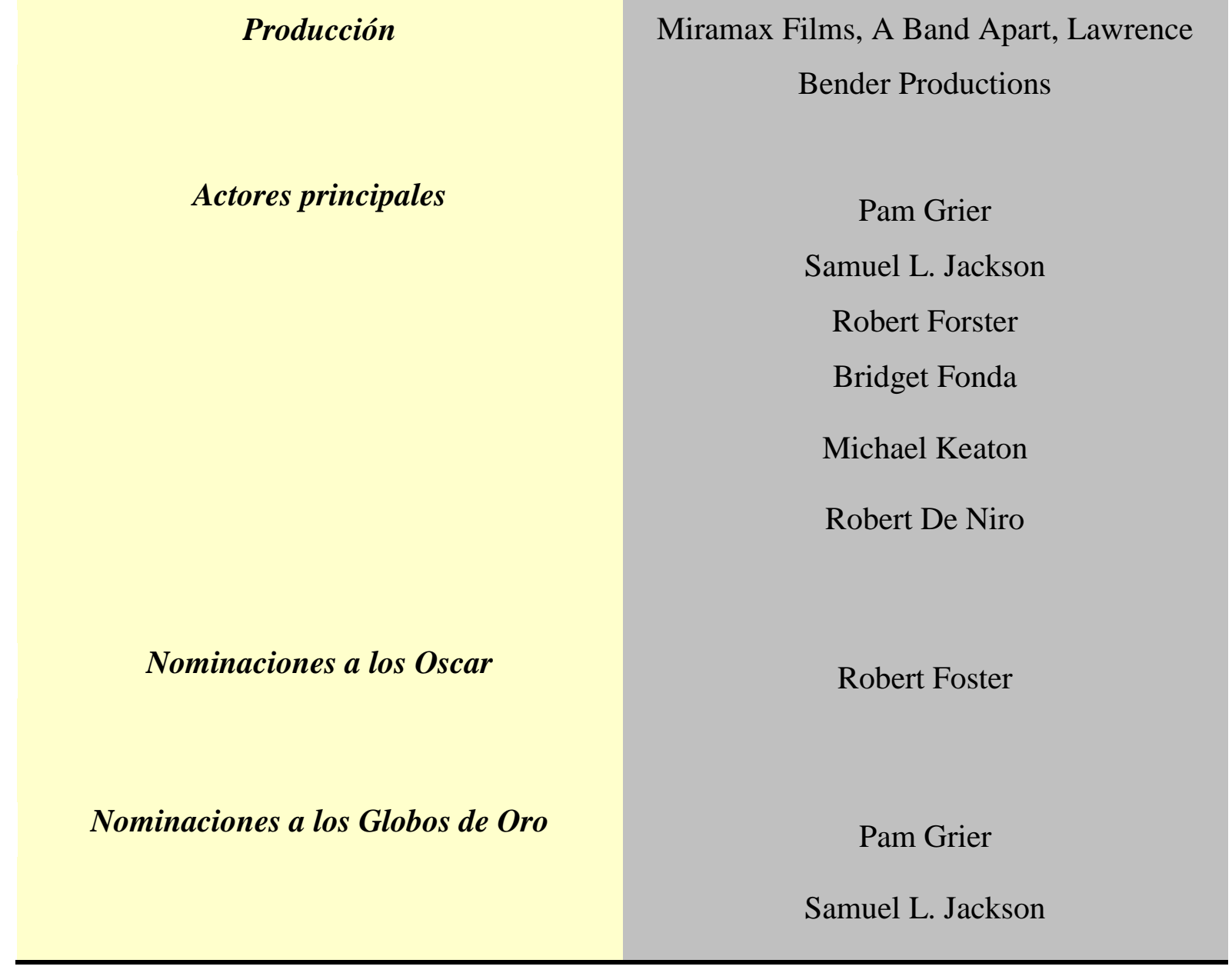

Tabla 4. Ficha técnica del filme Jackie Brown (fuente: The Internet Movie Database, IMDb)

Esta película de Tarantino vio la luz después de las exitosas Reservoir Dogs (1992) y Pulp Fiction (1994), por lo que las expectativas de los seguidores de este director eran muy altas. En este sentido, Jackie Brown recibió duras críticas porque había muchas cuestiones de estilo que se alejaban de sus dos anteriores filmes (menos violencia y sangre, narración más clásica, diálogos extraídos de una novela...). Sin embargo, fue una película bien recibida por la crítica especializada (fuente: IMDb)

\subsection{Sinopsis}

El film está ambientado en Los Angeles (California) en 1995. Jackie Brown (Pam Grier) es una azafata de vuelo que se las arregla para sacar un dinero extra haciendo de correo para un traficante de armas, Ordell Robbie (Samuel L. Jackson), y trayendo dinero 
Estudio descriptivo de la traducción para el doblaje del slang en el largometraje Jackie Brown (Quentin Tarantino, 1997)

en metálico desde México a Estados Unidos. En uno de estos viajes dos agentes de la policía (Michael Keaton y Michael Bowen) la detienen por tráfico de drogas y evasión del capital.

Ordell tramita la fianza de la azafata con un colaborador suyo, Max Cherry (Robert Foster) quien la saca de la cárcel. Ordell se presenta esa misma noche en casa de Jackie con intención de matarla para que no filtre información a la policía, pero ella le ofrece un plan mejor, mediante el cual le ayudará a conseguir medio millón de dólares, dinero con el que Ordell pretende retirarse del negocio de las armas.

Sin embargo, para no ingresar en prisión, Jackie también tendrá que colaborar con la policía en un intento de detener a Ordell. A pesar de que Jackie juega a dos bandas, tiene un tercer plan: quedarse para ella el dinero y huir. Con la ayuda de Max Cherry consiguen engañar a ambas partes. Ordell, su compañera de piso Melanie Ralston (Bridget Fonda) y su ayudante Louis Gara (Robert De Niro) acaban muertos en la trama y Jackie consigue despistar a la policía por lo que respecta al millón de dólares.

Con los delincuentes muertos, Jackie decide huir a España y retirarse con el dinero. Le ofrece a Max Cherry que vaya con ella y empezar una vida juntos, algo que Max, a su pesar, acaba por rechazar.

\subsection{Justificación de la película escogida}

Hay varias razones por las que hemos decidido escoger esta y no otra película. Para empezar, la hemos escogido por su director. Quentin Tarantino es uno de los directores más influyentes de la década de los 90 del siglo pasado y de la primera década del siglo XXI. Este director y sus películas son dignos de estudio, por ejemplo y entre otros motivos, por sus estructuras temporales tan sugestivas, por su dominio del espacio cinematográfico, por sus mensajes escondidos en los escenarios, por su uso de los diferentes planos cinematográficos y de los colores, por sus alusiones a la cultura pop y, sobre todo, por la peculiaridad, imaginación e innovación de sus películas.

Esta argumentación, no obstante, podría usarse para justificar el estudio de cualquier otra película de Tarantino. Además, la de nuestro objeto de estudio no es ni la que más premios ha ganado, ni la más famosa, ni la que mejores críticas obtuvo en su época. ¿Qué tiene esta película, pues, que la diferencia de las demás de Tarantino y la hace susceptible al 
Estudio descriptivo de la traducción para el doblaje del slang en el largometraje Jackie Brown (Quentin Tarantino, 1997)

estudio del slang y su traducción? Este film resulta ser un constante ir y venir de situaciones entre policías y traficantes de armas. Hay, pues, dos grupos sociales claramente diferenciados, que mostrarán en la película formas de hablar y slang diferente. Y lo que es más, la actriz protagonista se ve involucrada en ambos grupos sociales, lo que le llevará a adaptarse al slang de ambos grupos para identificarse con los mismos.

Por otro lado, esta película de Tarantino está considerada como su film de blaxploitation (como Pulp Fiction se identifica con el cine negro o Kill Bill con las artes marciales). La blaxploitation es un movimiento cinematográfico con origen en Estados Unidos en la década de los 70 del siglo pasado que tiene a la comunidad de negros afroamericanos como figura principal. Este movimiento hizo que aumentara el número de actores y espectadores afroamericanos y surgiera, incluso, un género musical específico asociado a estos filmes. Samuel L. Jackson y, sobre todo, Pam Grier — considerada la musa de este género fílmico- son dos actores que representan este movimiento y género en Jackie Brown. En el análisis del slang de la película, por consiguiente, esperamos encontrarnos con términos y fraseología específica de y asociada con la comunidad afroamericana de Estados Unidos.

Se trata, como vemos, de una película en la que coinciden varios grupos sociales que mostrarán diferentes estilos y términos a la hora de hablar. Es, pues, un film en el que no esperamos encontrarnos rasgos del slang asociados a un grupo en concreto, sino más bien pequeños segmentos con diferentes tipos de slang asociados a diferentes grupos sociales, que ayudarán tanto a la caracterización de los personajes como a la trama principal del largometraje. 
Estudio descriptivo de la traducción para el doblaje del slang en el largometraje Jackie Brown (Quentin Tarantino, 1997)

\section{Análisis del corpus}

\subsection{Recopilación de muestras y datos para el análisis}

En el Anexo 1: Muestras de slang original y traducido de Jackie Brown se presentan las muestras de slang extraídas de la película Jackie Brown, siguiendo el esquema que mostrábamos en el apartado 3.3.1. Procesamiento de datos).

En el Anexo 2: Recopilación de datos para su análisis se presentan tres tablas con los datos extraídos a partir de las muestras, según el esquema que mostrábamos en el apartado 3.3.1. Procesamiento de datos). Las tablas corresponden a los datos extraídos de las muestras en las que el TM presenta homofuncionalidad (Tabla 6), datos extraídos de las muestras en las que el TM presenta pérdida de carga pragmática con respecto al TO (Tabla 7) y datos extraídos de las muestras en las que el TM presenta una carga pragmática añadida con respecto al TO (Tabla 8).

Debido a la enorme cantidad de muestras extraídas en torno al slang de los dos gurpos sociales más diferenciados de la película y por cuestiones de tiempo y espacio, hemos decidido acotar las muestras extraídas y obviar aquellas que tienen que ver con el grupo social asociado con los policías.

\subsection{Análisis preliminar}

Para comenzar con el análisis del largometraje analizaremos la posición de la obra original y la traducida en sus polisistemas origen y meta.

Como hemos visto en el apartado 4. (Justificación del corpus), Quentin Tarantino es un director muy influyente que no deja impasible a nadie y cuyas películas resultan ser un modelo de inspiración en la comunidad fílmica. Parece, pues, evidente que cualquier filme original de Tarantino tendrá, en el polisistema en el que se desarrolla, una posición central que le permitirá ser el modelo en el que otros filmes con posición periférica se fijen. La película original (sin traducir) en el polisistema de llegada, sin embargo, tiene una posición obligatoriamente periférica, en tanto que el polisistema de llegada, en nuestro caso, es un país doblador en el que rara vez se proyectan largometrajes en su versión original. No obstante, cabe destacar que existe una comunidad creciente con conocimientos de inglés que opta por ver películas en versión original o con fansubs. Sin embargo, esta comunidad está lejos de representar la realidad de la cultura de llegada. 
Estudio descriptivo de la traducción para el doblaje del slang en el largometraje Jackie Brown (Quentin Tarantino, 1997)

La película traducida también ocupa una posición central en el polisistema de llegada por los mismos motivos que la película original, algo que puede verse en las reseñas externas de la Internet Movie Database (IMDb), si bien Como apuntábamos en el apartado 3.1.2. Teoría de los Polisistemas), el hecho de que este filme ocupe una posición central dentro del polisistema receptor no significa que todo el cine traducido vaya a ocupar una posición central, pero sí que este filme traducido sea el «que exporte ideas y modelos» (Even-Zohar, 1999:227) a la producción de cine local. Even-Zohar apunta que cuando la literatura (o el cine, en este caso) traducida ocupa una posición periférica, este se convierte «en factor principal de conservadurismo»(1999:227). Si, como en este caso, la obra traducida ocupa una posición central, el traductor podrá «ir más allá de las opciones que le ofrece su repertorio local establecido» $\mathrm{y}$ «transgredir las convenciones locales» (EvenZohar, 1999:230).

El género fílmico ante el que nos encontramos, la blaxploitation, ocupa una posición periférica en la cultura origen y, mucho más, en la cultura meta. Esto quiere decir que el género tomará modelos e ideas de otros géneros con más fuerza en el polisistema. Por ejemplo, la primera escena de Jackie Brown en la que la protagonista recorre el aeropuerto por las cintas transportadoras toma su inspiración de la película de 1967 The Graduate, dirigida por Mike Nichols (fuente: IMDb) cuyo género, el drama, sí que ocupa una posición central en el polisistema.

La modalidad de traducción, por su parte, ocupa una posición central en el polisistema de llegada. El doblaje es la modalidad más usada en la traducción de largometrajes al español de España (Chaume, 2004). En este sentido, y como se señala más arriba, el traductor tendrá la opción de transgredir convenciones e, incluso, normas para que su traducción sirva de modelo a otras modalidades en una posición periférica.

Es evidente que la función principal de toda película de estas características es entretener. Sin embargo, este director tan polémico e innovador no deja pasar la oportunidad de intercalar otros objetivos en sus largometrajes. Cabe reiterar el hecho de que el estreno de dos películas con gran esencia tarantiana como Reservoir Dogs (1992) y Pulp Fiction (1994) lanzaron al director a la fama, algo que, junto con su carácter extrovertido y mediático creó un fenómeno y unas expectativas sorprendentes en torno a su figura. Antes de embarcarse en el proyecto de Jackie Brown, Tarantino supo sacarle partido a su personalidad y al rápido éxito que le trajeron sus dos primeros largometrajes. Es posible que, tras el fenómeno Tarantino, el director simplemente quisiera demostrar con este nuevo 
Estudio descriptivo de la traducción para el doblaje del slang en el largometraje Jackie Brown (Quentin Tarantino, 1997)

largometraje que no sólo sabía dirigir películas llenas de violencia, sangre y adrenalina, sino que también era capaz de reescribir diálogos, sacarle partido a las miradas, caracterizar sutilmente a los personajes y mantener la tensión sin recurrir a una violencia tan explícita como la de sus dos anteriores filmes. En definitiva, parece que en la que hasta hoy se ha caracterizado por ser la película menos tarantiana del director, Tarantino pretendía reinventarse a sí mismo y, de alguna manera, romper el molde que él mismo había creado. Por otro lado, el género en el que se enmarca el largometraje y la elección de Pam Grier como actriz principian, hacen pensar que Jackie Brown se presenta como un homenaje a la blaxploitation y a la cultura pop de la década de los 70 del siglo pasado.

\subsection{Análisis cuantitativo y cualitativo de los datos recopilados}

Procedemos ahora al análisis de las muestras de slang recogidas en nuestro corpus. Para ello, presentaremos unas tablas con el segmento del texto origen (replaced segment) y el segmento del texto meta que lo reemplaza (replacing segment). Asimismo, acompañaremos los ejempos del código de tiempo que facilite su búsqueda en el filme (TCR) y numeraremos cada ejemplo. Opcionalmente, añadiremos una casilla más en la que anotaremos la técnica de traducción empleada, y otra con comentarios.

\subsubsection{Muestras en las que el TM presenta homofuncionalidad}

De las 378 muestras extraídas del largometraje 238 muestran una homofuncionalidad del segmento del TM respecto al segmento del TO. Esto supone un 63\% de las muestras analizadas. Las técnicas usadas con más frecuencia son el equivalente acuñado (152 casos), la creación discursiva (96 casos) y la modulación (76 casos).

Tanto la creación discursiva como la modulación se presentan como técnicas clave para mantener la naturalidad del texto y la homofuncionalidad respecto al TO. Esto puede observarse, entre otros, en los siguientes casos (en el TM se subraya el segmento en el que se observa el uso de dichas técnicas):

\begin{tabular}{|c|c|c|c|c|}
\hline$N^{\circ}$ & $T C R$ & TO & $T M$ & $\begin{array}{l}\text { TÉCNICA } \\
\text { GENERAL }\end{array}$ \\
\hline 37 & $00: 11: 40$ & $\begin{array}{l}\text { Man, he's a big one. You're } \\
\text { all tight? }\end{array}$ & $\begin{array}{l}\text { joder, qué grande es. ¿ㅎis } \\
\text { colegas? }\end{array}$ & $\begin{array}{l}\text { modulación } \\
\text { creación }\end{array}$ \\
\hline
\end{tabular}


Estudio descriptivo de la traducción para el doblaje del slang en el largometraje Jackie Brown (Quentin Tarantino, 1997)

\begin{tabular}{|c|c|c|}
\hline 48 & $00: 13: 33$ & $\begin{array}{l}\text { You ain't got to do nothing, } \\
\text { man. }\end{array}$ \\
\hline 63 & $00: 15: 52$ & $\begin{array}{l}\text { They just tryin' to put a } \\
\text { fright in your ass. }\end{array}$ \\
\hline
\end{tabular}

All you have to do is lay in here and hold on to this motherfucker, alright? And I'm going to tell them I'm

83 00:18:29 opening up my trunk to show 'em my goods. I open up the trunk, you pop up, rack this motherfucker.

Hell yeah. First

129 00:35:34 motherfuckin' thing they did.
Jackie ain't no criminal. She ain't used to this kinda treatment. I mean, gangsters don't give a fuck - but for the average citizen, coupla nights in County get fucking with your mind

Yeah, there's another bowl $186 \quad$ 01:00:57 left.

Damn! I bet you come here on a Saturday night, you 201 01:07:04 need nigga repellent keep those motherfuckers off your ass.
Está tirado, tío.

vamos, tío. Sólo intentan acojonarte.

mira, negro, sólo tienes que tumbarte ahí dentro con esta belleza en tus manos ¿vale? Les diré que llevo la mercancía en el maletero y en cuanto lo abra, les apuntas y cargas esta hija de puta.

claro que sí. Fue la primera cabronada que se les ocurrió.

Jackie no es una criminal. No está acostumbrada a estos malos rollos. A un gangster le importa un huevo, pero a un ciudadano corriente, un par de noches en el talego le comen el coco.

generalización modulación reducción reducción creación discursiva

creación discursiva particularización creación discursiva creación discursiva

sí queda para otro viaje

vaya, cuando vienes aquí los sábados por la noche debes necesitar un spray antinegros para alejar a tanto moscón

mala puta generalización

creación

discursiva

creación

discursiva

creación discursiva

En las muestras 48 y 83 , entre otras, se observa la intencionalidad de buscar no equivalentes linguísticos o acuñados que se ajusten a cada segmento, sino de buscar 
Estudio descriptivo de la traducción para el doblaje del slang en el largometraje Jackie Brown (Quentin Tarantino, 1997)

equivalentes funcionales que consigan una reacción del receptor meta lo más parecida posible a la reacción del receptor origen .

Aunque las arriba mencionadas sean las técnicas más usadas en Jackie Brown para mantener la funcionalidad, se observan segmentos en los que, en una misma muestra, se compensa la pérdida de carga pragmática que supone una determinada técnica (la reducción en la mayoría de casos) con el uso de otra técnica compensatoria (la ampliación o amplificación, por ejemplo). Esto se puede observar en las muestras siguientes (en el TO se subraya el elemento reducido en la traducción y en el TM se subraya el elemento que lo compensa):

\begin{tabular}{|c|c|c|c|}
\hline$N^{\circ}$ & $T C R$ & TO & $T M$ \\
\hline 3 & $00: 04: 15$ & $\begin{array}{l}\text { They advertise it as being the } \\
\text { most popular gun in American } \\
\text { crime Can you believe that } \\
\text { shit? }\end{array}$ & $\begin{array}{l}\text { y esos capullos las promocionan como si } \\
\text { fueran el arma más popular del crimen } \\
\text { americano. ¿Cómo pueden tener tanta cara? }\end{array}$ \\
\hline 23 & 00:08:26 & $\begin{array}{l}\text { Start adding these } \\
\text { motherfuckin' figures up, and } \\
\text { you tell me this ain't a business } \\
\text { to be in. }\end{array}$ & $\begin{array}{l}\text { haz los putos cálculos y verás que este } \\
\text { negocio es para forrarse. }\end{array}$ \\
\hline 29 & 00:09:45 & $\begin{array}{l}\text { Goddam, ain't you got better } \\
\text { sense than to be drivin' drunk } \\
\text { with a goddam pistol }\end{array}$ & $\begin{array}{l}\text { eres un capullo, negro. A quién se le ocurre } \\
\text { conducir borracho con una pistola en la } \\
\text { mano. }\end{array}$ \\
\hline 42 & $00: 12: 19$ & $\begin{array}{l}\text { Cost you a thousand for the } \\
\text { bond. }\end{array}$ & eso te costará mil pavos. \\
\hline 109 & $00: 25: 51$ & $\begin{array}{l}\text { I'm gonna have me over } \\
\text { a million. }\end{array}$ & tendré más de un kilo. \\
\hline 210 & 01:08:31 & $\begin{array}{l}\text { I ain't goin anywhere near that } \\
\text { money. }\end{array}$ & $\begin{array}{l}\text { si lo recojo me trincarían, no pienso } \\
\text { acercarme a ese dinero. }\end{array}$ \\
\hline
\end{tabular}

En las muestras recogidas se observan muy pocos casos (un total de 12 casos para todas las muestras recogidas) en los que se opte por una traducción con transgresión de la norma lingüística. Si bien son pocos los casos, estas transgresiones son las que, en ocasiones, permiten mantener la naturalidad en el TM. Algunas de las muestras en las que se observa tal fenómeno son las siguientes (en el TM se subraya el elemento con transgresión): 
Estudio descriptivo de la traducción para el doblaje del slang en el largometraje Jackie Brown (Quentin Tarantino, 1997)

\begin{tabular}{|c|c|c|c|}
\hline$N^{\circ}$ & $T C R$ & TO & $T M$ \\
\hline 74 & $00.17: 16$ & $\begin{array}{l}\text { Oh, man, I wasn't plannin' on } \\
\text { goin no place. It's late as hell, } \\
\text { man. I'm home, I'm high, man. } \\
\text { C'mon. }\end{array}$ & $\begin{array}{l}\text { oh, tío, yo no pensaba ir a ninguna parte. Es } \\
\text { la hostia de tarde, macho, estoy en casa, } \\
\text { colocao, janda ya! }\end{array}$ \\
\hline 77 & $00: 17: 36$ & $\begin{array}{l}\text { Get inside, put some shit on, } \\
\text { let's walk out to the county, } \\
\text { C'mon }\end{array}$ & $\begin{array}{l}\text { Entra en casa y ponte lo que pilles encima. } \\
\text { Iremos a dar un voltio. }\end{array}$ \\
\hline 93 & $00: 19: 20$ & $\begin{array}{l}\text { Man, I wanna help you, but I } \\
\text { won't be locked in no godamm } \\
\text { trunk of no car }\end{array}$ & $\begin{array}{l}\text { quiero echarte una mano, pero no quiero } \\
\text { estar ahí apretao como una puta sardina. }\end{array}$ \\
\hline 214 & 01:10:11 & $\begin{array}{l}\text { So he says, fuck that - moves } \\
\text { over to guns. You can sell guns } \\
\text { wherever there's a demand. No } \\
\text { one gives a shit. He acts like } \\
\text { he's this big international arms } \\
\text { dealer, when, come on, face it, } \\
\text { the only people he ever sold to } \\
\text { were dopers. }\end{array}$ & $\begin{array}{l}\text { lo envió todo a la mierda y se pasó a las } \\
\text { armas. Las armas se venden sin problemas y } \\
\text { todos pasan de ti. Se comporta como un } \\
\text { traficante internacional de armas, sin } \\
\text { embargo, es un matao, sólo se las vende a } \\
\text { camellos y drogatas. }\end{array}$ \\
\hline 220 & 01:12:05 & $\begin{array}{l}\text { Oh, man. You ain't gonna get } \\
\text { serious on me while we are } \\
\text { here chillin' }\end{array}$ & $\begin{array}{l}\text { oh, tío. ¿no irás a ponerte serio? Ahora } \\
\text { estamos de tranquis, ¿verdad? }\end{array}$ \\
\hline 234 & 01:16:05 & $\begin{array}{l}\text { it's my ass facin' the } \\
\text { penitentiary. You send some } \\
\text { hard-headed roc whore, and } \\
\text { she... }\end{array}$ & $\begin{array}{l}\text { es mi culo el que corre peligro. Como me } \\
\text { envíes a una puta crakera la va a joder... }\end{array}$ \\
\hline 249 & 01:28:46 & $\begin{array}{l}\text { Now, hold on there. I ain't } \\
\text { pullin' no shit. It's my godamn } \\
\text { money, I can do the fuck I } \\
\text { wanna do with it. }\end{array}$ & $\begin{array}{l}\text { tranqui, tranqui, yo no te he hecho ninguna } \\
\text { putada. Es mi dinero, ¿de qué vas? Puedo } \\
\text { hacer con él lo que me dé la puta gana. }\end{array}$ \\
\hline 369 & $02: 12: 33$ & $\begin{array}{l}\text { Goddamn! All the time I've } \\
\text { known her, I never heard her } \\
\text { sound scared like that. } \\
\text { Ordinarily she's too cool for } \\
\text { school. }\end{array}$ & $\begin{array}{l}\text { es la hostia, la conozco hace un montón de } \\
\text { años y nunca la había oído tan asustada. } \\
\text { Siempre va de } \underline{\text { tranquis, }} \text {, no se agobia }\end{array}$ \\
\hline
\end{tabular}

Cabe destacar, sin embargo, que el TO contiene muchas más transgresiones lingüísticas, casi todas correspondientes a procedimientos sintácticos propios de personajes con una posición social determinada como los siguientes (en el TO se subraya la transgresión y en el TM se subraya el elemento que la compensa, si es que lo hay): 
Estudio descriptivo de la traducción para el doblaje del slang en el largometraje Jackie Brown (Quentin Tarantino, 1997)

\begin{tabular}{|c|c|c|c|}
\hline $\boldsymbol{N}^{\circ}$ & $T C R$ & TO & $T M$ \\
\hline 12 & 00:05:20 & $\begin{array}{l}\text { It's damn near the same } \\
\text { weapon, and ain't have the half } \\
\text { jammin'problems }\end{array}$ & $\begin{array}{l}\text { es prácticamente igual y esta, tío, funciona } \\
\text { de puta madre }\end{array}$ \\
\hline 203 & 01:07:19 & $\begin{array}{l}\text { I don't think so, but it don't } \\
\text { really matter. }\end{array}$ & no lo creo, pero no importa. \\
\hline 356 & 02:07:33 & $\begin{array}{l}\text { If she go to the police, you tell } \\
\text { her I will name her ass as my } \\
\text { accessory. And we'll go } \\
\text { upstate hand in handcuf } \\
\text { motherfucking hand. }\end{array}$ & $\begin{array}{l}\text { Y si me delata a la policía, dile que cuando } \\
\text { me trinquen la acusaré de ser mi cómplice y } \\
\text { los dos iremos a la cárcel y acabaremos con } \\
\text { las putas manos esposadas. }\end{array}$ \\
\hline
\end{tabular}

Estos procedimientos sintácticos con transgresión resultan difícilmente trasladables al TM sin que este resulte excesivamente familiarizante, algo que chocaría con las convenciones de esta modalidad, asentadas en el inconcsciente colectivo a lo largo de la historia, ya que el doblaje se ha caracterizado históricamente por mostrar un modelo de lengua estándar y altamente conservador (Chaume, 2004). Las transgresiones en el TM están meticulosamente escogidas para mantener la funcionalidad y la naturalidad de escenas con gran carga de slang sin que su uso resulte familarizante. La creación discursiva y la modulación son las dos técnicas más usadas para compensar la dificultad de trasladar el efecto de las transgresiones sin usar estrategias demasiado familiarizantes.

\subsubsection{Muestras en las que el TM presenta pérdida de carga pragmática}

De las 378 muestras extraídas, 103 muestras presentan una pérdida de la carga pragmática, lo que supone un $\mathbf{2 7 . 2 \%}$ de los casos analizados. Las técnicas más presentes en las muestras en las que se observa una pérdida de carga pragmática son la reducción (98 casos) y el equivalente acuñado (30 casos). En nuestras muestras, lo que Martí Ferriol (2010) llama reducción se usa, en realidad, como técnica de nivelación mediante la cual el registro del TO se nivela al nivel estándar en el TM. En 47 de estas 103 muestras la pérdida se produce, en parte o en su totalidad, por la dificultad de trasladar el slang surgido de un procedimiento sintáctico al TM. Ese es el caso de, entre otras, las muestras siguientes (se subraya en el TO el procedimiento sintáctico): 
Estudio descriptivo de la traducción para el doblaje del slang en el largometraje Jackie Brown (Quentin Tarantino, 1997)

\begin{tabular}{|c|c|c|c|}
\hline $\boldsymbol{N}^{\circ}$ & $T C R$ & TO & $T M$ \\
\hline 51 & 00:14:09 & Ain't got a clue. & Ni idea. \\
\hline 52 & $00: 14: 26$ & $\begin{array}{l}\text { He ain't gonna like that. } \\
\text { Beaumont ain't got a doin' time } \\
\text { kinda disposition. }\end{array}$ & $\begin{array}{l}\text { no le va a gustar nada. Beaumont no tiene } \\
\text { carácter para aguantar una condena. }\end{array}$ \\
\hline 66 & 00.16:06 & It ain't what they're telling me. & pues a mí no me han dicho eso. \\
\hline 81 & 00.18 .12 & $\begin{array}{l}\text { They don't want no trouble. } \\
\text { You might argue about price } \\
\text { and shit, but you ain't gotta } \\
\text { worry about them shootin' you } \\
\text { in the back }\end{array}$ & $\begin{array}{l}\text { no suelen buscarse problemas. A lo mejor te } \\
\text { regatean un poco el precio, pero no hay que } \\
\text { preocuparse por si te pegan un tiro por la } \\
\text { espalda. }\end{array}$ \\
\hline 203 & 01:07:19 & $\begin{array}{l}\text { I don't think so, but it don't } \\
\text { really matter. }\end{array}$ & no lo creo, pero no importa. \\
\hline 331 & 01:59:42 & $\begin{array}{l}\text { Why should I think anything's } \\
\text { weird, if I don't know nothin' } \\
\text { about them knowing each } \\
\text { other? }\end{array}$ & $\begin{array}{l}\text { yo no vi nada raro porque no sabía que se } \\
\text { conocían. }\end{array}$ \\
\hline
\end{tabular}

En casi todas las muestras de pérdida de carga pragmática se observa el uso de la reducción (o nivelación, en estos casos). Este es el caso de, entre otras, las muestras 51, 52, 66, 81, 203 y 331 presentadas más arriba. Estas muestras, además, optan por una opción sin marcas y convencional, algo que se repite en muchas de las muestras que presentan pérdida de carga pragmática.

Muchas de las pérdidas están, en parte, justificadas por la presencia de otras restricciones del texto además de la restricción linguiística que por definición presenta la traducción del slang. Estas restricciones son casi siempre formales (como en las muestras 21, 139 y 148, por isocronía), aunque se observa un caso de restricción sociocultural (muestra 45) y un caso de restricción icónica (muestra 36) que han podido contribuir a la pérdida de la funcionalidad:

\begin{tabular}{ccll}
\multicolumn{1}{c}{$\boldsymbol{N}^{\circ}$} & \multicolumn{1}{c}{$\boldsymbol{T} \boldsymbol{T}$} & \multicolumn{1}{c}{$\boldsymbol{T M}$} \\
\hline 21 & $00: 07: 58$ & $\begin{array}{l}\text { Shit, I'm immpressed! } \\
\text { Who's that big Mandingo }\end{array}$ & estoy impresionada \\
36 & $00: 11: 34 \begin{array}{l}\text { looking nigga you got up there } \\
\text { in that picture with you? }\end{array}$ & $\begin{array}{l}\text { iquién es ese negro enorme con pinta de } \\
\text { Mandinga que sale en la foto? }\end{array}$ \\
\hline
\end{tabular}


Estudio descriptivo de la traducción para el doblaje del slang en el largometraje Jackie Brown (Quentin Tarantino, 1997)

\begin{tabular}{|c|c|c|c|}
\hline 45 & $00: 12: 38$ & $\begin{array}{l}\text { I think they're kinda prejudiced } \\
\text { against brothers from down the } \\
\text { South out here. }\end{array}$ & $\begin{array}{l}\text { y por aquí son muy racistas con los } \\
\text { hermanos del sur, ¿sabes? }\end{array}$ \\
\hline 139 & $00: 37: 06$ & I just ain't got it with me & pero no la llevo encima. \\
\hline 148 & $00: 46: 07$ & $\begin{array}{l}\text { The same guy who put my ass } \\
\text { in jail. }\end{array}$ & el mismo tío que me metió en ella \\
\hline
\end{tabular}

En ocasiones, gracias al significado transmitido por otros códigos de significación del texto audiovisual, estas pérdidas de la carga pragmática hacen que cambie la funcionalidad de la escena. Este es el caso de la muestra 36 (que se ve compensada por lo que aparece en el canal visual).

Sin embargo, lo que realmente determina casi todas las pérdidas en la funcionalidad (en 92 de las 103 muestras con pérdida) es la decisión de optar por una traducción más convencional que natural. Algunas de las traducciones que optan por la convencionalidad lo hacen debido a las restricciones formales (como el caso de la muestra 124, por respetar la isocronía), por escoger un equivalente acuñado poco natural (como en la muestra 88) o por no presentar un registro vulgar tan marcado como en el TO (como ocurre con puñetero en la muestra 61). Esta convencionalidad, en ocasiones, se presenta mediante un lenguaje prefabricado (Chaume, 2004) demasiado extranjerizante o propio del tipo de lenguaje que parece darse sólo en las películas (dubbese, Freddi y Pavesi, 2009) pero que difícilmente se encuentra en la realidad. Este es el caso claro de las muestras 88, 107 y 123 (se subraya en el TM el elemento que hace que la traducción suene a traducción, a la lengua del doblaje, a dubbese):

\begin{tabular}{|c|c|c|c|}
\hline$N^{\circ}$ & $T C R$ & TO & $T M$ \\
\hline 18 & 00:06:23 & $\begin{array}{l}\text { Girl, don't make me put my } \\
\text { feet in your ass. }\end{array}$ & no me obligues a darte una patada en el culo \\
\hline 61 & 00:15:32 & $\begin{array}{l}\text { You goddam right! See, that's } \\
\text { how that shit works. You get } \\
\text { your ass in trouble, I get your } \\
\text { ass out. That's my } \\
\text { motherfucking job. And I don't } \\
\text { mind tellin ya, nigga, it's steady } \\
\text { work }\end{array}$ & $\begin{array}{l}\text { no te quepa la menor duda, así funciona este } \\
\text { mundo. La jodes y tienes problemas, y yo } \\
\text { pongo tu culo a salvo, ese es mi puñetero } \\
\text { trabajo. Y no olvides nunca, negro, que yo } \\
\text { no fallo. }\end{array}$ \\
\hline 88 & $00: 18: 52$ & Man, I ain't riding in no & no pienso viajar en un jodido maletero ni un \\
\hline
\end{tabular}


Estudio descriptivo de la traducción para el doblaje del slang en el largometraje Jackie Brown (Quentin Tarantino, 1997)

godamm trunk for no minute, minuto.

man

Including telling the Federal government any and every

$107 \quad 00: 25: 12$ motherfucking thing about my black ass.

incluyendo contarle a los federales todo, con pelos y señales, sobre mi negro culo.

\begin{tabular}{|c|c|c|}
\hline 123 & $00: 31: 16$ & $\begin{array}{l}\text { I'm not saying } \\
\text { godamm word. }\end{array}$ \\
\hline 124 & $00: 32: 03$ & My diet shit. \\
\hline
\end{tabular}

no diré ni una maldita palabra más. era mi desayuno.

Además, cabe destacar que Jackie Brown presenta mucho slang asociado a un determinado grupo social que simplemente no existe en la cultura meta. En este sentido, la película se enmarca en un contexto sociocultural que no puede manipularse y las situaciones comunicativas que se presentan no siempre pueden encontrar un equivalente en la cultura meta. Por estas razones, muchos segmentos traducidos no encajan en el TM de la misma manera que en el TO. Aunque son cuestiones que el espectador comprende perfectamente, difícilmente puede evitarse una pérdida de la carga pragmática de algunos segmentos. Este es el caso de las siguientes muestras (en el TO se subrayan los elementos con algún tipo de componente sociocultural que no funcionan de la misma manera en el TM):

\begin{tabular}{|c|c|c|c|}
\hline$N^{\circ}$ & $T C R$ & TO & $T M$ \\
\hline 36 & $00: 11: 34$ & $\begin{array}{l}\text { Who's that big Mandingo } \\
\text { looking nigga you got up there } \\
\text { in that picture with you? }\end{array}$ & $\begin{array}{l}\text { ¿quién es ese negro enorme con pinta de } \\
\text { Mandinga que sale en la foto? }\end{array}$ \\
\hline 45 & $00: 12: 38$ & $\begin{array}{l}\text { I think they're kinda prejudiced } \\
\text { against brothers from down the } \\
\text { South out here. }\end{array}$ & $\begin{array}{l}\text { y por aquí son muy racistas con los } \\
\text { hermanos del sur, ¿sabes? }\end{array}$ \\
\hline 47 & $00: 13: 20$ & $\begin{array}{l}\text { Yo, yo. You take out some } \\
\text { music, while you're sitting in } \\
\text { the car. }\end{array}$ & $\begin{array}{l}\text { Escucha un poco de música mientras } \\
\text { esperas. }\end{array}$ \\
\hline 54 & $00: 15: 01$ & It's your benefactor, nigga & tu benefactor, negro. \\
\hline 57 & $00: 15: 24$ & Yeah, my nigga. & mi negro. \\
\hline 146 & $00: 45: 45$ & $\begin{array}{l}\text { Well, then, why don't you be a } \\
\text { good hostess and make a good }\end{array}$ & $\begin{array}{l}\text { pues sé una buena anfitriona y prepárame } \\
\text { un destornillador }\end{array}$ \\
\hline
\end{tabular}


Estudio descriptivo de la traducción para el doblaje del slang en el largometraje Jackie Brown (Quentin Tarantino, 1997)

brother a screwdriver?

$\begin{array}{lll}156 & 00: 48: 47 & \begin{array}{l}\text { Now take your hands from } \\ \text { around my throat, nigga. }\end{array} \\ 185 & 01: 00: 44 & \underline{\text { Yo }} \\ 203 & 01: 07: 19 & \begin{array}{l}\text { I don't think so, but it don't } \\ \text { really matter. }\end{array}\end{array}$

You're takin' a hell of a chance

271

\section{1:33:22 kid.}

ahora quita tus manos de alrededor de mi cuello, negro.

¿sí?

no lo creo, pero no importa.

te estás arriesgando demasiado.

Si bien, en general, podríamos decir que la mayoría de pérdidas de carga pragmática están justificadas o no son demasiado significativas, sí que se observan muestras en las que, por diferentes razones, la pérdida de la funcionalidad es más importante. Este es el caso de las siguientes muestras (a las muestras se adjuntan los comentarios extraídos de la Tabla 7):

\begin{tabular}{cccc}
$\boldsymbol{N}^{\circ}$ & TCR & \multicolumn{1}{c}{ TO } & \multicolumn{1}{c}{ TM } \\
\hline 35 $00: 11: 24$ & $\begin{array}{l}\text { And I need me a } \\
\text { bond for ten } \\
\text { thousand }\end{array}$ & $\begin{array}{l}\text { necesito una fianza } \\
\text { de diez mil. }\end{array}$
\end{tabular}

Who's that big Mandingo looking

36 00:11:34 nigga you got up there in that picture with you?

¿quién es ese negro enorme con pinta de Mandinga que sale en la foto?

I'm not saying

123 00:31:16 another godamm word.

Then we ain't got 134 00:36:15 $\begin{aligned} & \text { no...what you call } \\ & \text { that shit? }\end{aligned}$

Well, then, why

146 00:45:45 good hostess and no diré ni una maldita palabra más.

entonces no tenemos nada de... ¿cómo se llama eso?

pues sé una buena anfitriona $\mathrm{y}$ prepárame un destornillador make a good

\section{COMENTARIOS}

en este fragmento es difícil superar la restricción lingüística de orden sintáctico. Primera ocasión en la que el slang se usa para rebelarse contra el lenguaje estándar. También es la primera vez que en la película, Ordell se encuentra con alguien que no es de su entorno.

Según el Urbandictionary, Mandingo no sólo se refiere a alguien de una tribu de África, sino también «African male who knows that he has a huge penis that can hit all night and keep a female comin back for more» ese aspecto se pierde en la traducción

esta escena incluye varios segmentos con uso de slang para rebelarse contra el lenguaje estándar. Jackie Brown pretende rebelarse ante los policías y mostrar, al igual que ellos, una actitud desafiante.

Sin embargo, el uso de la palabra «maldita» resulta muy convencional e, incluso, extranjerizante.

caso claro en el que se usa el slang para provocar empatía.

se pierde la intención de provocar empatía con la expresión «good brother» 
Estudio descriptivo de la traducción para el doblaje del slang en el largometraje Jackie Brown (Quentin Tarantino, 1997)

brother a

screwdriver?

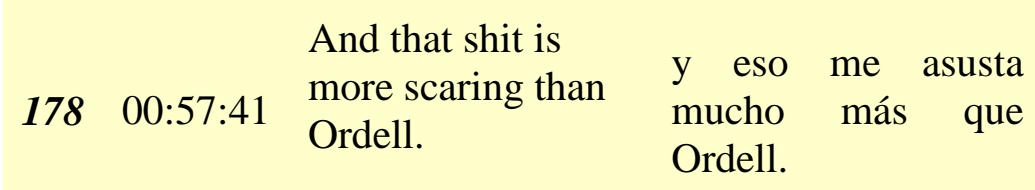

Because they are

259 01:30:24 gonna be watching my ass, hard.

He ain't here right

352 02:06:16 now, man. porque voy a tener a la poli muy encima desde el TCR 00:55:00 hasta esta muestra, hay muchos casos de pérdida de funcionalidad. Es posible que sea porque la conversación es entre Jackie y Max Cherry. Jackie hace uso de slang, pero Max Cherry (cuando habla con ella, al menos) no. Dada la situación comunicativa y la relación entre los personajes, la pérdida de funcionalidad en esta escena no es tan relevante como en otras. pérdida considerable. El registro de de esta muestra intenta hacer ver que Jackie pretende que piensen que no les va a fallar, que como están dentro del mismo grupo social no les delatará a la policía

la dificultad de trasladar el procedimiento sintáctico y la restricción formal hacen que se pierda la funcionalidad. Al ser la única frase que Winston le dice a Ordell en toda la película, no se puede recuperar la funcionalidad en otros segmentos

\subsubsection{Muestras en las que el TM presenta carga pragmática añadida}

De las 378 muestras extraídas 37 presentan una carga pragmática añadida en el TM respecto al TO, lo que supone un $\mathbf{9 . 8 \%}$ de todas las muestras. Se observan un total de 12 casos de particularización, 11 casos de creación discursiva, 8 casos de ampliación y 8 casos de modulación, que son las técnicas que con más frecuencia se usan. Casi todas las muestras en las que se observa una funcionalidad añadida (29 de 37) parten de un segmento del TO en el que no se observa slang. Además, en el 100\% de los casos se opta por una técnica que aporte naturalidad al TM.

Aunque el hecho de que exista una adición de tipo pragmático nos haga pensar que el TM pueda estar modificando la caracterización de los personajes, en realidad no es así. Muchos de los casos que añaden un rasgo no existente en el TO se muestran como segmento compensatorio para otros segmentos en los que existe una pérdida pragmática. Ese es el caso de las siguientes muestras, en las que, a pesar de que claramente se añada slang al TM, la caracterización de los personajes no se ve afectada: 
Estudio descriptivo de la traducción para el doblaje del slang en el largometraje Jackie Brown (Quentin Tarantino, 1997)

\begin{tabular}{|c|c|c|c|}
\hline$N^{\circ}$ & $T C R$ & TO & $T M$ \\
\hline 113 & $00: 27: 24$ & Bad knees & tengo las rodillas jodidas \\
\hline 119 & $00: 30: 02$ & $\begin{array}{l}\text { Jackie, do you know a guy } \\
\text { named Beaumont Livingston? }\end{array}$ & $\begin{array}{l}\text { Jackie, ¿conoce a un tipejo llamado } \\
\text { Beaumont Livingston? }\end{array}$ \\
\hline 195 & 01:04:06 & C'mon, don't lie & no cuela... \\
\hline
\end{tabular}

Si bien la mayoría de significados pragmáticos añadididos resultan compensar otros segmentos con reducción o con pérdida de funcionalidad, sí que se observan algunas muestras en las que la adición de carga pragmática sí que es relevante. Es el caso de las siguientes muestras (se subraya en el TM los elementos que aportan una adición significativa de esa carga y se añaden los comentarios de la Tabla 8):

\begin{tabular}{|c|c|c|c|c|}
\hline$N^{\circ}$ & $T C R$ & TO & $T M$ & COMENTARIOS \\
\hline 97 & $00: 19: 35$ & $\begin{array}{l}\text { Now look, man. All I'm } \\
\text { asking you to do is get in the } \\
\text { trunk and hold to this } \\
\text { fucking shotgun and point it } \\
\text { at peoples'head when I open } \\
\text { it }\end{array}$ & $\begin{array}{l}\text { mira, tío, sólo te he } \\
\text { pedido que te metas } \\
\text { ahí, cojas esta } \\
\text { escopeta y apuntes a } \\
\text { esos amarillos cuando } \\
\text { abra el maletero. }\end{array}$ & $\begin{array}{c}\text { el TM, con el apelativo } \\
\text { «amarillos» también pretende } \\
\text { mostrar una desvinculación de } \\
\text { cierto grupo social }\end{array}$ \\
\hline 133 & $00: 36: 11$ & $\begin{array}{l}\text { You are not my client until } \\
\text { you get busted and I bond } \\
\text { you out. }\end{array}$ & $\begin{array}{l}\text { no serás cliente mío } \\
\text { hasta que te trinquen } \\
\text { y te saque bajo } \\
\text { fianza. }\end{array}$ & $\begin{array}{l}\text { en el TM el slang es mucho más } \\
\text { marcado, algo que hace que se } \\
\text { advierta cierta empatía entre los } \\
\text { personajes. }\end{array}$ \\
\hline 219 & $01: 11: 13$ & $\begin{array}{l}\text { That's not what I'm saying at } \\
\text { all }\end{array}$ & eso es una gilipollez & $\begin{array}{c}\text { el slang otorga cierta actitud al } \\
\text { personaje que no se muestra en el } \\
\text { TO }\end{array}$ \\
\hline 269 & $01: 32: 55$ & So he's sweating a little bit? & está cagao de miedo. & $\begin{array}{l}\text { se advierte una actitud desafiante } \\
\text { que muestra la actitud del grupo } \\
\text { social de forma más marcada en } \\
\text { el TM que en el TO }\end{array}$ \\
\hline 314 & 01:56:04 & $\begin{array}{l}\text { If you had to do it, then you } \\
\text { had to do it }\end{array}$ & $\frac{\text { la has jodido bien }}{\text { jodida, tío }}$ & $\begin{array}{c}\text { el TM muestra una actitud } \\
\text { asociada al slang que no muestra } \\
\text { el TO. }\end{array}$ \\
\hline
\end{tabular}

Como apuntábamos más arriba para los casos en los que se producía una pérdida en la carga pragmática, también en algunos de los casos en los que existe una adición pragmática, la funcionalidad de la escena no se ve afectada, ya que otros códigos de significación la compensan. Este es el caso de la muestra 314, en la que la trama del filme compensa la adición pragmática del segmento. 
Estudio descriptivo de la traducción para el doblaje del slang en el largometraje Jackie Brown (Quentin Tarantino, 1997) 
Estudio descriptivo de la traducción para el doblaje del slang en el largometraje Jackie Brown (Quentin Tarantino, 1997)

\section{Conclusiones}

\subsection{Resultados del análisis}

Tras el análisis de los datos llevado a cabo en el apartado anterior, estamos en disposición de inferir algunas conclusiones que se derivan del análisis de los datos:

A rasgos generales, se trata de una traducción homofuncional donde se prioriza la naturalidad de los enunciados.

Las técnicas más usadas para mantener la funcionalidad del TO son la creación discursiva, la modulación y el equivalente acuñado.

Las pérdidas de carga pragmática en el TM se producen, en su mayoría, por la dificultad de trasladar a la lengua meta los rasgos del slang en ciertos niveles de la lengua (rasgos del nivel sintáctico como ain't o como la falta de sujeto al principio de la frase, o procedimientos léxicos formales como el apócope o la aféresis en fella, gonna, ya o nigga), porque finalmente se opta por una traducción convencional y sin marcas y/o por el uso de la técnica de reducción.

Las pérdidas pragmáticas concretas de segmentos determinados no suponen una pérdida en la funcionalidad de la escena a la que pertenecen ni de la película. Otros elementos tanto lingüísticos como visuales de la película ayudan a compensar esas pérdidas.

Los segmentos con carga pragmática añadida (compensación) pretenden ser una estrategia compensatoria para los segmentos donde hay una pérdida en la carga pragmática y no suponen un cambio en la caracterización de los personajes.

El hecho de que se observen pocas transgresiones lingüísticas en el TM hace que la traducción no resulte excesivamente familiarizante, algo que no encajaría con el contexto sociocultural en el que se enmarca la historia.

Las pocas transgresiones observadas sirven para compensar pérdidas en la carga pragmática o para mantener la funcionalidad de determinados segmentos con mucha variación lingüística en el TO. 
Estudio descriptivo de la traducción para el doblaje del slang en el largometraje Jackie Brown (Quentin Tarantino, 1997)

\subsection{Conclusiones generales sobre la traducción del slang en el corpus}

En cuanto a las conclusiones generales sobre la traducción del slang en el corpus analizado, concluimos lo siguiente:

Según lo analizado, intuimos que el método usado para la traducción de las muestras de slang que componen nuestro corpus, según la taxonomía de Hurtado (2001:252-253) es el interpretativo-comunicativo. Esta afirmación se basa en la conclusión sobre la homofuncionalidad de ambas versiones, y también en el tipo de técnicas empleadas (de tipo ligeramente familiarizante). Haría falta un análisis exhaustivo de los demás problemas de traducción del largometraje para poder afirmarlo.

La presencia de grupos sociales que no se encuentran en la cultura meta (y la presencia del slang asociado a ese grupo) no hace ni que el texto sea intraducible ni que las escenas y la película en general pierdan su carga pragmática. Las imágnes, la fotografía, la planificación o el montaje, así como la trama argumental y los rasgos suprasegmentales en la enunciación de los diálogos compensan la pérdida de dichos elementos.

De cada conclusión presentada en este capítulo puede derivarse una norma de traducción que dé cuenta de las prioridades establecidas y, en definitiva, de las decisiones tomadas por el traductor.

\subsection{Grado de cumplimiento de los objetivos y validación de hipótesis}

Los objetivos que se pretendían alcanzar con el presente trabajo y que se presentaban al incio del mismo eran los siguientes:

Describir el tipo de slang que aparece en el largometraje.

Estudiar de qué manera un tipo de slang es asociable a ciertas técnicas de traducción general o técnicas de traducción de la variación lingüística.

Describir la función que cumple el slang en la película original y analizar si la versión doblada es homofuncional. 
Estudio descriptivo de la traducción para el doblaje del slang en el largometraje Jackie Brown (Quentin Tarantino, 1997)

Teorizar sobre qué ventajas o desventajas puede tener la jerarquización de ciertas prioridades o el uso de ciertas técnicas de traducción.

Podemos afirmar que, a grandes rasgos, los objetivos planteados para el trabajo se han cumplido. La especulación de las ventajas y desventajas no se ha llevado a cabo tan exhaustivamente como el resto de objetivos. Sin embargo, tanto en los comentarios de las Tablas 6, 7 y 8, como en el análisis de los datos extraídos sí que se observan las consideraciones respecto a este punto.

Dado que lo que se presenta es una estudio empírico observacional de carácter exploratorio, el trabajo no tiene la intención previa de preguntarse por una idea en concreto, de probar una hipótesis en concreto o de plantear o llegar a una idea en concreto. Por este motivo, no se han planteado hipótesis concretas ni podemos validarlas.

\subsection{Perspectivas de futuro}

Cabe destacar que este trabajo sólo abarca y puede inferir conclusiones y normas para un tipo concreto de problemas de traducción, así como para una pequeña parte de lo que comprenden los estudios en TAV y los Estudios de Traducción. Sería muy recomendable llevar a cabo estudios similares al que aquí se presenta en torno a otras cuestiones, y con miras a otros objetivos distintos pero vinculables a los nuestros, para tener una visión más amplia del método, las estrategias y las técnicas usadas en la traducción y poder derivar normas de traducción más específicas. En resumen, tras la reflexión de lo que este trabajo representa, estamos en disposición de afirmar que el presente estudio puede ampliarse con:

$>\quad$ el estudio de otras películas del mismo género

$>\quad$ el estudio de otras películas del mismo director

$>\quad$ el estudio de otras películas de otros géneros

$>\quad$ el estudio de otros elementos de esta misma película (además del slang) que supongan problemas en la traducción y que ayuden a descubrir cuál ha sido el método de traducción global

$>\quad$ el estudio de la traducción del slang con otros pares de lenguas diferentes 
Estudio descriptivo de la traducción para el doblaje del slang en el largometraje Jackie Brown (Quentin Tarantino, 1997)

$>$ el estudio de la traducción del slang en otras modalidades de traducción audiovisual (como la subtitulación y la subtitulación para sordos que ayuden a completar el mapa de la TAV)

Todas estas posibles investigaciones futuras ayudarían a completar todos esos aspectos que este trabajo no alcanza a analizar. 
Estudio descriptivo de la traducción para el doblaje del slang en el largometraje Jackie Brown (Quentin Tarantino, 1997)

\section{$\underline{\text { 7. Bibliografía }}$}

Adams, M. (2009): Slang - The People's Poetry, Oxford Press, Indianapolis.

BASSNETT, S. (1998): «Researching Translation Studies: The Case for Doctoral Research», en Bush, P. y MALMKJÆR, K. (eds.) Rimbaud's Rainbow: Literary Translation in Higher Education, John Benjamins, Amsterdam y Philadelphia (105-18).

BELL, R. T. (1991): Translation and Translating, Theory and Practice, Longman, Londres.

CAlvo Ferrer, J.R. (2010): «Análisis contrastivo de las escuelas lingüísticas de traducción y de la escuela de polisistemas aplicado al estudio del argot» en Tonos Digital. Revista electrónica de estudios filológicos, (20).

CAlZAda PÉRez, M. (2007): El espejo traductológico: teorías y didácticas para la formación del traductor, Octaedro, Barcelona.

CATFORD, J.C. (1965): A Linguistic Theory of Translation: an Essay on Applied Linguistic, Oxford University Press. Londres.

CHE SuH, J. (2002): «Compounding Issues on the Translation of Drama/Theatre Texts» en Meta, (47/1: 51-57).

Dumas, B.K., y LighteR, J. (1978): «Is Slang a word for linguists?» en American Speech (53: 5-17).

EbLE, C. (1996): Slang and Sociability: In-Group Language among College Students, University of North Carolina Press, Chapel Hill y Londres.

ERIKSEN, M.H. (2010): Translating the use of slang- A study of microstrategies in subtitling with a view to researching the transfer of the use of slang from source text to target text with I Love You, Man as empirical example, including a study of the function of slang. Tesis doctoral de Aarhus School of Business, Aarhus University. 
Estudio descriptivo de la traducción para el doblaje del slang en el largometraje Jackie Brown (Quentin Tarantino, 1997)

Even-ZoHAR, I. (1999): «La posición de la literatura traducida en el polisistema literario» en Iglesias Santos, M. (ed.) Teoría de los Polisistemas, Arco, Madrid (223-231).

FERnÁNDEZ, R. y SAMANIEGO, E. (2002): «La variación lingüística en los Estudios de Traducción» en Epos: Revista de Filología, Madrid (18: 325-342).

Freddi, M. y PAVESI, M. (eds.) (2009): Analysing Audiovisual Dialogue: Linguistic and Translational Insights, Clueb, Bolonia.

GARCía YeBra, V. (1994): Traducción: historia y teoría, Gredos, Madrid.

GrahA, E.B. (2010): An Analysis of Slang Translation in the Subtitles of The Departed Movie. Tesis presentada en la Univesitas Pendidikan, Indonesia.

HATim, B. E MASON, I. (1990): Discourse and the Translator, Longman, Londres.

Hatim, B. E Mason, I. (1997): The Translator as Communicator, Routledge, Londres.

House, J. (1977): A Model for Translation Quality Assessment, Gunter Narr, Tübingen.

HuRTAdo AlbiR, A. (2001): Traducción y Traductología: Introducción a la traductología. Cátedra, Madrid.

MARCO BORILlO J. (2001): «La descripción y comparación de traducciones: hacia un modelo integrador» en Sendebar, (12: 129-152).

MARCO BorILlo, J. (2002): El fil d'Ariadna: anàlisi estilística i traducció literària, Eumo, Vic.

MARTí Ferriol, J.L. (2010): Cine independiente y traducción, Tirant Lo Blanch, Valencia.

Martínez SiERRA, J.J. (2008): Humor y traducción. Los Simpson cruzan la frontera, Publicacions de la Universitat Jaume I, Castelló de la Plana 
Estudio descriptivo de la traducción para el doblaje del slang en el largometraje Jackie Brown (Quentin Tarantino, 1997)

MAyoral Asensio, R. (1990): «Comentario a la traducción de algunas variedades de la lengua» en Sendebar (1: 35-46).

Mayoral Asensio, R. (1997): La traducción de la variación lingüística. Tesis doctoral de la Universidad de Granada

MAYORAl AsENSiO, R. (1999): «La traducción de la variación lingüística» en Hermeneus: Revista de la Facultad de Traducción e Interpretación de Soria, Excma. Diputación de Soria, Soria (Número extraordinario 1: 1-219).

Mayoral Asensio, R. (2000): «Parámetros sociales y traducción» en Trans, (4: 111-20).

MuÑOZ MARTín, R. (1995): Lingüística per a traduir, Eumo, Vic.

NeWMaRK, P. (1988): A Textbook of Translation, Prentice Hall, Nueva York y Londres.

TOURY, G. (1999): «La naturaleza y el papel de las normas en la traducción» en IGLESIAS Santos, M. (ed.) Teoría de los Polisistemas, Arco, Madrid (233-255).

Vermeer, H. (2000): «Skopos and Commission in Translational Action» en VenUti, L. (ed.) The Translation Studies Reader, Routledge, Nueva York (221-232).

WILLIS, H. (1964): Structure style usage: a guide to expository Writing, Holt Rinehart and Winston, Inc, Austin.

ZabAlBeAsCOA, P. (1996): «La didáctica de la traducción: desarrollo de la competencia traductora» en Aproximaciones a la traducción, disponible en pdf en la dirección: http://cvc.cervantes.es/obref/aproximaciones/zabalbeascoa.htm [consultado en junio de 2011] 
Estudio descriptivo de la traducción para el doblaje del slang en el largometraje Jackie Brown (Quentin Tarantino, 1997)

\section{Diccionarios:}

Cambridge Advanced Learner's Dictionary (versión on-line)

http://dictionary.cambridge.org/

Cambridge Dictionary of American English (versión on-line)

http://dictionary.cambridge.org/

Diccionario de uso del español. (2001): Edición electrónica -Versión 2.0-. A partir del Diccionario de uso del español de María Moliner. Segunda edición, preparada por la Editorial Gredos, Editorial Gredos, Madrid.

Longman's Dictionary of Contemporary English (versión on-line)

http://www.ldoceonline.com/

Merriam Webster (edición on-line)

http://www.merriam-webster.com/dictionary/

Real ACADEMia EsPañola. (2001): Diccionario de la lengua española, 22. edición. Madrid: Espasa Calpe. [Edición en CD-Rom de la 22. a ed., Madrid, Espasa Calpe, 2003] [Disponible en http://www.rae.es].

Oxford Advanced Learner's Dictionary (versión on-line)

http://www.oup.com/elt/catalogue/teachersites/oald7/?cc=global 
Estudio descriptivo de la traducción para el doblaje del slang en el largometraje Jackie Brown (Quentin Tarantino, 1997)

\section{Anexo 1: Muestras de slang original y traducido de Jackie}

\section{Brown}

\begin{tabular}{|c|c|c|c|}
\hline$N^{\circ}$ & $T C R$ & TO & $T M$ \\
\hline 1 & 00:03:45 & CHICKS WHO LOVE GUNS & 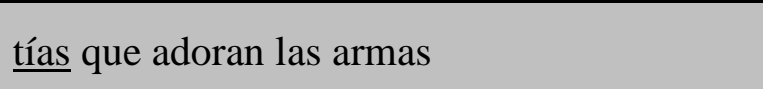 \\
\hline 2 & 00:04:08 & $\begin{array}{l}\text { And that there is a TEC-9. It's a } \\
\text { cheap ass spray gun outta } \\
\text { South Miami }\end{array}$ & $\begin{array}{l}\text { mira, eso es una TEC-9. Un subfusil barato } \\
\text { que fabrican en el sur de Miami. }\end{array}$ \\
\hline 3 & 00:04:15 & $\begin{array}{l}\text { They advertise it as } \\
\text { being the most popular gun in } \\
\text { American crime Can you } \\
\text { believe that shit? }\end{array}$ & $\begin{array}{l}\text { y esos capullos las promocionan como si } \\
\text { fueran el arma más popular del crimen } \\
\text { americano. ¿Cómo pueden tener tanta cara? }\end{array}$ \\
\hline 4 & 00:04:24 & Like they're proud of that shit & están orgullosos de esa mierda. \\
\hline 5 & 00:04:36 & $\begin{array}{l}\text { Styer Aug's a bad } \\
\text { motherfucker. }\end{array}$ & es una hija de puta muy peligrosa. \\
\hline 6 & 00:04:42 & That $\underline{\text { shit's }}$ expensive too, $\underline{\operatorname{man}}$ & además, cuestan un pastón. \\
\hline 7 & 00:04:45 & $\begin{array}{l}\text { My customers don't know shit } \\
\text { about it, so there ain't no } \\
\text { demand. }\end{array}$ & $\begin{array}{l}\text { mis clientes no tienen ni puta idea de esto, } \\
\text { así que nadie me las pide. }\end{array}$ \\
\hline 8 & 00:05:00 & $\begin{array}{l}\text { You put this bad boy in a flick, } \\
\text { every motherfucker out there } \\
\text { want one. }\end{array}$ & $\begin{array}{l}\text { puedo asegurarte que si metes ese cacharro } \\
\text { en una peli, todos los cabrones que la vean } \\
\text { lo querrán }\end{array}$ \\
\hline 9 & 00:05:06 & $\begin{array}{l}\text { When the Hong Kong flicks } \\
\text { came out, every nigga in the } \\
\text { world had to have a forty-five. }\end{array}$ & $\begin{array}{l}\text { cuando salieron aquellas pelis de Hong } \\
\text { Kong, todos los negros del mundo querían } \\
\text { una cuarenta y cinco. }\end{array}$ \\
\hline 10 & 00:05:11 & $\begin{array}{l}\text { 'Cause all the nigga want to be } \\
\text { "The Killer." }\end{array}$ & porque querían parecerse al asesino. \\
\hline 11 & 00:05:16 & $\begin{array}{l}\text { A } .45 \text { has a serious } \\
\text { fuckin' jammin' problem. }\end{array}$ & $\begin{array}{l}\text { tiene un jodido problema, se encasquilla un } \\
\text { huevo }\end{array}$ \\
\hline 12 & 00:05:20 & $\begin{array}{l}\text { It's damn near the same } \\
\text { weapon, and ain't have the half } \\
\text { jammin'problems }\end{array}$ & $\begin{array}{l}\text { es prácticamente igual y esta, tío, funciona } \\
\text { de puta madre }\end{array}$ \\
\hline 13 & 00:05:25 & But you know some niggas out & pero ya sabes cómo son esos negros, no \\
\hline
\end{tabular}


Estudio descriptivo de la traducción para el doblaje del slang en el largometraje Jackie Brown (Quentin Tarantino, 1997)

there, you can't tell them shit

Nigga didn't have a pot to piss

14 00:05:44 프

Now, that motherfucker's rollin'

15

16

All kinds of high tech

00:05:53 navigational shit

When you absolutely, positively, gotta kill every

17

00:06:01 motherfucker in the room, accept no substitute

Girl, don't make me put my

Shit, I'm immpressed!

It's the same gun that nigga on "New York Undercover" uses.

Because of that nigga, I'm gonna make twelve-fifty out of this nigga .

Start adding these motherfuckin' figures up, and you tell me this ain't a business to be in.

The motherfuckers came straight from Gulf War. I sold

00.08:50 grand a piece

I'm gonna make me a million

00:08:57 dollars out of this, man.

Don't cry on me, bitch

What the fuck you doin' in jail? tienen ni pajolera idea.

no tenía ni un orinal en el que $\underline{\text { mear }}$

ahora ese hijo de puta está forrado hasta los cojones

toda clase de artilugios de alta tecnología

si quieres estar seguro de que vas a cepillarte a todos los hijos de puta de una habitación, no aceptes imitaciones

no me obligues a darte una patada en el $\underline{\text { culo }}$ hola, Junenburg, ¿qué me cuentas?

sólo repite las paridas que oye. Es tan experto en armas como yo.

estoy impresionada

es la misma que utiliza aquel negro en Policías de Nueva York. Gracias a aquel negro voy a sacarle 1.200 pavos a ese primo.

haz los putos cálculos y verás que este negocio es para forrarse.

me llegaron directamente de la puta Guerra del Golfo. He vendido tres de esas piezas a 20.000 pavos.

pienso sacar medio millón de dólares de esta historia.

no jueges conmigo, zorra.

¿qué coño haces en la cárcel? 
Estudio descriptivo de la traducción para el doblaje del slang en el largometraje Jackie Brown (Quentin Tarantino, 1997)

$$
\text { 00:09:40 for? }
$$

Goddam, ain't you got better

29

00:09:45

30

31 sense than to be drivin' drunk with a goddam pistol

00:09:58 Number one, you gotta chill

That's what these motherfuckers get paid for 00:10:03 scarin' the shit outta ya. That's their motherfucking job

The judge doesn't give a fuck

$\underline{\text { Man, he's a big one. You're all }}$

And I need me a bond for ten

Who's that big Mandingo

\section{looking nigga you got up there} in that picture with you? tight?

\section{0:12:05 You got cash.}

C'mon, $\underline{\text { man }}$, you know how 00:12:06 they do.

A black man comes in with ten 00:12:09 thousand

They gonna keep a big chunk of it - start talkin' that court

cost shit. Fuck that noise, Jack. I'll go through you.

Cost you a thousand for the 42 00:12:19 $\overline{\text { bond. }}$ ¿por qué coño hiciste eso?

eres un capullo, negro. A quién se le ocurre conducir borracho con una pistola en la mano.

para empezar, tienes que calmarte

para eso pagan a esos hijos de puta. Hacen que te cagues de miedo, ese es su puto trabajo

al juez eso le importa una mierda.

pero te tocará pringar esta noche.

Reggie, no hay otra alternativa.

necesito una fianza de diez mil.

¿quién es ese negro enorme con pinta de Mandinga que sale en la foto?

joder, qué grande es. ¿sois colegas?

tienes pasta.

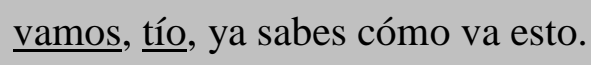

un negro se presenta con diez mil pavos

luego quieren sacar tajada y te sueltan un montón de gilipolleces sobre gastos de jucio. No soy tonto, lo haré a través de ti.

eso te costará mil pavos.

se llama Beaumont. Está en la cárcel del 
Estudio descriptivo de la traducción para el doblaje del slang en el largometraje Jackie Brown (Quentin Tarantino, 1997)

have him up at county. It started out drunk driving, but they wrote it up as "possession of a concealed weapon." Dumb monkey-ass had a pistol on him.

I think they're kinda prejudiced

They ran his name and got a 00:12:35 hit. He's been inside.

against brothers from down the South out here.

Allright, man. Cool. We almost 00:13:17 done, ain't we?

Yo, yo. You take out some music, while you're sitting in the car.

You ain't got to do nothing,

Now play the volume as loud as you want but don't touch my

He ain't gonna like that.

Beaumont ain't got a doin' time kinda disposition.

Look at you and your free ass. Come over, boy. Give me a motherfuckin' hug. condado. Le detuvieron por conducir borracho, pero llevaba un arma y la cosa se complicó. Ese gilipollas la ha pringado bien.

Beaumont tenía antecedentes, estuvo en el $\underline{\text { trullo. }}$

y por aquí son muy racistas con los hermanos del sur, ¿sabes?

Vale, cojonudo. Ya casi hemos acabado, ¿verdad?

Escucha un poco de música mientras esperas.

\section{Está tirado, tío.}

sube el volumen todo lo que quieras pero no toques el ecualizador, macho. Lo tengo justo como me gusta.

\section{No me jodas.}

Ni idea.

no le va a gustar nada. Beaumont no tiene carácter para aguantar una condena.

¿quién coño es?

tu benefactor, negro.

sube, negro.

¿cómo se siente tu culo en libertad? Vamos, chico, dame un puto abrazo.

mi negro. 
Estudio descriptivo de la traducción para el doblaje del slang en el largometraje Jackie Brown (Quentin Tarantino, 1997)

$00: 16: 28$

\section{0:15:27}

I dunno what to say, $\underline{\operatorname{man}}$.

\section{0:15:29 Who was there for your ass? \\ 00:15:30 You was there for me.}

You goddam right! See, that's how that shit works. You get your ass in trouble, I get your ass out. That's my motherfucking job. And I don't mind tellin ya, nigga, it's steady work

I'm still scared as a motherfucker, Ordell. They talkin' like they serious as hell give me time for that machine gun shit.

They just tryin' to put a 00:15:52 fright in your ass.

How old is that machine gun 00.15:55 shit?

That's an old crime, man. They ain't got room in jail for 00.16:00 all this niggas out there killin' people now.

It ain't what they're telling me.

That's why they call it "fuckin' with ya." Now let me tell you how we retaliate?

This brother's name is Stacin Goins and this nigga is a junkyard dog!

Matter of fact, he'd kick Johnie Cochran's ass. And like Johnie Cochran, this nigga hates cops. I'm serious, man, he lives to fuck with the police.

You ain't got shit to worry 00:16:39 about. They just fuckin' with ya. So we sic the junkyard dog no sé qué decir, tío.

¿quién a salvado tu culo?

tú, tío.

no te quepa la menor duda, así funciona este mundo. La jodes y tienes problemas, y yo pongo tu culo a salvo, ese es mi puñetero trabajo. Y no olvides nunca, negro, que yo no fallo.

esos hijos de puta me han asustado de verdad. Decían muy en serio lo de encerrarme por lo de las ametralladoras, ¿sabes?

vamos, tío. Sólo intentan acojonarte.

¿cuándo la cagaste con las ametralladoras?

qué coño, eso pertenece al pasado. No tienen sitio en el trullo para todos los negros que se cargan a la gente hoy en día, ¿cómo van a encontrar sitio para ti?

pues a mí no me han dicho eso.

esos capullos disfrutan dándote por culo. Voy a explicarte cómo tomar represalias.

es un tío muy enrollado. Ese hermano se llama Stacin Goins y te aseguro que es como un perro de presa.

comparado con él, Johnie Cochran es una $\underline{\text { mierda. }}$ Y no se corta un pelo, odia a la policía. Te lo aseguro, ese tío disfruta jodiendo a los polis.

no te preocupes, sólo intentan joderte. Así que vamos a enviar a ese perro de presa tras ellos para que te olviden y no te jodan. 
Estudio descriptivo de la traducción para el doblaje del slang en el largometraje Jackie Brown (Quentin Tarantino, 1997)

71

00:16:48 man.

72

00:17:01

73

74

75

$00: 17: 24$

76

77

78

00:17:44 more like a situation.

And they need weapons so the

79

$00: 17: 59$

neighborhood niggas know

they mean business.

The problem is I ain't never

80

00:18:07

done business with this

Koreans before. I ain't worried.

They don't want no trouble.

You might argue about price

$81 \quad 00.18 .12$ and shit, but you ain't gotta

in the back
But I got me a rule. Never do business with people you ain't te enrollas muy bien, eres un colega, vamos, pasa, tío.

Ya sabes, tío, que odio ser la clase de negro que le hace un favor a otro y ¡bum! le pide otro favor a cambio. Pero no tengo más remedio.

necesito un favor, negro.

oh, tío, yo no pensaba ir a ninguna parte. Es la hostia de tarde, macho, estoy en casa, colocao, ;anda ya!

estás en casa porque me gasté diez mil dólares para sacar tu culo del trullo.

enróllate, tengo un problemilla, ¿vale? Necesito ayuda, échame una mano.

Entra en casa y ponte lo que pilles encima. Iremos a dar un voltio.

no es un problema, tío, es una situación de emergencia.

necesitan armas para que los negros de la zona lo les toquen los cojones.

lo malo es que no había hecho negocio con estos coreanos hasta ahora. No estoy preocupado.

no suelen buscarse problemas. A lo mejor te regatean un poco el precio, pero no hay que preocuparse por si te pegan un tiro por la espalda.

verás, yo tengo una regla. No hagas negocios con gente con la que no los habías 
Estudio descriptivo de la traducción para el doblaje del slang en el largometraje Jackie Brown (Quentin Tarantino, 1997)

never done business with

before without backup.

All you have to do is lay in here and hold on to this motherfucker, alright? And I'm going to tell them I'm opening up my trunk to show 'em my goods. I open up the trunk, you pop up, rack this motherfucker.

Man, you must be out of your fucking mind if you thing I'm gonna get in this dirty ass trunk.

We ain't going nowhere but to

Koreatown, man. You ain't gonna be here no more than ten minutes.

Man, I ain't riding in no godamm trunk for no minute, $\underline{\text { man }}$

Well, I'm sorry, man, but I ain't

Do you like what, man? I just ain't climbin' in no godamm dirty ass trunk, man.

I got a problem spending ten thousand dollars on an ungrateful, peanut-head nigga

$91 \quad 00: 19: 10$ to get him outta jail, but I did it. And how small was that jail cell, motherfucker?

If you owe me, get your ass in

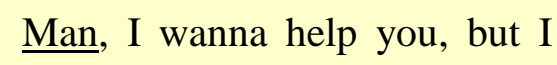
won't be locked in no godamm hecho sin contar con refuerzos.

mira, negro, sólo tienes que tumbarte ahí dentro con esta belleza en tus manos ¿vale? Les diré que llevo la mercancía en el maletero y en cuanto lo abra, les apuntas y cargas esta hija de puta.

¡y un huevo, tío! No pienso disparar a nadie.

no te he dicho que te cargues a nadie, sólo que la sujetes.

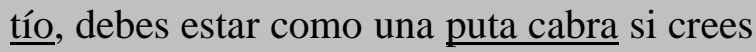
que voy a meterme en ese maletero de mierda.

sólo vamos hasta el barrio coreano. No estarás ahí más de diez minutos.

no pienso viajar en un jodido maletero ni un minuto.

lo siento, macho, pero paso de meterme ahí.

¿pero qué te enrolla? Sólo he dicho que paso de meterme en este maletero de mierda, macho.

y a mí no me gusta gastarme diez mil pavos en sacar a negros ingratos de la cárcel, pero lo hice. ¿era pequeña aquella celda, mamón?

pues si me debes una, métete ahí dentro.

quiero echarte una mano, pero no quiero estar ahí apretao como una puta sardina. 
Estudio descriptivo de la traducción para el doblaje del slang en el largometraje Jackie Brown (Quentin Tarantino, 1997)

trunk of no car

You think I wanted to spend $94 \quad 00: 19: 25$ ten thousand dollars on your

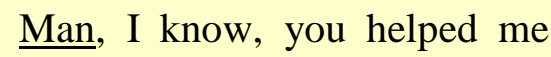
95 108 black ass.

And you best believe it ain't

$00: 19: 35$ hold to this fucking shotgun and point it at peoples head when I open it

You get your nigga off with After we're through fuckin' 00:19:47 with these Koreans

00:20:06 Man...

Now exactly how long I gotta Hey, motherfucker, you hit my 00:20:14 godamm head.

00:24:04 She ain't bad, is she?

I got some for-your-ass-only 00:24:26 shit to show you

00:24:44 An employee I had to let go.

If you know Beaumont, you know there ain't no godamm way he can do ten years

Including telling the Federal government any and every

gonna be me. ¿crees que yo quería gastarme diez mil pavos en un capullo como tú?

$\underline{\text { macho, }}$ ya sé que me echaste un cable.

esto es un putada

mira, tío, sólo te he pedido que te metas ahí, cojas esta escopeta y apuntes a esos amarillos cuando abra el maletero.

meterme ahí dentro es una putada

cuando jodamos a esos coreanos

macho...

¿cuánto tiempo tengo que aguantar este coñazo?

eh, hijo puta, casi me das en la maldita cabeza eres un mamón con una puta coleta

No está mal, ¿eh?

tengo algo en el coche, sólo para tus ojos

un empleado al que he tenido que liquidar

y conociendo a Beaumont, sé que sería incapaz de soportarlo

incluyendo contarle a los federales todo, con pelos y señales, sobre mi negro culo.

y de ningún modo iba a ser yo. 
Estudio descriptivo de la traducción para el doblaje del slang en el largometraje Jackie Brown (Quentin Tarantino, 1997)

109 00:25:51 a million.

Hey, you think I'm gonna let a

110

$00: 25: 52$

little cheese eatin' nigga like

this fuck that up?

I'll shoot this nigga in

111

112

113

114

115

116

117

118

119

120

121

00:30:45

00:29:28

the head, and ten niggas look just like em.

00:26:19 My nigga

00:27:24 Bad knees

It's a shitty flight down to Cabo. I went one time with 00:27:30 Susann, my wife, the fucking turbulence was unbelievable.

00:27:50 Damm!

Those guys down in Customs they're a bunch of fuckin' pricks

So, you get off with a slap on the wrist, but all this criminal 00:29:18 activites fuck up your shit for good with the big airlines

You're flying for the shittiest little shuttle fucking piece of shit Mexican airline that there is

Jackie, do you know a guy named Beaumont Livingston?

We don't give a fuck about 00:30:38 you.

If you refuse to cooperate and you continue to cop out with a shitty attitude like you re doing now

If I was a 44 year old black $12200: 31: 00$ woman desperately leaning on to one shitty little job tendré más de un kilo.

¿crees que iba a permitir que este negro muerto de hambre lo jodiera todo?

antes de pringarla le meto un tiro en la cabeza, y a diez negros más como él.

eres mi negro

tengo las rodillas jodidas

el trayecto hasta el Cabo es una puñetera mierda. Yo fui con mi mujer, y las turbulencias nos putearon el viaje.

$\underline{\text { vaya }}$

esos tíos de aduanas son unos capullos.

la dejaron salir con una palmadita en la espalda, pero al estar fichada no pudo entrar en ninguna compañía importante.

vuela con el puente aéreo más cutre de las líneas aéreas mexicanas más cutres que existen.

Jackie, ¿conoce a un tipejo llamado Beaumont Livingston?

usted nos importa una mierda.

si se niega a cooperar y sigue con esa estúpida actitud que muestra ahora

si yo fuera una mujer negra de cuarenta tacos que se aferrra desesperadamente a un trabajito de mierda 
Estudio descriptivo de la traducción para el doblaje del slang en el largometraje Jackie Brown (Quentin Tarantino, 1997)

\begin{tabular}{|c|c|c|}
\hline 123 & $00: 31: 16$ & $\begin{array}{l}\text { I'm not saying another } \\
\text { godamm word. }\end{array}$ \\
\hline 124 & $00: 32: 03$ & My diet $\underline{\text { shit. }}$ \\
\hline 125 & $00: 32: 15$ & What's that shit? \\
\hline 126 & $00: 34: 37$ & $\begin{array}{l}\text { Got caught coming back from } \\
\text { Mexico with some blow. }\end{array}$ \\
\hline 12 & $00: 34: 52$ & $\begin{array}{l}\text { They fuckin' wit' her. They } \\
\text { callin' that shit Possession with } \\
\text { Intent. A } 44 \text { year old black } \\
\text { woman caught with less than } \\
\text { two ounces they call that shit } \\
\text { Intent. }\end{array}$ \\
\hline
\end{tabular}

They roust my ass outta bed, ten o'clock in the morning, scared the shit out of my woman, Sheronda. She thought they were gonnatake my ass away for sure.

\section{1}

132

133

134 00:35:59 me?

Who says she do anything for Is this me and you talking like you know lawyer-client thing and you can't tell anything I say to you?

You are not my client until you 00:36:11 get busted and I bond you out.

Then we ain't got no...what 00:36:15 you call that shit?

Cause you want me to know 135 00:36:22 what a slick guy you are. You got stewardesses bringing you fifty grand no diré ni una maldita palabra más.

era mi desayuno.

¿qué es esa mierda?

la pillaron volviendo de México con farlopa.

intentan putearla. La han acusado de posesión con intención. Ella era una pobre mujer negra con menos de 50 gramos y la acusan de intento de distribución

alguien a quien le había cabreado a Beaumont se ha cepillado. Joder...eso rima

claro que sí. Fue la primera cabronada que se les ocurrió.

esos cabrones me sacaron a las diez de la mañana, le pegaron un susto de muerte a Sheronda, mi mujer, creía que iban a meter mi culo en una celda.

¿quién dice que haga algo para mí?

¿esta conversación es como ese rollo abogado-cliente y de aquí no saldrá nada?

no serás cliente mío hasta que te trinquen y te saque bajo fianza.

entonces no tenemos nada de... ¿cómo se llama eso?

porque quieres que sepa lo astuto que eres. Tienes azafatas que te traen 50.000 pavos. 
Estudio descriptivo de la traducción para el doblaje del slang en el largometraje Jackie Brown (Quentin Tarantino, 1997)

136

137

138

00:36:59

139

140

141

142

143

144

145

146

147

148

00:43:29

And they found a guy in a 00:43:40 trunk with his head blown off

Well, then, why don't you be a good hostess and make a good brother a screwdriver?

Who you think got your ass 00:46:04 outta jail?

The same guy who put my ass 00:46:07 in jail.

Hey, you got caught with blow, $149 \quad 00: 46: 11$ that's your business. ¿y por qué iba una azafata a traerme tanta pasta?

para el carro. Jackie no tiene tiempo para esas gilipolleces.

sólo te estoy explicando lo que tengo que hacer. Y te recuerdo, por si lo has olvidado, que tienes que pagarme otros mil pavos.

pero no la llevo encima.

Jackie no es una criminal. No está acostumbrada a estos malos rollos. A un gangster le importa un huevo, pero a un ciudadano corriente, un par de noches en el $\underline{\text { talego le comen el coco. }}$.

si tenía esa mierda, y que conste que no lo aseguro, debió comprarla para ella, para colocarse.

tengo tus mil pavos de mierda.

si no me dejan volar me costará muchísimo encontrar mi marca de tabaco.

esos cabrones me esperaban.

encontraron a un tío en el maletero de un coche con los sesos esparcidos.

pues sé una buena anfitriona y prepárame un destornillador

¿quién coño crees que te ha sacado de la cárcel?

el mismo tío que me metió en ella

eh... te pillaron con coca, fue culpa tuya 
Estudio descriptivo de la traducción para el doblaje del slang en el largometraje Jackie Brown (Quentin Tarantino, 1997)

150

00:46:20 Oh, shit.

Damn that shit's uncalled for, baby, I'm sorry. I bet they

151

00:46:29 asked you a whole shitload of questions about it, huh?

If you did, I ain't mad at you, I 152

153

154

155

156

157

158

159

00:49:04 strangle my ass.

I ain't playing with you. I'm gonna unload both these

$160 \quad 00: 49: 07$ motherfuckers, if you don't do what I tell you.

Do you understand what the

161 00:49:15 fuck I'm saying?

162 00:49:16 Yeah, woman, damn!

$163 \quad 00: 49: 18$ sofa

The police starting fucking

164 00:49:20 with your mind. Start playing black against black, that's how oh, $\underline{\text { mierda }}$

joder, menuda putada te han hecho, nena, lo siento. Seguro que esos capullos te hicieron la hostia de preguntas.

si lo hubieras hecho, no estaría enfadado contigo, pero tengo que saberlo

no haces las preguntas adecuadas

¿no les dijiste nada sobre mí?

seguro que esos mamones te frieron a preguntas. ¿Y mantuviste la boca cerrada?

ahora quita tus manos de alrededor de mi cuello, negro.

¿qué coño te pasa, Jackie?

Cierra el pico y no muevas ni un dedo. ¿qué es esto? ¿qué coño es esto?

la policía no ha intentado estrangularme.

pues yo no estoy jugando. Voy a vaciarte dentro estas dos hijas de puta como no hagas lo que te diga.

¿te ha quedado claro, joder?

sí, mujer, sí

ahora siéntate en ese sofá.

la policía te ha tocado el coco. Enfrentan a los negros con los negros, eso es lo que hacen. Siempre han intentado putearnos. 
Estudio descriptivo de la traducción para el doblaje del slang en el largometraje Jackie Brown (Quentin Tarantino, 1997)

165

166

167

168

169

170

171

172

173

174

175

176

177

178

179

180 they do.

Shut your raggedy ass up and 00:49:26 sit the fuck down.

You wanna see some 00:49:38 motherfucking silly?

Way I see it, me and you only got one motherfucking thing to talk about.

00:50:05 I ain’t come here to kill you.

00:50:47 I got me a idea.

We're friends again. Now, point that motherfucking gun somewhwere else.

00:55:00 Because he needs my ass

They're crooks. He might try bring the money in himself, but 00:55:14 Ordell ain't want to stand in no Customs line.

Yeah, if I get let off. 00:55:30 Otherwise, fuck them.

I ain't goin' back to jail, and I

00:55:40 $\frac{\text { ain't doin' that probation thing }}{\text { again }}$

00:55:40 $\frac{\text { ain't doin' that probation thing }}{\text { again }}$

00:56:38 Well... my ass ain't the same

00:56:44 Ain't nothing wrong with that

00:57:24 Ain't worth a damn

And that shit is more scaring

00:57:41 than Ordell.

00:58:58 No shit!

Anything I can to help you throw his ass. Short of wearing a wire. cierra tu jodido pico del oro y siéntate de una puta vez.

¿una tontería, capullo?

tú y yo sólo tenemos que hablar de una puta cosa, amigo.

yo no he venido a matarte.

y tengo una idea.

volvemos a ser amigos. Deja de apuntarme con esa pistola.

porque me necesita.

son ladrones. Y podría intentar traer el dinero él mismo, pero no creo que quiera hacer cola en Aduanas.

sí, si me absuelven, si no, que se jodan.

no pienso volver a la cárcel y quiero librarme de la condicional.

bueno...mi culo no está igual.

pero eso no es malo.

no vale una mierda.

y eso me asusta mucho más que Ordell.

¡no me joda!

haré todo que pueda para que le cojan, excepto llevar micro. 
Estudio descriptivo de la traducción para el doblaje del slang en el largometraje Jackie Brown (Quentin Tarantino, 1997)

182

183

184

185

186

187

188

189

190

191

192

193

194

195

196

197
Salvation Army thing going

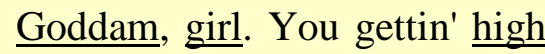
01:00:21 already.

You smoke too much of that

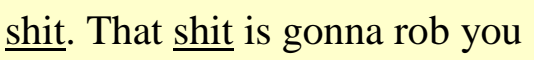
of your ambition.

Not if your ambition is to get 01:00:29 high and watch TV.

01:00:44 $\underline{\text { Yo }}$

01:00:57 Yeah, there's another bowl left.

Coughing's good, gets ya 01:01:39 higher

So since you like gettin' high so much, why don't you stay 01:01:46 here with Mel and watch some TV

See, I get high later on, when I come back. I get high at night 01:01:51 when I get to do all my business.

Why don't you walk me to the 01:02:06 door, space girl?

$\underline{\text { Yo, }}$ Louis, I'll get to you later, 01:02:20 man.

01:02:31 I can't...hell

01:02:38 Is it like a diet thing?

01:03:18 Shit, I thought you were like 16

01:04:06 C'mon, don't lie

Not really. We didn't have much to say to each other anyway.

I keep that picture, because of all the fuckin' time I was there, that's the only picture I got of ejército de salvación

joder, tía, ¿ya te estás colocando?

fumas demasiada mierda. Esa basura te quita la ambición.

no si tu ambición es colocarte y ver la tele.

¿sí?

sí queda para otro viaje

toser es bueno, te coloca más

así que como te apetece tanto colocarte, puedes quedarte aquí con Mel

yo ya me colocaré cuando vuelva. Lo hago por la noche, cuando no tengo asuntos pendientes.

acompáñame a la puerta, flipada.

oye, Louis, nos vemos, tío.

joder, coño, qué asco

¿una coña de régimen?

joder, parece que tuvieses 16 .

no cuela...

estaba cantado. No teníamos gran cosa que decirnos.

conservo esta foto para recordar el tiempo que pasé ahí. Es la única que tengo de Japón. 
Estudio descriptivo de la traducción para el doblaje del slang en el largometraje Jackie Brown (Quentin Tarantino, 1997)

me in Japan.

198

199

200

201

01:07:04

Saturday night, you need

nigga repellent keep those

$\underline{\text { motherfuckers off your ass. }}$

Bullshit, Jackie! You a fine

202

203

204

205

206

207

208

01:07:54

motherfucker I bet you do a

damn sight better than okay.

I don't think so, but it don't 01:07:19 really matter.

01:07:22 How the fuck they know that?

Godamn! That don't mean you 01:07:31 gotta confirm it!

01:07:51 It's true, ain't it?

What the fuck that got to do 01:07:52 with anything?

They know I'm delivering for you. I told them about the halfmillion - they can give a fuck about it. All they wanna do is catch your ass with guns.

This shit is seeming kinda risky

209 01:08:15 now, you know?

210 01:08:31 money.

If you just listen, it's a damn

211 01:08:39 good idea.

Yeah, but it's my money and I

212 01:09:35 don't need no fucking partner.
Jackie Jack, qué sorpresa.

a dos minutos de tu choza y a diez del curro.

¿qué tomas, hermano?

vaya, cuando vienes aquí los sábados por la noche debes necesitar un spray antinegros para alejar a tanto moscón

y una mierda, Jackie. Estás maciza, mamona. Con un spray no tienes suficiente

no lo creo, pero no importa.

¿cómo coño lo saben?

¿pero por qué cojones has tenido que confirmárselo?

es verdad, ¿no?

¿y eso qué coño tiene que ver?

saben que te traía dinero. Lo del medio millón les importa una mierda. Lo que quieren es engancharte con las armas.

verás, ese rollo es demasiado arriesgado, me acojona

si lo recojo me trincarían, no pienso acercarme a ese dinero.

ya te he dicho que era una idea cojonuda.

sí, pero es mi dinero y no necesito una socia.

y tendré que hacerlo delante de las narices 
Estudio descriptivo de la traducción para el doblaje del slang en el largometraje Jackie Brown (Quentin Tarantino, 1997)

under the nose of the cops

So he says, fuck that - moves over to guns. You can sell guns wherever there's a demand. No one gives a shit. He acts like

01:10:11 he's this big international arms dealer, when, come on, face it, the only people he ever sold to were dopers.

215

216

217

218

219

220

221

222

223

224

225
$01: 12: 36$ anything?

01:12:43

But you fucked her anyways

01:10:27 Is it $\underline{\text { dead? }}$

Let's say he's streetwise. I'll give 'im that. He's still a fuckup.

He killed a man who worked for him the other day

That I should get out of here?

That's not what I'm saying at

Oh, man. You ain't gonna get serious on me while we are here chillin'

I figured, shit, Louis ain’t got no pussy for a while, so I

01:12:15 thought, let him kick it with Mel

She ain't have to say shit! I know Melanie. That bitch is gonna be fucking you two minutes after I'm out the door.

01:12:26 Melanie is real good about doing the fuckin niggars way. She ain't no damn good at it but she likes to fuck

So, she ain't your girlfriend or

01:12:59 Oh, $\underline{\text { shit }}$ de la pasma.

lo envió todo a la mierda y se pasó a las armas. Las armas se venden sin problemas y todos pasan de ti. Se comporta como un traficante internacional de armas, sin embargo, es un matao, sólo se las vende a camellos y drogatas.

¿ya estás?

es un tío que domina la calle, eso sí. Pero la caga cada vez más.

se cargó a uno que trabajaba para él.

¿que me largue de aquí?

eso es una gilipollez

oh, tío. ¿no irás a ponerte serio? Ahora estamos de tranquis, ¿verdad?

y pensé, joder, el pobre Louis, hace mucho que no prueba un conejito y me dije...que se lo monte aquí con Mel

esa putilla no ha abierto la boca. Pero conozco a Melanie. Se te habrá follado dos minutos después de que yo me fuera. No se corta un pelo. Se tira a todo lo que pilla, lo hace de puta pena pero le gusta follar.

¿así que no es tu novia ni nada?

pero te la tiraste de todas formas

joder 
Estudio descriptivo de la traducción para el doblaje del slang en el largometraje Jackie Brown (Quentin Tarantino, 1997)

226

01:13:09

She is just one of the bitches I

got set up

227

01:13:29

Hell, yeah. To her dumb country ass, Compton is Hollywood.

228

229

230

231

233

234

01:16:05

She tryin' to play your ass

01:13:43 against me, ain't she?

You ain't have to say nothing. I

01:13:49 know that bitch

I don't understand why you

keep someone in your business

if you can't even trust them

I don't know what taht means, 01:13:57 man.

I don't understand why you

01:14:08 keep her the fuck around?

She ain't as pretty as she used to be and she bitches a whole

01:14:14 lot more as she used to, but she's white.

it's my ass facin' the penitentiary. You send some hard-headed roc whore, and she...

She ain't gonna be no roc $235 \quad$ 01:16:11 $\begin{aligned} & \text { whore. The woman's cool, I } \\ & \text { promise. }\end{aligned}$

236

237

238

01:17:01 $\underline{\text { Shit }}$

What the fuck is up with this 01:17:41 shit?

He wanted to talk about the sting we're plotting. That's what he calls it. A sting.

He's a young guy havin' fun $239 \quad 01: 18: 26$ being a cop. I know the type, trust me on this. He's more interested in Ordell than the sólo es una de las zorras a las que he montado un piso

claro que sí. Para esa tonta del culo Compton es Hollywood.

intenta ponerte en mi contra ¿verdad?

no me digas nada, conozco a esa zorra.

¿por qué dejas que trapichee en tus asuntos si no te fías de ella?

me estoy haciendo la picha un lío, tío.

no puedo entender por qué la sigues manteniendo.

no está tan buena como antes y te da el coñazo mucho más que antes, pero es blanca.

es mi culo el que corre peligro. Como me envíes a una puta crakera la va a joder...

para el carro, no será una puta crakera, será alguien legal, te lo prometo, joder.

joder

¿a qué coño están jugando?

para que pudiéramos hablar del golpe que estamos tramando. Así lo llama, le gusta.

Sólo es un tío joven que se divierte siendo poli. No busca pasta, confía en mí. Le interesa más trincar a Ordell que la pasta. 
Estudio descriptivo de la traducción para el doblaje del slang en el largometraje Jackie Brown (Quentin Tarantino, 1997)

money.

240

241

242

243

244

245

246

247

248

249

01:28:46

01:28:36

What the hell I'm talkin' bout?
Sheronda passing the money to

hell I'm talking about

I know, but I hung around, 'cause I figured you'd try an' pull some shit like this.

Now, hold on there. I ain't pullin' no shit. It's my godamn money, I can do the fuck I wanna do with it.

I don't give a shit. When it's my ass on the line, oh, no, you

250 01:28:49 fucking don't. We do this my way or fuck it.

251

252

253
01:28:55 Just chill, chill.

01:28:56 Jackie, my ass.

Louis, call Simone and tell her to get her ass over here. We're waitin' on her.

Damn! Is that what you are a bit pissed about? llevo años rodeado de mierda

el dinero le importa una mierda, por la pasta no pueden condenarle

bueno, eso es lo que se hace cuando estás de mierda hasta el cuello, empiezas a pensar.

no tengo reloj, señora.

y darse el piro.

y esa tía que está montando la escenita es Melanie, que va a pirarse.

¿de qué coño estás hablando?

¿me estás tomando por idiota? Sheronda le entregó el dinero a otra persona, de eso te estoy hablando.

me quedé porque sabía que intentarías hacerme alguna putada.

tranqui, tranqui, yo no te he hecho ninguna putada. Es mi dinero, ¿de qué vas? Puedo hacer con él lo que me dé la puta gana.

me cago en tu dinero, me la estoy jugando, así que no vuelvas a putearme. O lo hacemos a mi manera o te jodes. A mí no me puteas.

vamos, Jackie, no te pases. Tranqui, nena.

ni Jackie ni pollas.

Louis, llama a Simone y dile que venga cagando hostias, la estamos esperando

joder, ¿estás cabreada por eso? 
Estudio descriptivo de la traducción para el doblaje del slang en el largometraje Jackie Brown (Quentin Tarantino, 1997)

\section{1:29:15}

Just a little pissed?

256

257

258

259

260

261

262

263

264

$01: 31: 14$

If I wasn't so buddy-buddy with that motherfucker this wouldn't work

Some white chick named

265

266

01:32:18

Melanie, another girlfiend of Ordell's

It was her coke I got busted with. She knows everything, but she's not

part of it, and she's pissed cause she's not part of it.

You know, a good cop won't 267 por supuesto, ¿es que te extraña?

no me gusta esa parte.

oye, Louis, ¿no está? ¿no contesta? Pues entonces afina el oído, macho, porque esto te interesa.

donde os probáis los trapos

porque voy a tener a la poli muy encima

estará esperando en el probador hasta que le des la señal de que no vigilan

pues como me has echado esos perros encima, me iré a un bar del centro y esperaré a que Louis llame diciendo que todo va de puta madre.

joder ¿quién te llama tanto al busca?

me está empezando a tocar la moral que ese hijo de puta y tú seáis tan colegas.

si no me llevara bien con ese hijo de puta esto se iría al carajo.

es blanca. Se llama Melanie, es otra de sus novias.

la coca que me trincastéis era para ella. Lo sabe todo pero pasan de ella, y está cabreada porque no la dejan participar.

¿sabes? Un buen poli no dejará que notes que sabe que le has soltado un pegote. 
Estudio descriptivo de la traducción para el doblaje del slang en el largometraje Jackie Brown (Quentin Tarantino, 1997)

268

01:32:52

Ordell thinks it's way too hot right now to bring in all his money. He knows you're watching him, and he's fucking paranoid.

269

01:32:55 So he's sweating a little bit?

He is gonna keep his half meal where it is, but he wants to 01:32:57 bring in fifty thousand just in case he needs a bail.

You're takin' a hell of a chance 01:33:22 kid.

01:33:55 Ain't no thing.

You know that bitch Simone you saw in the mall? She

01:34:00 wasn't here today, 'cause she split on my ass.

She's gone, her shit's gone and my ten thousand motherfucking dollars is gone.

Don't start barking on me. God

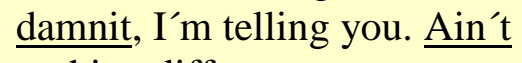
nothing different.

God damnit, Melanie got just as much sense as that bitch. 01:34:23 God, she'1l be in the same fucking place. All right?

\section{1:34:41 Chicken shit.}

01:37:12 Three: your ass is dead.

What the fuck are you two still 01:37:43 doing there, $\underline{\text { man? }}$ ?

Well, you the one in 01:37:48 motherfuckin' charge

Go in there, grab her by the hair, and drag her big ass out of there. This is my goddam money
Ordell cree que el ambiente está demasiado caldeado. Sabe que le vigilan y está paranoico perdido.

está cagao de miedo.

va a dejar el medio kilo donde está, pero van a enviarle 50.000 por necesita una fianza.

te estás arriesgando demasiado.

poca cosa.

Simone, aquella zorra a la que viste en el centro no se ha presentado aquí, me ha dejado plantado.

hemos pasado por su choza. Se ha pirado, está vacía y mis diez mil dólares han volado.

no me des la bulla. Ya te he dicho que no va a cambiar nada, ninguna diferencia.

no me toques los huevos, Melanie es tan lista como aquella zorra. Estará en el mismo jodido sitio, ¿vale?

cobarde de mierda.

tres: estás muerto

¿por qué coño estáis todavía ahí?

pero tú eres el que manda, joder.

pues entra, cógela por los pelos y llévala a rastras hasta ahí, se trata de mi puto dinero. 
Estudio descriptivo de la traducción para el doblaje del slang en el largometraje Jackie Brown (Quentin Tarantino, 1997)

282

283

284

285

286

287

288

289

290

291

292

293

294

295

296

297

298

299

300

301
01:38:08

C'mon, we've got to go

Kiss my ass, fuckass

01:41:32 It looks really good on you

I put a cherry on top. Boo ya!

What the fuck did Ordell ever do for us, uh?

01:45:10 Fuck!

C'mon, we're godamn late,

01:45:12 c'mon!

01:45:16 What the fuck!

We shoulda been there already and we woulda been if it hadn't been for your fuckin' around!

01:45:24 Jesus, auch!

shut the fuck up!

just let go

01:45:33 Just letgo

01:45:35 Straight it up, bitch!

Just stay right fuckin' here, all

01:46:00 right?

01:46:20 Fucking stay here.

01:46:43 What the fuck?

01:47:15 Fuck you, I can carry it.

01:47:17 Godam you, give me the bag.

Watch it. You wanna rip the

01:47:20 fuckin' bag?

Gimme that bag before I knock 01:47:23 you out your fucking head.

Okay, Jesus, what's wrong 01:47:25 with you? sal de una puta vez, vámonos

que te den por culo, gilipollas

te queda cojonudo

le he puesto una guinda de postre. Oh, sí. Ordell nunca ha hecho nada por nosotras, ¿eh?

joder

venga, espabila, llegamos tarde, vamos.

¿qué coño haces?

ya deberíamos estar allí. Estoy hasta los $\underline{\text { huevos de tus gilipolleces. }}$

cabrón, joder

estate calladita, coño

¿quieres soltarme de una puta vez?

no me va tu rollo, zorra.

no te muevas de aquí, me cago en la puta, aquí quieta

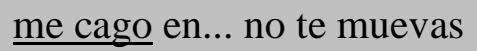

$\underline{\text { mala puta }}$

puedo llevarla yo

no me cabrees, dámela

vas a romper la puta bolsa

dame la bolsa, dámela o te suelto una hostia, tocapelotas

vale, vale, quédatela, ¿pero qué coño te pasa? 
Estudio descriptivo de la traducción para el doblaje del slang en el largometraje Jackie Brown (Quentin Tarantino, 1997)

302

303

304

305

306

307

308

309

01:55:12

01:55:03

We're gonna leave this heap in a parking lot and get one the cops don't know about.

She bugged me the whole time. Got pissy with me 'cause I wouldn't let her carry the bag. Started running her fuckin' mouth...

310

311

312

313

314

315

316

317

$01: 56: 52$

I swear to fucking God,man. I swear to my life she came out with that fucking bag and I took it from her.
You sure Melanie ain't in a room somewhere with a half-a- a la mierda tu calmante

¿tú qué coño...?

Jesús, Odell y tú sois la pareja de chapuzas más inútiles que he visto en mi vida.

es normal que te trincaran

no digas ni una puta palabra más, ¿vale?

$\underline{\text { maldita zorra }}$

dejaremos este trasto en el parking y cogeremos uno que la pasma no controle

ella estuvo chinchándome todo el rato y se puso gilipollas porque no dejé que llevara la bolsa, y luego empezó a hincharme las pelotas, ya sabes.

así que empezó a darme el coñazo

me estaba poniendo de los putos nervios

me la he cargado

eso no es una puta respuesta. ¿sí o no? ¿está muerta?

la has jodido bien jodida, tío

no nos interesa que esa zorra sobreviva.

sí, aquí falta un mogollón.

escucha te juro por Dios, macho, te juro por mi vida, que ella salió con esa bolsa y yo se la quité

¿seguro que Melanie no está en un motel esperándote con el medio millón que 
Estudio descriptivo de la traducción para el doblaje del slang en el largometraje Jackie Brown (Quentin Tarantino, 1997)

million dollars I worked my ass off to get waiting for you?

319

320

321

322

323

324

325

326

327

328

01:59:25

01:58:58 Oh, man. You know what?

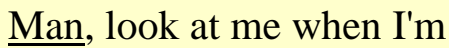
talking to you! You see that motherfucker in the dress

department while we are about to get a half million dollars and you don't think nothing of him being there!

Hell, yeah, they know each

01:59:33

other. He bonded her ass out of county.

You know all of them

330

331 motherfuckers is crooked as

bell of snakes, don't you?

Why should I think anything's weird, if I don't know nothin' about them knowing each conseguí trabajando como un cabrón?

que te follen, ¿cómo puedes preguntarme eso?

¿cómo has podido? eres un cabrón. que te jodan, hermano, eres un hijo de puta

sé que esa zorra quería engañarme

joder

oye ¿así que vas a averiguar?

se lo preguntaré a esa zorra antes de volarle la cabeza.

pero ha puesto esos libros para engañarnos.

y luego ha metido esos cuarenta mil para restregármelo por las narices, encima recochineo. Quiere que sepa que me la ha jugado.

Eh, tío ¿sabes qué?

$\underline{\text { tío, }}$ mírame cuando te hablo. ¿Ves a ese hijo de puta cuando estamos a punto de recibir medio millón de dólares y no le das ninguna importancia?

pues claro que se conocen. Él la sacó de la cárcel del condado.

y como todos es un hijo de puta tramposo y sin ningún escrúpulo.

yo no vi nada raro porque no sabía que se conocían. 
Estudio descriptivo de la traducción para el doblaje del slang en el largometraje Jackie Brown (Quentin Tarantino, 1997)

332

333

334

335

336

337

338

339

340

341

342

343

344 other?

Man, I don't want to hear no 01:59:43 fuckin' excuses!

I ain't givin' you fuckin' excuses, man. All I'm telling 01:59:44 you, I don't fucking... I'm givin' you fucking reasons.

Oh, you gonna tell me the reason you lost every goddam cent I got in the world! You 01:59:49 telling me reasons? Let me tell you the reason, motherfucker! The reason is, your ass ain't worth a shit no more!

You better fucking back off, 02:00:01 man!

What the fuck happened to you, man? Your ass used to be beautiful.

If it's me, and I got all that shit hanging over my head, like you got hanging over yours...

Just wait a fucking second, all 02:01:26 right?

02:01:44 and go home

Somebody fucking killed her

\section{2:01:51 for it.}

I couldn't go after her, because 02:02:11 I was in my fucking underwear.

I don't have an idea where the 02:03:06 motherfuckin money is.

02:03:10 $\begin{aligned} & \text { Not even a little tiny } \\ & \text { motherfucking idea. }\end{aligned}$

Yeah, if it'll motherfucking 02:03:12 make you happy. estoy harto de tus estúpidas excusas, Louis.

¿pero qué dices? No son excusas ¿vale, tío? Te estoy diciendo que lo hice por un montón de razones.

¿y puedes decirme por qué has perdido hasta el último centavo que tenía en este mundo? ¿vas a inventarte otra razón? La cabeza no te rula hijo puta. La única razón es que ya no vales una puta mierda.

oye, será mejor que aflojes, $\underline{\text { macho. }}$

¿qué coño te ha pasado, tío? Antes eras de puta madre.

me pasa a mí, y hay un montón de buitres sobre mi cabeza intentando darme por culo y, no sé...

no me atosigues, dame un puto respiro, ¿vale?

y me daría el piro

y luego alguien se la cargó por eso.

no puede ir tras ella porque estaba en ropa interior, joder.

no tengo ni idea de dónde está ese puto dinero.

no lo sé, y además me importa una mierda.

sí, si así dejas de putearme 
Estudio descriptivo de la traducción para el doblaje del slang en el largometraje Jackie Brown (Quentin Tarantino, 1997)

345

02:03:52 Fuck

346

347

348

349

350

351

352

353

354

355

02:07:15 $02: 05: 48$ 02:06:04 this? 02:06:10 shit.

\section{2:04:04 That's it.}

I thought you were fucking

02:04:16 watching him.

I ain't goin' no godamn anywhere till I get my motherfucking money. C'mon, man. If it weren't for me, you

02:05:33 wouldn't have that motherfucking boat. Yeah, right, I'm seeing who my friends are, motherfucker.

Motherfucker hang up on me. Can you believe that shit? Ingrate nigger. See? You help a motherfucker up, next thing you know they're bringing you some goddamn disrespect. Motherfucker. Shit.

$\underline{\text { Damn, }}$ girl, how you live like

This, this is some repugnant

02:06:16 He ain't here right now, $\underline{\text { man. }}$.

All right, break out the beeper 02:06:23 number, nigger.

02:07:09 Look here, $\underline{\text { man. }}$

Jackie can tell me any story come into her that pretty little head. As long as at the end of that story, she hands me my motherfucking money. She wanna be my friend, she do that. She don't wanna be my friend no more, you tell her to think about old Beaumont.

If she go to the police, you tell 02:07:33 her I will name her ass as my accessory. And we'll go joder.

sí, qué putada

creía que vigilabais a ese capullo.

no me iré a ninguna parte hasta que recupere mi puto dinero. Vamos, hombre, si no fuera por mí no tendrías ese barco de mierda. Oh, sí, sí, claro, ya veo quiénes son mis amigos, hijo de puta.

¿será hijo de puta? Ese cabrón me ha colgado, ¿has visto que cojones tiene? Maldito negro ingrato. ¿Lo ves? Ayudas a un mamón a prosperar y cuando creen que son alguien te pierden el jodido respeto. Hijo de puta. Mierda.

joder, tía, ¿cómo puedes vivir así?

así, esto esta lleno de mierda.

ahora no, tío.

vale, pues dame el de su busca, $\underline{\text { negro. }}$.

escúchame, tío.

que Jackie me cuente cualquier historia que salga de esa cabeza tan bonita, pero cuando la acabe quiero que me entregue mi puto dinero. Y si quiere ser amiga mía, lo hará. $\mathrm{Si}$ quiere dejar de serlo, dile que piense en el viejo Beaumont.

Y si me delata a la policía, dile que cuando me trinquen la acusaré de ser mi cómplice y los dos iremos a la cárcel y acabaremos con 
Estudio descriptivo de la traducción para el doblaje del slang en el largometraje Jackie Brown (Quentin Tarantino, 1997)

upstate hand in handcuf motherfucking hand.

What's wrong with you

357

02:08:30

knocking at the door like the goddamn police?

You keep fuckin' with me, money, ain't it? Ain't got

My ass be dumb, but I ain’t no

And split the half million 02:09:46 amongst themselves.

02:10:06 dumbass.

That's why she's givin' up my about Melanie, uh?

I told that fucking Louis all he

That big ass nigger Winston had to do was hit her on the mouth.

\section{ain't there, is he?}

Goddamn! All the time I've known her, I never heard her 369 $02: 12: 33$ sound scared like that. Ordinarily she's too cool for school.
Hold on, bro. Give me the keys.I'm driving. las putas manos esposadas.

¿de qué coño vas llamando a la puerta como la puta policía?

como sigas jodiéndome serás tú el que acabe durmiendo, para siempre.

vamos dentro.

eh, quieto hijo de puta, ¿qué haces?

no, no, cabronazo, ya sabes a qué me refiero bravo por ese negro.

yo también quiero saberlo

y para repartirse el medio kilo entre las dos.

a lo mejor mi culo está tonto, pero no soy $\underline{\text { tonto del culo }}$

y por eso quiere darme mi dinero, ¿verdad? No tiene nada que ver con esa gilipollez sobre Melanie.

ya le dije al gilipollas de Louis que sólo hacía falta darle una buena hostia.

no estará allí ese gigantón de Winston, ¿verdad?

es la hostia, la conozco hace un montón de años y nunca la había oído tan asustada. Siempre va de tranquis, no se agobia

espera colega, dame la llave, conduzco yo. 
Estudio descriptivo de la traducción para el doblaje del slang en el largometraje Jackie Brown (Quentin Tarantino, 1997)

371
She starts givin' me some bullshit about it ain't there and we gotta go someplace else and get it, I'll shoot you in the head right there.

Then I'm gonna shoot that bitch in the kneecap, find 02:15:24 out where my godamn money is.

Look at me when I'm talking to 02:15:32 you, motherfucker.

I go walkin' in there and that nigga Winston or anybody else is in there, you're the first motherfucker to get shot, you understand me?

Last chance, motherfucker. Are 02:15:59 you sure?

02:16:06 You better be, motherfucker

Keep your ass in front of me. 02:16:36 Don't be fucking around.

Godamn, girl, what you doing 02:17:06 sitting here all in the dark? como empecéis con la típica chorrada de que no está ahí y de que hay que ir a otro sito a buscarlo, te pego un tiro en la cabeza y te dejo seco.

le disparo a esa zorra en las rodillas hasta que descubra dónde está el dinero.

mírame cuando te hablo, hijo de puta.

voy a entrar ahí, y como esté Winston o cualquier otra persona serás el primero al que me cepille, ¿entendido, Max?

última oportunidad, mamón, ¿seguro?

más te vale, cabrón de mierda.

quiero ver tu culo delante de mí, no hagas ningún movimiento brusco o te abro un boquete.

¿qué pasa tía? ¿qué haces ahí sentada en la oscuridad? 
Estudio descriptivo de la traducción para el doblaje del slang en el largometraje Jackie Brown (Quentin Tarantino, 1997) 


\section{Anexo 2: Recopilación de datos para su análisis}

Muestras en las que el TM presenta homofuncionalidad:
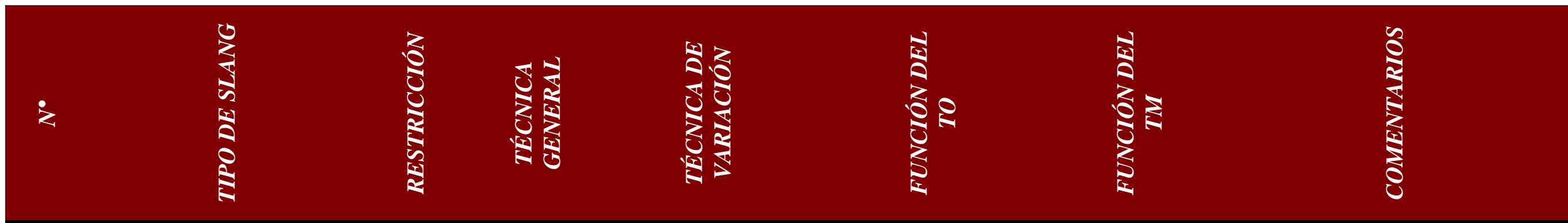

marcar pertenencia

procedimiento léxico formal

1

variedad según la actitud

formal

e

icónica

procedimiento léxico

semántico.

3

variedad según posición e individuo

procedimiento léxico semántico

\section{equivalente acuñado sin transgresión. naturalidad}

amplificació

$\mathrm{n}$

creación

discursiva

equivalente acuñado

con marcas. sin transgresión. naturalidad

con marcas sin transgresión con marcas. a/identificación con un grupo o establecer las relaciones sociales dentro del grupo

marcar pertenencia a/identificación con un grupo o establecer las relaciones sociales dentro del grupo convencionalidad marcar pertenencia grupo o establecer las a/identificación con un homofunciona

lidad

homofunciona lidad

homofunciona

lidad es un texto que aparece escrito en la televisión. En la versión traducida se oye en vez de leerse

la amplificación capullo compensa la pérdida de carga de slang producida por traducción de shit por tanta cara 
variedad según posición e individuo

\section{procedimiento léxico}

semántico y formal.

5

variedad según posición e individuo

procedimiento léxico

6 formal y semántico

variedad según posición, origen e individuo

procedimiento léxico semántico y

7

procedimiento sintáctico.

variedad según posición, origen e individuo

procedimiento léxico semántico

8

variedad según posición, origen, individuo y tema procedimiento léxico semántico

variedad según posición

relaciones sociales

dentro del grupo

marcar pertenencia

equivalente

acuñado

amplificació

con marcas sin transgresión convencionalidad

modulación

adaptación

con marcas sin transgresión convencionalidad

creación

discursiva

reducción

con marcas

naturalidad

adaptación

equivalente

acuñado

equivalente

acuñado

con marcas

sin transgresión naturalidad

con marcas sin transgresión

/identificación con un

grupo o establecer las

relaciones sociales

dentro del grupo

marcar pertenencia a/identificación con un grupo o establecer las relaciones sociales dentro del grupo

marcar pertenencia a/identificación con un grupo o establecer las relaciones sociales dentro del grupo

mostrar cierta actitud sin transgresión naturalidad asociada con ese slang o el grupo que lo utiliza

homofunciona

lidad

marcar pertenencia

a/identificación con un grupo o establecer las relaciones sociales

homofunciona

lidad homofunciona lidad

aunque la funcionalidad se mantiene, es muy poco natural usar insultos que normalmente van dirigidos a personas para cosas en la LM. Esta convencionalidad puede resultar extraña.

\section{homofunciona}

lidad

resulta complicado mantener la funcionalidad en procedimientos sintácticos pero la creación discursiva permite mantener la funcionalidad del segmento

la opción de no traducir bad boy por algo asociable a personas hace que el texto sea muy natural $\mathrm{y}$ se mantenga la funcionalidad. 
origen e individuo

procedimiento léxico

$$
\text { semántico }
$$

y procedimiento léxico

11

$$
\text { formal }
$$

variedad según posición, origen e individuo

procedimiento léxico semántico y formal y

procedimiento sintáctico

12

variedad según posición, origen e individuo

procedimiento léxico semántico

13

variedad según posición, origen e individuo

procedimiento sintáctico, procedimiento léxico semántico

15

variedad según posición, origen e individuo

\section{dentro del grupo}

marcar pertenencia a/identificación con un grupo o establecer las relaciones sociales dentro del grupo con marcas acuñado naturalidad

creación discursiva

reducción

reducción

creación

discursiva

equivalente acuñado

con marcas

con marcas sin transgresión naturalidad

creación

discursiva sin transgresión convencionalidad

creación

discursiva

con marcas sin transgresión naturalidad marcar pertenencia a/identificación con un grupo o establecer las relaciones sociales dentro del grupo

marcar pertenencia a/identificación con un grupo o establecer las relaciones sociales dentro del grupo

mostrar cierta actitud asociada con ese slang o el grupo que lo utiliza homofunciona

lidad

la creación discursiva permite
una traducción muy natural.

homofunciona

lidad

el procedimiento léxico formal de composición del verbo ain't es difícilmente trasladable al español, pero la ampliación con la palabra tío hace que se mantenga la funcionalidad

la creación discursiva es un buen método para mantener la

homofunciona

lidad

funcionalidad proponiendo un punto de vista más acorde con la cultura meta

homofunciona lidad la creación discursiva permite gran naturalidad. 
formal y semántico

variedad según posición e individuo

procedimiento léxico semántico y

procedimiento sintáctico

variedad según posición, origen e individuo

procedimiento léxico formal y semántico y procedimiento sintáctico

variedad según posición e individuo

procedimiento léxico

formal y semántico

24

variedad según posición e individuo

procedimiento léxico

\author{
creación \\ discursiva \\ equivalente \\ acuñado \\ equivalente \\ acuñado \\ equivalente \\ acuñado \\ sin transgresión \\ naturalidad \\ con marcas \\ sin transgresión \\ naturalidad
}

creación

discursiva

modulación

equivalente

acuñado

reducción y

amplificació

n

equivalente acuñado

equivalente acuñado

equivalente

acuñado

con marcas

sin transgresión

naturalidad

con marcas sin transgresión naturalidad

con marcas sin transgresión asociada con ese slang o el grupo que lo utiliza

lidad convencionalidad mostrar cierta actitud asociada con ese slang o el grupo que lo utiliza

lidad

\section{marcar pertenencia a/identificación con un grupo o establecer las relaciones sociales
dentro del grupo}

\section{mostrar cierta actitud} asociada con ese slang homofunciona o el grupo que lo utiliza lidad

mostrar cierta actitud asociada con ese slang homofunciona o el grupo que lo utiliza creación discursiva hace que se
mantenga la funcionalidad

compensación del procedimiento sintáctico difícilmente trasladable a la cultura meta con la creación discursiva. Modulación para evitar repetitividad, aporta naturalidad.

compensación del procedimiento sintáctico difícilmente trasladable a la cultura meta con la amplificación. aunque se opta por un equivalente muy convencional, se mantiene la funcionalidad

variedad según posición, 
sexo e individuo procedimiento léxico

$$
\text { semántico }
$$

27

variedad según posición e individuo

procedimiento léxico semántico

28

variedad según posición e individuo

procedimiento sintáctico y procedimiento léxico semántico

29

variedad según posición e individuo

procedimiento sintáctico

31

variedad según posición e individuo

procedimiento sintáctico

$$
\text { individuo }
$$

procedimiento sintáctico. con marcas

modulación sin transgresión naturalidad

con marcas

modulación sin transgresión naturalidad

reducción y ampliación

reducción

con marcas sin transgresión convencionalidad

equivalente acuñado

equivalente acuñado

con marcas sin transgresión naturalidad

equivalente acuñado

modulación

con marcas sin transgresión naturalidad

con marcas

creación mostrar cierta actitud

asociada con ese slang homofunciona

o el grupo que lo utiliza

mostrar cierta actitud

asociada con ese slang homofunciona

o el grupo que lo utiliza lidad

mostrar cierta actitud

asociada con ese slang homofunciona

o el grupo que lo utiliza lidad

cambio del registro

lingüístico para

provocar empatía

cambio del registro

discursiva sin transgresión lingüístico para

provocar empatía

homofunciona

lidad

cambio del registro

lingüístico para

homofunciona lidad lidad

homofunciona

lidad

muy natural el equivalente encontrado

la reducción se compensa con la ampliación, decisión ventajosa para superar el problema del procedimiento sintáctico este fragmento recompensa otros fragmentos en los que había una 
variedad según posición e individuo

procedimiento léxico semántico y

37

procedimiento sintáctico.

variedad según posición e individuo

procedimiento léxico semántico

39

variedad según posición, individuo y sexo

procedimiento léxico semántico y

41 procedimiento sintáctico

variedad según posición e individuo

procedimiento sintáctico.

variedad según posición e individuo

43 procedimiento léxico

formal y semántico naturalidad

modulación

creación

discursiva

equivalente

acuñado

equivalente

acuñado

creación

discursiva

modulación

modulación

con marcas

sin transgresión

naturalidad

con marcas
sin transgresión

naturalidad

in transgresión

naturalidad

reducción

con marcas

sin transgresión

ampliación

naturalidad

reducción

con marcas

sin transgresión provocar empatía

marcar la

desvinculación de un grupo y rebelarse contra el lenguaje

estándar

homofunciona

lidad

cambio del registro

lingüístico para

provocar empatía

marcar la

desvinculación de un grupo y rebelarse contra el lenguaje

estándar

cambio del registro lingüístico para

provocar empatía

homofunciona

lidad

mostrar cierta actitud

asociada con ese slang

\section{homofunciona \\ lidad}

homofunciona

lidad homofucionali

dad pérdida notable de la funcionalidad

modulación para mantener funcionalidad

los procedimientos sintácticos de supresión de sujeto son

difícilmente trasladables al español, pero se consigue mediante otra técnica de

traducción que lo compense, como la ampliación en este caso

el segmento es homofuncional pero se pierde la función 


$$
\begin{gathered}
\text { variedad según posición e } \\
\text { individuo } \\
\text { procedimiento léxico } \\
\text { semántico y }
\end{gathered}
$$

44

procedimiento sintáctico

$$
\text { variedad según tema y }
$$$$
\text { actitud }
$$

procedimiento léxico

$$
\text { semántico y }
$$

46

$$
\text { procedimiento sintáctico }
$$

variedad según posición e

$$
\text { individuo }
$$

procedimiento sintáctico y

procedimiento léxico

48 semántico

variedad según posición, actitud e individuo

procedimiento léxico semántico

variedad según posición e individuo

procedimiento léxico

semántico

$$
\text { creación }
$$

discursiva

naturalidad

o el grupo que lo utiliza

marcar pertenencia

a/identificación con un

grupo o establecer las

relaciones sociales

dentro del grupo

modulación

reducción

con marcas

sin transgresión

naturalidad

creación

discursiva

con marcas

sin transgresión

naturalidad

con marcas

formal modulación

variedad según posición sin transgresión

naturalidad

equivalente

acuñado con marcas naturalaidad sin transgresión cambio del registro

lingüístico para

provocar empatía

mostrar cierta actitud asociada con ese slang o el grupo que lo utiliza

homofunciona lidad

rebelarse contra el lenguaje estándar

cambio del registro lingüístico para provocar empatía

homofunciona

$$
\text { lidad }
$$

\section{homofunciona}

lidad

homofunciona

lidad metalinguiística de posesión of a concealed weapon

homofunciona

$$
\text { lidad }
$$

la pérdida de funcionalidad en el procedimiento sintáctico se recupera con un slang muy marcado en la primera parte.

traducción muy natural 
origen e individuo

procedimiento léxico semántico

59

variedad según posición y actitud

procedimiento sintáctico

60

variedad según posición

procedimiento sintáctico y procedimiento léxico

62 semántico

variedad según actitud e individuo

procedimiento sintáctico y procedimiento léxico

63 semántico

variedad según actitud e individuo

procedimiento léxico semántico.

64

variedad según posición e individuo

procedimiento léxico semántico y

procedimiento sintáctico modulación

$$
\mathrm{y}
$$

equivalente acuñado

sin transgresión

naturalidad

reducción y

creación

con marcas

discursiva

sin transgresión

naturalidad

modulación

reducción sin transgresión

naturalidad

ampliación

creación

discursiva

con marcas

sin transgresión

naturalidad

con marcas

modulación

sin transgresión

naturalidad

modulación

con marcas

sin transgresión

reducción y

naturalidad con marcas cambio del registro

lingüístico para

provocar empatía

cambio del registro

lingüístico para

provocar empatía

cambio del registro

lingüístico para

provocar empatía

cambio del registro

lingüístico para

provocar empatía

homofunciona

lidad

cambio del registro

lingüístico para

provocar empatía

cambio del registro

lingüístico para

provocar empatía

\section{homofunciona}

lidad

homofunciona

lidad

homofunciona

lidad

homofunciona

lidad

homofunciona

lidad la ampliación permite un discurso homofuncional. La modulación

hace que sea más natural que si se hubiera utilizado un

equivalente acuñado como culo

en este caso como negro no tiene una función fática el equivalente acuñado funciona perfectamente 
variedad según actitud, posición, sexo e individuo

procedimiento sintáctico y procedimiento léxico

67

formal y semántico

variedad según actitud, posición e individuo

procedimiento léxico semántico

68

variedad según actitud, origen posición e individuo

procedimiento léxico semántico

69

variedad según actitud, posición e individuo

$$
\begin{gathered}
\begin{array}{c}
\text { particulariza } \\
\text { ción }
\end{array} \\
\text { equivalente } \\
\text { acuñado } \\
\text { particulariza } \\
\text { ción } \\
\text { amplificació }
\end{gathered}
$$

n

creación

discursiva

amplificació

$\mathrm{n}$

equivalente

acuñado

equivalente

acuñado

modulación

creación

discursiva

equivalente

acuñado marcar pertenencia

con marcas

sin transgresión

naturalidad

a/identificación con un grupo o establecer las

relaciones sociales

dentro del grupo

homofunciona

lidad

marcar pertenencia

con marcas

sin transgresión

convencionalidad/

naturalidad

a/identificación con un

grupo o establecer las

relaciones sociales

dentro del grupo

homofunciona

lidad

con marcas

sin transgresión

naturalidad mostrar cierta actitud

asociada con ese slang homofunciona

o el grupo que lo utiliza lidad se mantiene la funcionalidad del segmento pero se pierde la función metalingüística

el equivalente hermano no cumple la misma función en la cultura meta, pero se mantiene la funcionalidad gracias a la amplificación 
procedimiento sintáctico y procedimiento léxico formal y semántico

variedad según actitud, posición e individuo

procedimiento sintáctico y procedimiento léxico

variedad según actitud, sexo, tema, posición e individuo

procedimiento léxico semántico equivalente acuñado

reducción

reducción

equivalente acuñado

formal

equivalente

acuñado

equivalente acuñado

equivalente acuñado

reducción

creación

discursiva

equivalente acuñado

equivalente acuñado equivalente acuñado con transgresión naturalidad

con marcas sin transgresión naturalidad naturalidad

con marcas sin transgresión convencionalidad/ marcar pertenencia a/identificación con un grupo o establecer las relaciones sociales dentro del grupo

homofunciona lidad

cambio del registro lingüístico para provocar empatía

homofunciona lidad

mostrar cierta actitud asociada con ese slang o el grupo que lo utiliza

homofunciona lidad se pierde el efecto de los procedimientos sintácticos pero, en general, se mantiene la funcionalidad.

esta es de las pocas muestras en las que se advierte una traducción con transgresión en colocao, algo que marca más la variedad linguiística y ayuda a que exista una homofuncionalidad. Un uso excesivo (que no se observa) podría resultar demasiado familiarizante y transgrediría normas de traducción actuales. la amplificación ayuda a compensar otros segmentos 
variedad según actitud, posición e individuo

procedimiento léxico semántico

variedad según actitud, posición e individuo

procedimiento léxico semántico

79

variedad según actitud, posición e individuo procedimiento sintáctico y procedimiento léxico semántico

83

variedad según actitud, posición e individuo

procedimiento sintáctico y procedimiento léxico semántico

variedad según actitud, posición e individuo procedimiento sintáctico variedad según actitud, posición e individuo procedimiento léxico formal y semántico amplificació naturalidad

$\mathrm{n}$

creación

discursiva

ampliación

con marcas

con transgresión

naturalidad

equivalente

acuñado

creación

con marcas

sin transgresión

naturalidad

discursiva

ampliación

modulación

equivalente

acuñado

con marcas

sin transgresión

naturalidad

creación

discursiva

reducción

con marcas

sin transgresión

naturalidad

reducción

con marcas

sin transgresión

naturalidad

discursiva

equivalente

con marcas

sin transgresión marcar pertenencia a/identificación con un grupo o establecer las relaciones sociales dentro del grupo

mostrar cierta actitud asociada con ese slang homofunciona o el grupo que lo utiliza lidad

mostrar cierta actitud asociada con ese slang o el grupo que lo utiliza homofunciona lidad

cambio del registro lingüístico para

provocar empatía

homofunciona lidad

cambio del registro

lingüístico para

provocar empatía

cambio del registro

lingüístico para

homofunciona

lidad

homofunciona

lidad la transgresión permite mantener la homofuncionalidad de la escena

la creación discursiva permite que haya homofuncionalidad

la traducción uno por uno de motherfucker por belleza aporta naturalidad para que se mantenga la funcionalidad

a pesar de la reducción impuesta por el procedimiento sintáctico, la creación discursiva mantiene la funcionalidad 
variedad según actitud, posición e individuo

procedimiento sintáctico y procedimiento léxico semántico

variedad según actitud, posición, sexo e individuo

procedimiento sintáctico y procedimiento léxico

90 semántico

variedad según actitud, posición, sexo e individuo

procedimiento léxico semántico

91

variedad según actitud, posición e individuo

procedimiento léxico
creación
discursiva
modulación
equivalente
acuñado

reducción

creación

discursiva

creación

discursiva

creación

discursiva

modulación

con marcas

sin transgresión

naturalidad

equivalente

acuñado

ampliación

generalizaci

ón semántico y

con marcas

sin transgresión

naturalidad

sin transgresión

naturalidad

equivalente

acuñado

reducción con marcas

con transgresión naturalidad

$$
\begin{gathered}
\text { linguístico para } \\
\text { provocar empatía }
\end{gathered}
$$

cambio del registro

cambio del registro

lingüístico para

provocar empatía

mostrar cierta actitud

asociada con ese slang

o el grupo que lo utiliza cambio del registro lingüístico para homofunciona

lidad

homofunciona

homofunciona

lidad

el mismo procedimiento sintáctico que en el ejemplo anterior se supera con una creación discursiva

aunque la generalización hace que el slang en el TM no sea tan marcado se consigue mantener la homofucionalidad

homofunciona lidad la transgresión y la creación discursiva, así como el uso de 
94

procedimiento sintáctico

variedad según actitud, posición e individuo

procedimiento léxico semántico

variedad según actitud, posición e individuo

procedimiento léxico semántico

95

variedad según actitud, posición, sexo e individuo

procedimiento léxico semántico

96

variedad según actitud, posición e individuo procedimiento léxico semántico

98

variedad según actitud, posición e individuo procedimiento léxico

99 semántico y formal

variedad según actitud, posición e individuo

\begin{tabular}{|c|c|c|c|}
\hline $\begin{array}{l}\text { creación } \\
\text { discursiva }\end{array}$ & naturalidad & provocar empatía & $\begin{array}{l}\text { una expresión común en la } \\
\text { cultura meta mantienen la } \\
\text { funcionalidad }\end{array}$ \\
\hline
\end{tabular}

creación

discursiva

ampliación

con marcas

sin transgresión

modulación

naturalidad

equivalente

acuñado

con marcas

sin transgresión

naturalidad

con marcas

formal

creación

discursiva

sin transgresión

naturalidad
reducción y
creación
con marcas
discursiva
sin transgresión
naturalidad

formal

equivalente

acuñado

con marcas

sin transgresión

naturalidad mostrar cierta actitud

asociada con ese slang homofunciona

o el grupo que lo utiliza lidad

marcar pertenencia

a/identificación con un

grupo o establecer las homofunciona

relaciones sociales

dentro del grupo

lidad

cambio del registro

lingüístico para

provocar empatía

cambio del registro

lingüístico para

provocar empatía

homofunciona

lidad

mostrar cierta actitud

asociada con ese slang homofunciona

o el grupo que lo utiliza

lidad 
procedimiento léxico semántico

100

variedad según actitud,

posición, sexo e individuo

procedimiento léxico semántico

101

102

variedad según actitud, posición e individuo procedimiento léxico semántico

variedad según actitud, posición e individuo

procedimiento sintáctico

variedad según actitud, posición e individuo

procedimiento sintáctico

variedad según actitud, posición, tema e individuo procedimiento sintáctico variedad según actitud, posición e individuo

$\begin{array}{ccc}\text { formal } & \begin{array}{c}\text { equivalente } \\ \text { acuñado }\end{array} & \begin{array}{c}\text { con marcas } \\ \text { sin transgresión } \\ \text { naturalidad }\end{array} \\ -\quad \text { modulación } & \begin{array}{c}\text { con marcas } \\ \text { sin transgresión } \\ \text { naturalidad }\end{array} \\ \text { equivalente } & \\ \text { acuñado } & \text { con marcas } \\ & \text { amplificació } & \begin{array}{c}\text { sin transgresión } \\ \text { naturalidad }\end{array}\end{array}$

formal reducción

sin marcas sin transgresión convencionalidad

con marcas

formal modulación sin transgresión naturalidad

formal

reducción y ampliación

con marcas sin transgresión naturalidad

creación discursiva

con marcas sin transgresión

\author{
cambio del registro \\ lingüístico para \\ provocar empatía
}

mostrar cierta actitud asociada con ese slang o el grupo que lo utiliza

\section{homofunciona}

lidad

mostrar cierta actitud asociada con ese slang o el grupo que lo utiliza

\section{homofunciona}

lidad

\section{marcar pertenencia} a/identificación con un

$\begin{array}{cc}\text { grupo o establecer las } & \text { homofunciona } \\ \text { relaciones sociales } & \text { lidad }\end{array}$ dentro del grupo

mostrar cierta actitud asociada con ese slang homofunciona o el grupo que lo utiliza lidad

mostrar cierta actitud asociada con ese slang homofunciona o el grupo que lo utiliza lidad mostrar cierta actitud

asociada con ese slang homofunciona lidad apuesta por la naturalidad en sintonía con la actitud que muestra el personaje

la ampliación compensa la reducción.

la creación discursiva permite mantener la funcionalidad 
procedimiento sintáctico

variedad según actitud, posición e individuo

procedimiento léxico semántico

111

variedad según actitud, posición e individuo

procedimiento léxico semántico

112

variedad según actitud, posición e individuo

procedimiento léxico

114 semántico y formal

variedad según actitud procedimiento léxico

116 semántico y formal

variedad según actitud procedimiento léxico semántico

variedad según actitud procedimiento léxico semántico y formal

naturalidad

o el grupo que lo utiliza

reducción

$$
\begin{aligned}
& \text { creación } \\
& \text { discursiva } \\
& \text { equivalente } \\
& \text { acuñado }
\end{aligned}
$$

con marcas

sin transgresión

naturalidad

mostrar cierta actitud

asociada con ese slang

o el grupo que lo utiliza

con marcas

formal equivalente

acuñado

creación

discursiva

$-$

modulación

- $\quad$ compresión

con marcas

sin transgresión

naturalidad

con marcas

- $\quad$ modulación

sin transgresión

naturalidad

equivalente

acuñado con marcas

sin transgresión marcar pertenencia

a/identificación con un

grupo o establecer las homofunciona

dentro del grupo

cambio del registro

lingüístico para

provocar empatía

cambio del registro

lingüístico para

provocar empatía

mostrar cierta actitud

asociada con ese slang homofunciona

o el grupo que lo utiliza lidad

mostrar cierta actitud

asociada con ese slang

homofunciona

lidad

homofunciona

lidad

homofunciona

lidad relaciones sociales homofunciona

lidad

en este caso, como la palabra negro no tiene una función fática,

el equivalente acuñado no conlleva una pérdida de funcionalidad. 


\section{2} semántico y formal

variedad según actitud

procedimiento léxico

125

$$
\text { semántico }
$$

variedad según actitud

procedimiento léxico semántico

126 individuo

procedimiento léxico

variedad según actitud, posición e individuo procedimiento léxico semántico y formal naturalidad

o el grupo que lo utiliza

variedad según actitud

formal acuñado semántico y formal

equivalente

modulación con marcas sin transgresión naturalidad cambio del registro lingüístico para provocar empatía

marcar pertenencia a/identificación con un grupo o establecer las equivalente

con marcas sin transgresión naturalidad

con marcas

equivalente acuñado con transgresión naturalidad

ampliación sin transgresión naturalidad

mostrar cierta actitud asociada con ese slang o el grupo que lo utiliza

rebelarse contra el lenguaje estándar

marcar la desvinculación de un grupo

reducción

con marcas

sin transgresión

naturalidad

reducción

generalizaci

ón homofunciona lidad

homofunciona
lidad

se observa el uso de lenguaje estándar y altamente formal con la intercalación de slang. El personaje pretende a la vez conectar con Jackie Brown y mostrar una actitud desafiante sin dejar de lado su condición de policía.

homofunciona lidad

uno de los pocos casos en los que el slang se usa para desvincularse de un grupo social. En este segmento, Ordell intenta mostrar que él no tiene nada que ver con que Jackie Brown tuviera cocaína en el bolso. Con transgresión porque la RAE no reconoce la palabra farlopa

homofunciona lidad

homofunciona

lidad

la generalización ayuda a mantener la naturalidad y la modulación mantiene la 
variedad según individuo, posición y actitud

procedimiento léxico semántico

130

variedad según individuo, posición y actitud

procedimiento léxico semántico

135

variedad según individuo $\mathrm{y}$ actitud

procedimiento léxico semántico

136

variedad según individuo $y$ actitud

procedimiento léxico semántico y

137

procedimiento sintáctico

variedad según individuo, posición y actitud

procedimiento léxico modulación

ampliación

y reducción

modulación

equivalente

acuñado

equivalente

acuñado semántico

generalizaci

ón

ampliación

reducción

equivalente

acuñado

equivalente

acuñado relaciones sociales

dentro del grupo

marcar pertenencia

a/identificación con un

con marcas

sin transgresión

naturalidad

grupo o establecer las

relaciones sociales

dentro del grupo

marcar pertenencia

sin marcas

sin transgresión

naturalidad

a/identificación con un

grupo o establecer las

relaciones sociales

dentro del grupo sin marcas sin transgresión naturalidad

con marcas

sin transgresión

naturalidad

sin transgresión con marcas mostrar cierta actitud

asociada con ese slang

o el grupo que lo utiliza

marcar pertenencia

a/identificación con un

grupo o establecer las

relaciones sociales

dentro del grupo

marcar la

desvinculación de un funcionalidad.

homofunciona

$$
\text { lidad }
$$

homofunciona
lidad

aunque la técnica usada sea la generalización, aporta naturalidad, puesto que en la LM no se repiten tanto los sustantivos como en la LO. La generalización sigue marcando el slang y por eso

hay una homofuncionalidad.

homofunciona

lidad

homofunciona 
variedad según individuo

140

141

144 procedimiento léxico

semántico y formal

variedad según individuo, posición y actitud

procedimiento léxico semántico posición y actitud

procedimiento léxico semántico

variedad según individuo, posición y actitud

procedimiento léxico semántico y naturalidad

grupo

reducción

reducción

creación

procedimiento sintáctico y

discursiva

creación

discursiva

con marcas

sin transgresión

naturalidad

cambio del registro

lingüístico para

provocar empatía

homofunciona

lidad

particulariza

ción

creación

discursiva

variedad según individuo,

procedimiento sintáctico equivalente

acuñado

creación

discursiva

creación

discursiva

modulación con marcas

sin transgresión

naturalidad

con marcas

con marcas

sin transgresión

naturalidad

sin transgresión cambio del registro

lingüístico para

provocar empatía

cambio del registro

lingüístico para

provocar empatía

marcar pertenencia

a/identificación con un

grupo o establecer las

relaciones sociales

la creación discursiva y la particularización permiten una

traducción muy natural que conserva la funcionalidad del TO

homofunciona

lidad

homofunciona lidad

aunque las marcas de slang no están en el mismo sitio en ambos

textos, se mantiene la funcionalidad. 
Estudio descriptivo de la traducción para el doblaje del slang en el largometraje Jackie Brown (Quentin Tarantino, 1997)

variedad según individuo

$$
\text { y actitud }
$$

procedimiento léxico

$$
\text { semántico }
$$

147

variedad según individuo,

posición y actitud

procedimiento léxico

$$
\text { semántico }
$$

149

variedad según individuo

$$
\text { y tema }
$$

procedimiento léxico semántico

150

variedad según individuo, posición y actitud

procedimiento léxico semántico y formal

151

variedad según individuo, posición y actitud

procedimiento léxico

semántico y formal y

155 fromal modulación

ampliación

$-$

equivalente

acuñado

equivalente

acuñado

equivalente

acuñado

creación

discursiva

ampliación

modulación

ampliación

modulación

con marcas

sin transgresión

naturalidad

sin transgresión

naturalidad

con marcas

naturalidad

\section{dentro del grupo}

mostrar cierta actitud

asociada con ese slang

o el grupo que lo utiliza

sin transgresión

mostrar cierta actitud

asociada con ese slang homofunciona

o el grupo que lo utiliza lidad

cambio del registro

lingüístico para

provocar empatía

homofunciona

lidad

cambio del registro

lingüístico para

provocar empatía

homofunciona

lidad

cambio del registro

lingüístico para

provocar empatía

homofunciona

lidad

variedad según individuo,

reducción 
posición y actitud procedimiento léxico

$$
\text { semántico }
$$

157

variedad según individuo

$$
y \text { actitud }
$$

procedimiento léxico

$$
\text { semántico }
$$

158

variedad según individuo, posición y actitud procedimiento léxico

160 semántico y formal

variedad según individuo, posición y actitud procedimiento léxico semántico

161

variedad según individuo, posición y actitud procedimiento léxico semántico y formal

164

variedad según individuo, posición y actitud procedimiento léxico

165 procedimiento sintáctico y

- $\quad$ modulación

modulación

modulación

reducción

equivalente

acuñado

- $\quad$ modulación

creación

discursiva

amplificació

$\mathrm{n}$

creación

discursiva

variedad según individuo, con marcas

sin transgresión

naturalidad

con marcas

con marcas

sin transgresión

naturalidad

con marcas

sin transgresión

naturalidad

sin transgresión

naturalidad

con marcas

sin transgresión

naturalidad

con marcas

sin transgresión

naturalidad modulación mostrar cierta actitud

asociada con ese slang homofunciona

o el grupo que lo utiliza lidad

mostrar cierta actitud

asociada con ese slang homofunciona

o el grupo que lo utiliza lidad

mostrar cierta actitud

asociada con ese slang homofunciona

o el grupo que lo utiliza lidad

mostrar cierta actitud

asociada con ese slang homofunciona

o el grupo que lo utiliza lidad

cambio del registro

lingüístico para

provocar empatía

homofunciona

lidad

mostrar cierta actitud

asociada con ese slang homofunciona

o el grupo que lo utiliza lidad 
166

procedimiento léxico semántico y formal

variedad según individuo,

posición y actitud

procedimiento léxico

semántico y formal

167

variedad según individuo,

posición y actitud

procedimiento léxico

$$
\text { semántico }
$$

173

variedad según individuo, posición y actitud

procedimiento sintáctico y procedimiento léxico semántico

177

variedad según individuo, posición y actitud

procedimiento léxico

$$
\text { semántico }
$$

179

variedad según individuo, posición y actitud

procedimiento léxico

182

$\begin{array}{cc}\text { creación } & \text { con marcas } \\ \text { discursiva } & \begin{array}{c}\text { sin transgresión } \\ \text { naturalidad }\end{array}\end{array}$

equivalente

acuñado

ampliación

equivalente
acuñado

reducción

equivalente

acuñado

creación

discursiva

equivalente

acuñado

equivalente sin transgresión

con marcas sin transgresión naturalidad

con marcas sin transgresión naturalidad

con marcas sin transgresión naturalidad

con marcas sin transgresión naturalidad mostrar cierta actitud

asociada con ese slang homofunciona

o el grupo que lo utiliza lidad convencionalidad asociada con ese slang

o el grupo que lo utiliza

homofunciona

lidad

mostrar cierta actitud

asociada con ese slang

o el grupo que lo utiliza

homofunciona

lidad

mostrar cierta actitud asociada con ese slang o el grupo que lo utiliza

homofunciona lidad

mostrar cierta actitud asociada con ese slang homofunciona o el grupo que lo utiliza lidad

mostrar cierta actitud

asociada con ese slang homofunciona o el grupo que lo utiliza se recupera la funcionalidad perdida en otros segmentos con la función fática y desafiante d ela palabra amigo

aunque haya una reducción con ain't se mantiene la funcionalidad específica del segmento

variedad según individuo, 
183

procedimiento léxico semántico

variedad según individuo, posición y actitud

procedimiento léxico semántico

184

variedad según individuo y tema

186

procedimiento léxico semántico

187

variedad según individuo y tema

procedimiento léxico

188 acuñado

equivalente acuñado

equivalente acuñado

con marcas

sin transgresión

equivalente

acuñado

equivalente

acuñado

creación

discursiva

con marcas

sin transgresión

naturalidad

marcas

sin transgresión

naturalidad

con marcas

equivalente

acuñado

equivalente

acuñado sin transgresión

naturalidad

con marcas sin transgresión naturalidad marcar pertenencia a/identificación con un grupo o establecer las homofunciona relaciones sociales lidad

dentro del grupo

mostrar cierta actitud asociada con ese slang homofunciona o el grupo que lo utiliza lidad

marcar pertenencia a/identificación con un grupo o establecer las homofunciona relaciones sociales lidad dentro del grupo

marcar pertenencia a/identificación con un grupo o establecer las homofunciona relaciones sociales lidad dentro del grupo

marcar pertenencia a/identificación con un homofunciona grupo o establecer las lidad 
y tema

procedimiento léxico semántico

189

variedad según individuo y tema

procedimiento léxico

190

variedad según individuo

procedimiento léxico semántico

191

variedad según individuo, posición, sexo y actitud

procedimiento léxico

192

variedad según individuo

procedimiento léxico

$$
\text { semántico }
$$

194

variedad según individuo, posición y actitud

procedimiento léxico semántico dentro del grupo

sin transgresión

naturalidad

compresión

creación

discursiva

con marcas

sin transgresión

naturalidad

equivalente

acuñado

con marcas

sin transgresión

equivalente

naturalidad

acuñado

ampliación

modulación

con marcas

sin transgresión

naturalidad

equivalente

acuñado

con marcas

sin transgresión

naturalidad

equivalente

acuñado con marcas

sin transgresión

naturalidad mostrar cierta actitud asociada con ese slang homofunciona o el grupo que lo utiliza lidad

hay una compresión puesto que en el LM no es usual repetir

tantas veces una misma palabra en un segmento tan corto. Sin embargo, se mantiene la funcionalidad.

mostrar cierta actitud asociada con ese slang o el grupo que lo utiliza

homofunciona

lidad

marcar pertenencia a/identificación con un grupo o establecer las relaciones sociales dentro del grupo

mostrar cierta actitud asociada con ese slang o el grupo que lo utiliza

marcar pertenencia a/identificación con un grupo o establecer las relaciones sociales dentro del grupo

marcar pertenencia a/identificación con un grupo o establecer las homofunciona lidad homofunciona lidad homofunciona

homofunciona

lidad

lidad 
variedad según individuo, posición y actitud

procedimiento léxico semántico

200

variedad según individuo $\mathrm{y}$ origen

procedimiento léxico semántico

201

variedad según individuo, posición y actitud

procedimiento léxico semántico

202

variedad según individuo, posición y actitud

procedimiento léxico semántico

204

variedad según individuo, posición y actitud

procedimiento léxico ampliación

equivalente

acuñado

con marcas

sin transgresión

naturalidad

generalizaci

ón

creación

discursiva

creación

discursiva

modulación

creación

discursiva

creación

discursiva

con marcas

sin transgresión

naturalidad

transgresión

naturalidad semántico y

con marcas

modulación sin transgresión naturalidad

omisión

con marcas sin transgresión relaciones sociales

dentro del grupo

marcar pertenencia a/identificación con un grupo o establecer las relaciones sociales dentro del grupo

homofunciona

lidad

marcar pertenencia a/identificación con un grupo o establecer las relaciones sociales dentro del grupo

homofunciona

lidad

aunque no es habitual que dos personas de color en la cultura meta se llamen hermano, este término cumple aquí una función fática poco importante en la película

moscón aporta mucha naturalidad a la traducción y, aunque antinegros conlleve una transgresión que no se observa en el TO, mantiene la funcionalidad sin problemas

marcar pertenencia a/identificación con un grupo o establecer las relaciones sociales dentro del grupo

homofunciona

lidad

mostrar cierta actitud asociada con ese slang homofunciona o el grupo que lo utiliza lidad

mostrar cierta actitud

homofunciona asociada con ese slang aunque en este segmento se observe una omisión, la 
procedimiento sintáctico

variedad según individuo, posición y actitud

procedimiento léxico semántico

207

variedad según individuo, posición y actitud

procedimiento léxico semántico

208

variedad según individuo, posición y actitud

procedimiento léxico semántico

209

variedad según individuo, posición y actitud

procedimiento sintáctico

210

variedad según individuo, posición y actitud

procedimiento léxico semántico

211

variedad según individuo, posición y actitud modulación

naturalidad

o el grupo que lo utiliza

transgresión

naturalidad

modulación

generalizaci

ón

modulación

ampliación

con marcas sin transgresión

naturalidad

ampliación

reducción

con marcas

sin transgresión

naturalidad

creación

discursiva

con marcas

sin transgresión

naturalidad

modulación

con marcas

con transgresión

marcar pertenencia cambio del registro

lingüístico para

provocar empatía

mostrar cierta actitud

asociada con ese slang

o el grupo que lo utiliza

homofunciona

lida

marcar pertenencia

a/identificación con un

grupo o establecer las

relaciones sociales

dentro del grupo a/identificación con un

homofunciona

lidad

homofunciona lidad funcionalidad tanto del segmento como de la escena no se ve afectadas

rollo trasmite una actitud menos agresiva que shit, algo que se compensa con la ampliación de acojona

la reducción de ain't se ve compensada con la ampliación de trincarían

hay una transgresión con el término matao. Sin embargo, la 
variedad según individuo, posición y actitud

procedimiento léxico semántico

216

variedad según individuo, posición y actitud

procedimiento sintáctico y procedimiento léxico semántico

220

variedad según individuo, sexo, posición y actitud

procedimiento léxico semántico

variedad según individuo, posición, sexo y actitud procedimiento léxico modulación

naturalidad

ampliación

amplificació

$\mathrm{n}$

equivalente acuñado

ampliación

modulación

creación

discursiva

equivalente

acuñado

reducción

modulación

equivalente

acuñado

equivalente

acuñado

modulación

reducción con marcas

sin transgresión

naturalidad

con marcas

sin transgresión

naturalidad

con marcas

con transgresión

naturalidad

con marcas

sin transgresión grupo o establecer las

relaciones sociales

dentro del grupo

marcar pertenencia a/identificación con un grupo o establecer las relaciones sociales dentro del grupo

marcar pertenencia a/identificación con un grupo o establecer las relaciones sociales dentro del grupo

homofunciona lidad

marcar pertenencia a/identificación con un grupo o establecer las relaciones sociales dentro del grupo

\section{homofunciona} lidad

mostrar cierta actitud homofunciona asociada con ese slang funcionalidad es la misma. La transgresión no resulta extraña, ya que no se abusa de ella a lo largo de la película transgresión con la expresión estar de tranquis, que resulta funcionalmente equivalente al chillin' del TO

(a)




\section{semántico y formal}

variedad según individuo, sexo, posición y actitud

procedimiento léxico semántico

224

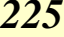

226

variedad según individuo,

variedad según individuo, posición y actitud

procedimiento léxico semántico

variedad según individuo, posición y actitud

procedimiento léxico

$$
\text { semántico }
$$

\author{
modulación \\ reducción \\ equivalente \\ acuñado \\ creación \\ discursiva \\ creación \\ discursiva \\ equivalente \\ acuñado
}

naturalidad

o el grupo que lo utiliza acuñado

equivalente

acuñado

equivalente

acuñado

acunado
( marcar pertenencia

con marcas a/identificación con un

sin transgresión

naturalidad

con marcas

sin transgresión

naturalidad

con marcas

sin transgresión

naturalidad

relaciones sociales de slang no estén en las mismas palabras en el TO y en el TM.

Aunque no estén en las mismas palabras, se mantiene sin problemas la funcionalidad $\begin{array}{cc}\text { grupo o establecer las } & \text { homofunciona } \\ \text { relaciones sociales } & \text { lidad }\end{array}$

dentro del grupo

marcar pertenencia

a/identificación con un

grupo o establecer las homofunciona

relaciones sociales

dentro del grupo

lidad

marcar pertenencia

a/identificación con un homofunciona

grupo o establecer las

lidad 
sexo, posición y actitud

procedimiento léxico semántico

variedad según individuo, posición y actitud

procedimiento sintáctico y procedimiento léxico

233 semántico

variedad según individuo, sexo, posición y actitud

procedimiento léxico semántico

234

variedad según individuo, posición y actitud

procedimiento sintáctico y procedimiento léxico semántico

variedad según individuo, posición y actitud

\section{dentro del grupo}

marcar pertenencia a/identificación con un grupo o establecer las relaciones sociales dentro del grupo

marcar pertenencia a/identificación con un grupo o establecer las relaciones sociales dentro del grupo

equivalente acuñado

ampliación $\mathrm{y}$ equivalente acuñado

amplificació $\mathrm{n}$

reducción ampliación $\mathrm{y}$ equivalente acuñado con marcas con transgresión naturalidad

con marcas con transgresión naturalidad cambio del registro lingüístico para provocar empatía

homofunciona lidad

marcar pertenencia a/identificación con un grupo o establecer las relaciones sociales dentro del grupo homofunciona

lidad homofuncionl aidad

la generalización no hace que el segmento pierda funcionalidad

homofunciona

lidad

la palabra crakera conlleva una transgresión, pero aporta naturalidad para mantener la funcionalidad 
236

procedimiento léxico semántico

variedad según individuo, posición y actitud

procedimiento léxico semántico

237

variedad según individuo, posición y actitud

procedimiento léxico semántico

240

variedad según individuo, posición y actitud

procedimiento léxico semántico

241

variedad según individuo, posición y actitud

procedimiento léxico semántico

242

variedad según individuo, posición y actitud modulación

ampliación

$\begin{array}{cc}\text { equivalente } & \text { con marcas } \\ \text { acuñado } & \begin{array}{c}\text { sin transgresión } \\ \text { naturalidad }\end{array}\end{array}$

modulación

reducción y

creación

in transgresión

naturalidad

discursiva

equivalente

acuñado

con marcas

sin transgresión

naturalidad

equivalente

acuñado

con marcas

sin transgresión

particulariza

ción

naturalidad

equivalente

acuñado

con marcas

sin transgresión

naturalidad marcar pertenencia

a/identificación con un

grupo o establecer las homofunciona

relaciones sociales

dentro del grupo

lidad

mostrar cierta actitud

asociada con ese slang homofunciona

o el grupo que lo utiliza lidad

marcar pertenencia

a/identificación con un

grupo o establecer las homofunciona

relaciones sociales lidad

dentro del grupo

marcar pertenencia

a/identificación con un

grupo o establecer las homofunciona

relaciones sociales

dentro del grupo

marcar pertenencia

a/identificación con un

grupo o establecer las

relaciones sociales

homofunciona

lidad 
245

procedimiento léxico

$$
\text { semántico }
$$

variedad según individuo, posición y actitud

\section{procedimiento léxico} semántico

246

247

249

variedad según individuo, posición y actitud

procedimiento léxico semántico

variedad según individuo, posición y actitud

procedimiento léxico semántico

248

variedad según individuo, posición y actitud

procedimiento sintáctico y procedimiento léxico semántico

variedad según individuo, posición y actitud equivalente

acuñado

creación

discursiva

con marcas

sin transgresión

naturalidad

mostrar cierta actitud

asociada con ese slang homofunciona

o el grupo que lo utiliza lidad

particulariza

ción

modulación

con marcas

sin transgresión

naturalidad

creación

discursiva

reducción

con marcas

sin transgresión

naturalidad

con marcas

modulación

sin transgresión

naturalidad

creación

discursiva

reducción

con marcas

con transgresión

naturalidad mostrar cierta actitud

asociada con ese slang homofunciona

o el grupo que lo utiliza lidad

mostrar cierta actitud

asociada con ese slang homofunciona

o el grupo que lo utiliza lidad

mostrar cierta actitud

asociada con ese slang homofunciona

o el grupo que lo utiliza lidad

mostrar cierta actitud

asociada con ese slang

o el grupo que lo utiliza homofunciona

lidad la creación discursiva hace que no se repita la estructura de la muestra anterior. Aunque sea diferente, sigue cumpliendo la misma función

hay una transgresión en tranqui.

Esto aporta naturalidad y no

resulta excesivamente

familiarizante porque no se abusa de esta transgresión 
250

\section{procedimiento léxico semántico y formal} posición y actitud

251

252

variedad según individuo, posición y actitud

procedimiento léxico

$$
\text { semántico }
$$

variedad según individuo, posición y actitud

procedimiento léxico

$$
\text { semántico }
$$

variedad según individuo, posición y actitud procedimiento léxico variedad según individuo, modulación

modulación

modulación

$$
\begin{aligned}
& \text { creación } \\
& \text { discursiva } \\
& \text { equivalente } \\
& \text { acuñado } \\
& \text { amplificació } \\
& \text { n } \\
& \text { creación } \\
& \text { discursiva }
\end{aligned}
$$

modulación

ampliación

creación

discursiva

creación

discursiva

equivalente

$$
\text { semántico }
$$

in transgresión asociada con ese slang

naturalidad

o el grupo que lo utiliza

lidad

con marcas

sin transgresión

naturalidad

asociada con ese slang

o el grupo que lo utiliza

homofunciona

lidad

mostrar cierta actitud

con marcas

sin transgresión

naturalidad

homofunciona

lidad homofunciona

con marcas

mostrar cierta actitud homofunciona la creación discursiva permite crear un texto muy natural 
Estudio descriptivo de la traducción para el doblaje del slang en el largometraje Jackie Brown (Quentin Tarantino, 1997)

semántico

variedad según individuo, posición y actitud

procedimiento sintáctico y procedimiento léxico

257 semántico y formal

variedad según individuo, sexo, posición y actitud

procedimiento léxico

$$
\text { semántico }
$$

258

variedad según individuo, posición y actitud

procedimiento léxico semántico

261

variedad según individuo, sexo, posición y actitud

procedimiento léxico semántico

variedad según individuo, sexo, posición y actitud procedimiento léxico

$$
\text { acuñado }
$$

generalizaci

ón

reducción

creación

discursiva

equivalente

acuñado

reducción

con marcas sin transgresión naturalidad

particulariza

ción

con marcas

sin transgresión

naturalidad

creación

discursiva

reducción

modulación

con marcas

sin transgresión

naturalidad

con marcas

- $\quad$ modulación sin transgresión

naturalidad asociada con ese slang

o el grupo que lo utiliza

lidad

$\begin{array}{cc}\text { marcar pertenencia } & \\ \text { a/identificación con un } & \\ \text { grupo o establecer las } & \text { homofunciona } \\ \text { relaciones sociales } & \text { lidad } \\ \text { dentro del grupo } & \end{array}$

marcar pertenencia a/identificación con un grupo o establecer las homofunciona relaciones sociales dentro del grupo

lidad

mostrar cierta actitud asociada con ese slang homofunciona o el grupo que lo utiliza lidad

mostrar cierta actitud asociada con ese slang o el grupo que lo utiliza

\section{homofunciona}

lidad 
semántico

variedad según individuo, posición y actitud

procedimiento léxico

$$
\text { semántico }
$$

264

variedad según individuo, posición y actitud

procedimiento léxico semántico

266

variedad según individuo, posición y actitud

procedimiento léxico semántico

267

268

variedad según individuo, posición y actitud

procedimiento léxico semántico y formal

variedad según individuo, posición y actitud

\section{sin transgresión naturalidad \\ asociada con ese slang o el grupo que lo utiliza}

equivalente acuñado

equivalente

acuñado

con marcas sin transgresión naturalidad

\section{particulariza} ción

generalizaci ón

creación

$$
\text { discursiva }
$$

creación discursiva con marcas sin transgresión naturalidad

con marcas sin transgresión naturalidad

con marcas sin transgresión naturalidad marcar pertenencia a/identificación con un grupo o establecer las relaciones sociales dentro del grupo

marcar pertenencia a/identificación con un relaciones sociales dentro del grupo

marcar pertenencia a/identificación con un grupo o establecer las relaciones sociales dentro del grupo

marcar pertenencia a/identificación con un grupo o establecer las relaciones sociales dentro del grupo grupo o establecer las lidad

\section{homofunciona \\ lidad}

\section{homofunciona}

lidad

la creación discursiva resulta un tanto extraña, ya que no es asociable con ningún grupo social. Por otro lado, es una opción que no desentona con la caracterización de Max Cherry

homofunciona

lidad

aunque el slang usado sea menos marcado, la funcionalidad se mantiene sin problemas 
270

procedimiento léxico semántico

variedad según individuo, posición y actitud

273

procedimiento léxico semántico

variedad según individuo, sexo, posición y actitud

procedimiento léxico semántico y

274

procedimiento sintáctico

variedad según individuo, posición y actitud

procedimiento léxico semántico

276

variedad según individuo, sexo, posición y actitud

procedimiento léxico semántico marcar pertenencia

a/identificación con un

grupo o establecer las homofunciona

relaciones sociales

dentro del grupo

mostrar cierta actitud

asociada con ese slang homofunciona

acuñado

modulación

con marcas

sin transgresión

naturalidad

ampliación

modulación

reducción

mostrar cierta actitud

asociada con ese slang sin transgresión naturalidad

creación

discursiva

creación

discursiva

equivalente

acuñado

con marcas

sin transgresión

naturalidad

equivalente

acuñado

equivalente

acuñado con marcas mostrar cierta actitud sin transgresión asociada con ese slang naturalidad o el grupo que lo utiliza la creación discursiva permite que la dificultad de trasladar el procedimiento sintáctico con el verbo to be mal conjugado no suponga una pérdida en la funcionalidad 
variedad según individuo,

posición y actitud

procedimiento léxico

$$
\text { semántico }
$$

variedad según individuo, sexo posición y actitud

procedimiento léxico semántico y formal

variedad según individuo posición y actitud

procedimiento léxico

$$
\text { semántico }
$$

281

variedad según individuo, posición y actitud

procedimiento sintáctico y procedimiento léxico

$$
\text { semántico }
$$

variedad según individuo, posición y actitud procedimiento léxico

$$
\text { semántico }
$$

variedad según individuo, posición y actitud

modulación

reducción

con marcas

sin transgresión

naturalidad

con marcas

- $\quad$ modulación

sin transgresión

naturalidad

reducción

equivalente

acuñado

con marcas

sin transgresión

naturalidad

creación

discursiva

equivalente

acuñado

equivalente

acuñado

modulación

con marcas sin transgresión naturalidad

con marcas sin transgresión naturalidad

con marcas mostrar cierta actitud

asociada con ese slang homofunciona

o el grupo que lo utiliza lidad

marcar pertenencia a/identificación con un grupo o establecer las relaciones sociales dentro del grupo

mostrar cierta actitud asociada con ese slang o el grupo que lo utiliza

homofunciona

$$
\text { lidad }
$$

mostrar cierta actitud asociada con ese slang homofunciona o el grupo que lo utiliza lidad

mostrar cierta actitud asociada con ese slang o el grupo que lo utiliza

\section{homofunciona} lidad la reducción, en este caso, no implica una pérdida de funcionalidad, porque la escena está muy marcad por el slang y una reducción no supone una pérdida significativa

procedimiento léxico

mostrar cierta actitud homofunciona 
289

semántico

variedad según individuo, posición y actitud procedimiento léxico semántico y formal

variedad según individuo, posición y actitud

procedimiento léxico semántico

291

variedad según individuo, posición y actitud procedimiento léxico semántico

293

294

295

296 variedad según individuo, sexo, posición y actitud procedimiento léxico semántico y formal

variedad según individuo, posición y actitud procedimiento léxico semántico y formal

variedad según individuo, posición y actitud procedimiento léxico semántico sin transgresión naturalidad

ampliación

modulación

con marcas sin transgresión naturalidad

con marcas

modulación sin transgresión naturalidad

creación

discursiva

equivalente acuñado

creación

discursiva

con marcas sin transgresión naturalidad

creación

discursiva

creación

discursiva

con marcas naturalidad sin transgresión naturalidad

con marcas sin transgresión con marcas

asociada con ese slang o el grupo que lo utiliza

mostrar cierta actitud asociada con ese slang homofunciona o el grupo que lo utiliza lidad

mostrar cierta actitud asociada con ese slang homofunciona o el grupo que lo utiliza lidad sin transgresión

mostrar cierta actitud asociada con ese slang homofunciona o el grupo que lo utiliza lidad

mostrar cierta actitud asociada con ese slang homofunciona o el grupo que lo utiliza lidad

mostrar cierta actitud asociada con ese slang homofunciona o el grupo que lo utiliza lidad mostrar cierta actitud homofunciona asociada con ese slang

lidad aunque la creación discursiva pueda ser arriesgada, se mantiene 
299

300

\section{2}

303

304 naturalidad

variedad según individuo, posición y actitud procedimiento léxico semántico y formal

variedad según individuo, posición y actitud procedimiento léxico semántico y firnak

variedad según individuo, posición y actitud procedimiento léxico semántico

variedad según individuo, posición y actitud procedimiento léxico semántico

variedad según individuo, posición y actitud procedimiento léxico semántico

variedad según individuo, posición y actitud

con marcas

naturalidad

equivalente

equivalente

acuñado

creación

discursiva

con marcas

naturalidad

con marcas

modulación

naturalidad

con marcas

modulación

naturalidad

sin marcas

generalizaci

ón o el grupo que lo utiliza

mostrar cierta actitud

sin transgresión

sin transgresión

sin transgresión

sin transgresión

sin transgresión

convencionalidad

mostrar cierta actitud

asociada con ese slang

o el grupo que lo utiliza

homofunciona

lidad

modulación

$\mathrm{y}$

particulariza con marcas

sin transgresión

naturalidad perfectamente la funcionalidad

aunque la técnica usada sea la generalización, no se observa una pérdida de la funcionalidad del segmento

aunque se añada slang al TM no se observa una funcionalidad añadida 
procedimiento léxico semántico y formal

306

variedad según individuo,

posición y actitud

procedimiento léxico

$$
\text { semántico }
$$

307

variedad según individuo, posición y actitud

308

309

procedimiento léxico

semántico y formal

variedad según individuo, posición y actitud

procedimiento léxico semántico y formal

311

variedad según individuo, sexo, posición y actitud

procedimiento sintáctico y procedimiento léxico

313 semántico y formal

variedad según individuo, posición y actitud ción

\begin{tabular}{|c|c|c|c|c|}
\hline $\begin{array}{l}\text { equivalente } \\
\text { acuñado }\end{array}$ & $\begin{array}{l}\text { con marcas } \\
\text { sin transgresión } \\
\text { naturalidad }\end{array}$ & $\begin{array}{c}\text { mostrar cierta actitud } \\
\text { asociada con ese slang } \\
\text { o el grupo que lo utiliza }\end{array}$ & $\begin{array}{c}\text { homofunciona } \\
\text { lidad }\end{array}$ & - \\
\hline $\begin{array}{l}\text { creación } \\
\text { discursiva }\end{array}$ & $\begin{array}{l}\text { con marcas } \\
\text { sin transgresión } \\
\text { naturalidad }\end{array}$ & $\begin{array}{c}\text { mostrar cierta actitud } \\
\text { asociada con ese slang } \\
\text { o el grupo que lo utiliza }\end{array}$ & $\begin{array}{l}\text { homofunciona } \\
\text { lidad }\end{array}$ & - \\
\hline ampliación & $\begin{array}{l}\text { con marcas } \\
\text { sin transgresión } \\
\text { naturalidad }\end{array}$ & - & $\begin{array}{l}\text { homofunciona } \\
\text { lidad }\end{array}$ & $\begin{array}{c}\text { aunque se añada slang al TM no } \\
\text { se observa una funcionalidad } \\
\text { añadida }\end{array}$ \\
\hline $\begin{array}{l}\text { equivalente } \\
\text { acuñado } \\
\text { creación } \\
\text { discursiva }\end{array}$ & $\begin{array}{l}\text { con marcas } \\
\text { sin transgresión } \\
\text { naturalidad }\end{array}$ & $\begin{array}{l}\text { cambio del registro } \\
\text { lingüístico para } \\
\text { provocar empatía }\end{array}$ & $\begin{array}{l}\text { homofunciona } \\
\text { lidad }\end{array}$ & 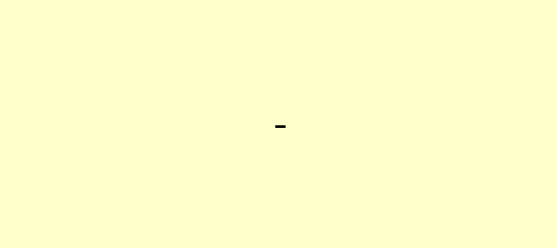 \\
\hline $\begin{array}{l}\text { modulación } \\
\text { reducción }\end{array}$ & $\begin{array}{l}\text { con marcas } \\
\text { sin transgresión } \\
\text { naturalidad }\end{array}$ & $\begin{array}{l}\text { cambio del registro } \\
\text { lingüístico para } \\
\text { provocar empatía }\end{array}$ & $\begin{array}{l}\text { homofunciona } \\
\text { lidad }\end{array}$ & - \\
\hline $\begin{array}{l}\text { reducción } \\
\text { equivalente } \\
\text { acuñado }\end{array}$ & $\begin{array}{l}\text { con marcas } \\
\text { sin transgresión } \\
\text { naturalidad }\end{array}$ & $\begin{array}{c}\text { mostrar cierta actitud } \\
\text { asociada con ese slang } \\
\text { o el grupo que lo utiliza }\end{array}$ & $\begin{array}{c}\text { homofunciona } \\
\text { lidad }\end{array}$ & - \\
\hline equivalente & con marcas & marcar pertenencia & homofunciona & - \\
\hline
\end{tabular}


semántico

variedad según individuo, sexo, posición y actitud

procedimiento sintáctico

variedad según individuo, posición y actitud

procedimiento sintáctico y procedimiento léxico semántico

318

variedad según individuo, posición y actitud procedimiento léxico semántico

319

variedad según individuo, posición y actitud

procedimiento léxico semántico y formal

320

variedad según individuo, posición y actitud acuñado sin transgresión
naturalidad

creación

discursiva

con marcas

sin transgresión

naturalidad

reducción

modulación

con marcas

sin transgresión

naturalidad

equivalente

acuñado

sin transgresión

naturalidad

creación

discursiva

equivalente

acuñado

con marcas

sin transgresión

naturalidad

creación

discursiva

equivalente con marcas con marcas

a/identificación con un grupo o establecer las relaciones sociales dentro del grupo

marcar pertenencia a/identificación con un $\begin{array}{cc}\text { grupo o establecer las } & \text { homofunciona } \\ \text { relaciones sociales } & \text { lidad }\end{array}$ dentro del grupo

mostrar cierta actitud asociada con ese slang homofunciona o el grupo que lo utiliza lidad

mostrar cierta actitud asociada con ese slang homofunciona o el grupo que lo utiliza lidad

mostrar cierta actitud asociada con ese slang o el grupo que lo utiliza homofunciona lidad lidad

aunque se pierde el efecto de repetir la misma palabra del TO, la funcionalidad sigue siendo la misma 
Estudio descriptivo de la traducción para el doblaje del slang en el largometraje Jackie Brown (Quentin Tarantino, 1997)

322

variedad según individuo, posición y actitud

procedimiento léxico semántico y

324 procedimiento sintáctico

variedad según individuo, sexo, posición y actitud procedimiento léxico semántico y

procedimiento sintáctico

variedad según individuo, posición y actitud

procedimiento léxico semántico

327

variedad según individuo, sexo, posición y actitud

\section{cedimiento léxico} semántico y

procedimiento sintáctico acuñado

sin transgresión naturalidad

asociada con ese slang o el grupo que lo utiliza

con marcas

equivalente

acuñado

sin transgresión

naturalidad

equivalente acuñado

equivalente acuñado

reducción

creación

discursiva

equivalente

acuñado

equivalente
acuñado

equivalente con marcas naturalidad

con marcas sin transgresión convencionalidad

con marcas sin transgresión naturalidad

con marcas sin transgresión naturalidad sin transgresión mostrar cierta actitud

asociada con ese slang homofunciona

o el grupo que lo utiliza lidad

mostrar cierta actitud asociada con ese slang homofunciona o el grupo que lo utiliza lidad

marcar pertenencia a/identificación con un grupo o establecer las homofunciona relaciones sociales lidad dentro del grupo

marcar pertenencia a/identificación con un grupo o establecer las homofunciona relaciones sociales dentro del grupo lidad

mostrar cierta actitud asociada con ese slang homofunciona o el grupo que lo utiliza lidad 
variedad según individuo, sexo, posición y actitud

procedimiento léxico semántico

330

variedad según individuo, posición y actitud

procedimiento léxico semántico y formal

332

variedad según individuo, sexo, posición y actitud

procedimiento léxico semántico y

334

procedimiento sintáctico

variedad según individuo, posición y actitud

procedimiento léxico semántico y

procedimiento sintáctico

variedad según individuo, sexo, posición y actitud acuñado

reducción

con marcas

equivalente

acuñado

sin transgresión

reducción

con marcas

generalizaci

ón

sin transgresión

naturalidad

reducción

creación

discursiva

con marcas

sin transgresión

equivalente

acuñado

naturalidad

mostrar cierta actitud

asociada con ese slang

o el grupo que lo utiliza

homofunciona

lidad

modulación

creación

discursiva

equivalente

acuñado

con marcas

sin transgresión

naturalidad

mostrar cierta actitud

asociada con ese slang homofunciona

o el grupo que lo utiliza lidad

modulación

relaciones sociales

dentro del grupo

mostrar cierta actitud asociada con ese slang homofunciona

lidad naturalidad semántico con marcas sin transgresión aunque la generalización hace que la variación lingüística no esté tan marcada, se conserva la funcionalidad

aunque la primera parte del segmento traducido no esté tan marcada, se mantiene la funcionalidad del segmento completo y de la escena 
variedad según individuo, sexo, posición y actitud

procedimiento léxico semántico

337

variedad según individuo, posición y actitud

\section{procedimiento léxico} semántico y formal

338

variedad según individuo, posición y actitud

procedimiento léxico semántico y formal

340

variedad según individuo, posición y actitud

procedimiento léxico semántico y formal

variedad según individuo, posición y actitud procedimiento léxico

$\begin{array}{cc}\begin{array}{c}\text { equivalente } \\ \text { acuñado }\end{array} & \text { naturalidad } \\ \begin{array}{c}\text { creación } \\ \text { discursiva }\end{array} & \\ \text { modulación } & \text { con marcas } \\ \text { creación } & \begin{array}{c}\text { sin transgresión } \\ \text { naturalidad }\end{array} \\ \text { discursiva } & \end{array}$

equivalente

acuñado

con marcas

sin transgresión

naturalidad

con marcas

compresión

sin transgresión

naturalidad

con marcas

modulación

sin transgresión

naturalidad

equivalente

acuñado con marcas sin transgresión naturalidad

\section{grupo o establecer las \\ relaciones sociales \\ dentro del grupo}

marcar pertenencia a/identificación con un

$\begin{array}{cc}\text { grupo o establecer las } & \text { homofunciona } \\ \text { relaciones sociales } & \text { lidad }\end{array}$ dentro del grupo

marcar pertenencia a/identificación con un grupo o establecer las relaciones sociales dentro del grupo

homofunciona

marcar pertenencia a/identificación con un grupo o establecer las relaciones sociales dentro del grupo

homofunciona lidad

se usa la técnica de compresión, pero la palabra utilizada contiene slang marcado

cambio del registro lingüístico para provocar empatía

homofunciona lidad

cambio del registro lingüístico para provocar empatía homofunciona

lidad 
343

344

345

347

variedad según individuo, posición y actitud procedimiento léxico semántico y formal

variedad según individuo, posición y actitud procedimiento léxico semántico y formal

variedad según individuo, posición y actitud procedimiento léxico semántico

variedad según individuo, posición y actitud procedimiento léxico semántico y formal

variedad según individuo, posición y actitud

procedimiento sintáctico y procedimiento léxico semántico

variedad según individuo, posición y actitud

\section{creación}

discursiva

(n)

creación

$$
\text { - discursiva }
$$

equivalente

acuñado

reducción y

ampliación

reducción

equivalente

acuñado

modulación

con marcas

sin transgresión

naturalidad

in transgresión

naturalidad

con marcas

sin transgresión

naturalidad

con marcas

sin transgresión

naturalidad

\author{
cambio del registro \\ lingüístico para \\ provocar empatía \\ homofunciona \\ lidad
}

cambio del registro

lingüístico para

provocar empatía

homofunciona

mostrar cierta actitud

asociada con ese slang homofunciona

o el grupo que lo utiliza lidad

mostrar cierta actitud

asociada con ese slang homofunciona

o el grupo que lo utiliza lidad

marcar pertenencia

a/identificación con un

grupo o establecer las homofunciona

relaciones sociales

dentro del grupo lidad

equivalente

acuñado 
Estudio descriptivo de la traducción para el doblaje del slang en el largometraje Jackie Brown (Quentin Tarantino, 1997)

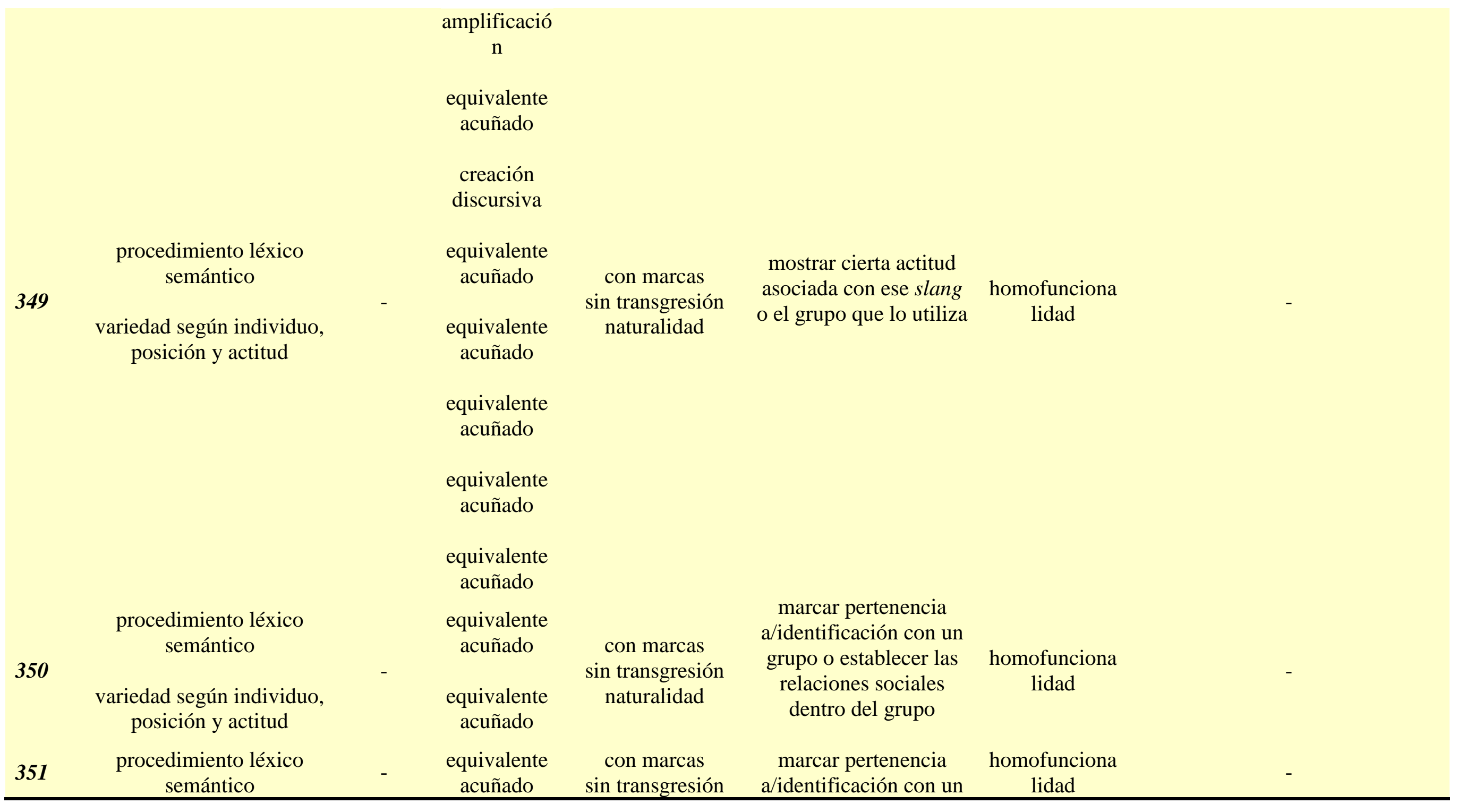


353

\section{4}

variedad según individuo, posición y actitud

\section{procedimiento léxico}

$$
\text { semántico }
$$

variedad según individuo, posición y actitud

procedimiento léxico semántico

variedad según individuo, posición y actitud procedimiento léxico semántico y procedimiento sintáctico

variedad según individuo, posición y actitud procedimiento léxico semántico

variedad según individuo, posición y actitud procedimiento léxico semántico y formal

variedad según individuo, posición y actitud naturalidad grupo o establecer las relaciones sociales dentro del grupo

marcar pertenencia a/identificación con un grupo o establecer las homofunciona relaciones sociales lidad dentro del grupo

mostrar cierta actitud asociada con ese slang homofunciona o el grupo que lo utiliza lidad acuñado con marcas sin transgresión naturalidad

marcar pertenencia equivalente acuñado

reducción

con marcas sin transgresión naturalidad

ampliación

con marcas

equivalente acuñado sin transgresión naturalidad

equivalente acuñado con marcas sin transgresión naturalidad a/identificación con un

grupo o establecer las homofunciona

relaciones sociales

dentro del grupo

mostrar cierta actitud asociada con ese slang homofunciona o el grupo que lo utiliza lidad

mostrar cierta actitud asociada con ese slang homofunciona o el grupo que lo utiliza lidad 
procedimiento léxico semántico

360

variedad según individuo, posición y actitud procedimiento léxico semántico

361

variedad según individuo, posición y actitud

procedimiento léxico semántico

362

variedad según individuo, posición y actitud

procedimiento léxico semántico y

365

procedimiento sintáctico

variedad según individuo, posición y actitud

procedimiento léxico semántico y

369

variedad según individuo,

origen, posición y actitud procedimiento léxico semántico

$\begin{array}{cc}\begin{array}{c}\text { equivalente } \\ \text { acuñado }\end{array} & \begin{array}{c}\text { con marcas } \\ \text { sin transgresión } \\ \text { naturalidad }\end{array} \\ \begin{array}{c}\text { equivalente } \\ \text { acuñado }\end{array} & \begin{array}{c}\text { con marcas } \\ \text { sin transgresión } \\ \text { naturalidad }\end{array}\end{array}$

acuñado

con marcas

sin transgresión

naturalidad

equivalente

acuñado

equivalente

acuñado

creación

discursiva

procedimiento sintáctico

con marcas

sin transgresión

convencionalidad

discursiva

con transgresión

naturalidad

con marcas

traducción equivalente

mostrar cierta actitud

asociada con ese slang

o el grupo que lo utiliza

mostrar cierta actitud

asociada con ese slang

o el grupo que lo utiliza

homofunciona

lidad

marcar pertenencia

a/identificación con un

$\begin{array}{cc}\text { grupo o establecer las } & \text { homofunciona } \\ \text { relaciones sociales } & \text { lidad }\end{array}$

dentro del grupo

mostrar cierta actitud

asociada con ese slang

o el grupo que lo utiliza

marcar pertenencia

a/identificación con un

grupo o establecer las

relaciones sociales

dentro del grupo

uno por uno sin transgresión marcar pertenencia

a/identificación con un

grupo o establecer las homofunciona

lidad

aunque el juego de palabras no funciona tan bien en el TM como en el TO y la traducción sea algo convencional y extranjerizante, se mantiene la funcionalidad

la transgresión de tranqui no homofunciona lidad produce un texto excesivamente familiarizante porque no se abusa de ella

homofunciona

lidad 
variedad según individuo, posición y actitud

procedimiento léxico semántico y

371

procedimiento sintáctico

variedad según individuo, posición y actitud

procedimiento léxico semántico

372

variedad según individuo, sexo, posición y actitud procedimiento léxico semántico

373

variedad según individuo, posición y actitud procedimiento léxico semántico

374

variedad según individuo, posición y actitud procedimiento léxico

$$
\text { semántico }
$$

variedad según individuo, posición y actitud

procedimiento léxico relaciones sociales dentro del grupo

generalizaci

ón

reducción sin transgresión
naturalidad

creación

discursiva

equivalente

acuñado

reducción

con marcas

sin transgresión

naturalidad

equivalente

acuñado

con marcas

sin transgresión

naturalidad

reducción

con marcas

sin transgresión

creación

discursiva

naturalidad

equivalente

acuñado

con marcas

sin transgresión

naturalidad

creación

con marcas mostrar cierta actitud

asociada con ese slang homofunciona

o el grupo que lo utiliza lidad

mostrar cierta actitud

asociada con ese slang homofunciona

o el grupo que lo utiliza lidad

mostrar cierta actitud

asociada con ese slang homofunciona

o el grupo que lo utiliza lidad

mostrar cierta actitud

asociada con ese slang homofunciona

o el grupo que lo utiliza lidad

mostrar cierta actitud

asociada con ese slang homofunciona

o el grupo que lo utiliza lidad

mostrar cierta actitud homofunciona 
Estudio descriptivo de la traducción para el doblaje del slang en el largometraje Jackie Brown (Quentin Tarantino, 1997)

377

variedad según individuo, posición y actitud

$\begin{array}{cccc}\text { discursiva } & \begin{array}{c}\text { sin transgresión } \\ \text { naturalidad }\end{array} & \begin{array}{c}\text { asociada con ese slang } \\ \text { o el grupo que lo utiliza }\end{array} & \text { lidad } \\ \begin{array}{c}\text { equivalente } \\ \text { acuñado }\end{array} & \begin{array}{c}\text { con marcas } \\ \text { sin transgresión } \\ \text { naturalidad }\end{array} & \begin{array}{c}\text { mostrar cierta actitud } \\ \text { asociada con ese slang } \\ \text { o el grupo que lo utiliza }\end{array} & \begin{array}{c}\text { homofunciona } \\ \text { lidad }\end{array} \\ \begin{array}{c}\text { creación } \\ \text { discursiva }\end{array} & \text { marcar pertenencia } & \\ \text { con marcas } & \begin{array}{c}\text { a/identificación con un } \\ \text { grupo o establecer las } \\ \text { relaciones sociales } \\ \text { discursiva }\end{array} & \begin{array}{c}\text { sin transgresión } \\ \text { naturalidad }\end{array} & \begin{array}{c}\text { homofunciona } \\ \text { lidad }\end{array} \\ & & & \end{array}$

Tabla 6. Datos extraídos de las muestras en las que el TM presenta homofuncionalidad 


\section{Muestras en las que el TM presenta una pérdida de carga pragmática:}

\begin{tabular}{|c|c|c|c|c|c|c|c|}
\hline$\stackrel{\circ}{\gtrless}$ & $\begin{array}{l}0 \\
\frac{1}{2} \\
0 \\
0 \\
0 \\
0 \\
0\end{array}$ & 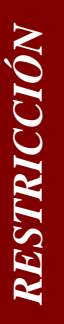 & 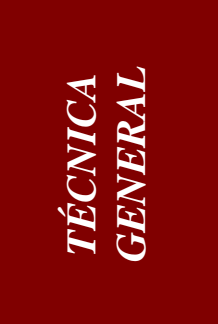 & $\sum_{\substack{x=1 \\
\hdashline}}^{\infty}$ & 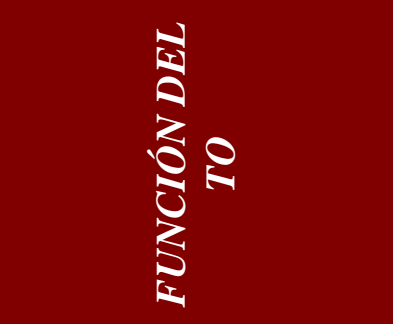 & $\sum_{\substack{a \\
\hdashline}}^{N}$ & $\sum_{0}^{2}$ \\
\hline 2 & $\begin{array}{l}\text { procedimiento léxico } \\
\text { semántico } \\
\text { variedad según origen, } \\
\text { posición e individuo }\end{array}$ & - & $\begin{array}{c}\text { generalizac } \\
\text { ión }\end{array}$ & $\begin{array}{l}\text { sin marcas. } \\
\text { sin transgresión. } \\
\text { convencionalida } \\
\text { d }\end{array}$ & $\begin{array}{l}\text { mostrar cierta actitud } \\
\text { asociada con ese } \\
\text { slang o el grupo que } \\
\text { lo utiliza }\end{array}$ & $\begin{array}{l}\text { pérdida de } \\
\text { carga } \\
\text { pragmática }\end{array}$ & - \\
\hline 10 & $\begin{array}{l}\text { procedimiento léxico } \\
\text { semántico } \\
\text { variedad según } \\
\text { posición, origen e } \\
\text { individuo }\end{array}$ & - & reducción & $\begin{array}{c}\text { sin marcas } \\
\text { sin transgresión } \\
\text { convencionalida } \\
\text { d }\end{array}$ & $\begin{array}{l}\text { marcar pertenencia } \\
\text { a/identificación con } \\
\text { un grupo o establecer } \\
\text { las relaciones sociales } \\
\text { dentro del grupo }\end{array}$ & $\begin{array}{l}\text { pérdida de } \\
\text { carga } \\
\text { pragmática }\end{array}$ & $\begin{array}{l}\text { reducción justificada para no } \\
\text { repetir constantemente la } \\
\text { palabra negro, pero, aún así, } \\
\text { pérdida de la funcionalidad }\end{array}$ \\
\hline 14 & $\begin{array}{c}\text { procedimiento léxico } \\
\text { semántico, } \\
\text { procedimiento } \\
\text { sintáctico } \\
\text { variedad según } \\
\text { posición, origen e } \\
\text { individuo }\end{array}$ & - & $\begin{array}{l}\text { reducción } \\
\text { equivalente } \\
\text { acuñado }\end{array}$ & $\begin{array}{c}\text { sin marcas } \\
\text { sin transgresión } \\
\text { convencionalida } \\
\text { d }\end{array}$ & $\begin{array}{c}\text { marcar pertenencia } \\
\text { a/identificación con } \\
\text { un grupo o establecer } \\
\text { las relaciones sociales } \\
\text { dentro del grupo }\end{array}$ & $\begin{array}{l}\text { pérdida de } \\
\text { carga } \\
\text { pragmática }\end{array}$ & - \\
\hline
\end{tabular}


16

procedimiento léxico semántico

variedad según posición e individuo

procedimiento léxico semántico

18

variedad según origen e individuo

procedimiento léxico formal

19

variedad según

posición, origen e individuo

procedimiento léxico semántico,

20 procedimiento léxico formal

variedad según posición e individuo

procedimiento léxico semántico

21

variedad según posición e individuo

procedimiento equivalente
acuñado

reducción

equivalente

acuñado

con marcas

sin transgresión

convencionalida

d

sin marcas

convencionalion

d

rebelarse contra el

lenguaje estándar

mostrar cierta actitud asociada con ese

slang o el grupo que

lo utiliza

marcar pertenencia

sin marcas

sin transgresión convencionalida

d

a/identificación con

un grupo o establecer

las relaciones sociales dentro del grupo

equivalente acuñado

reducción

sin marcas

sin transgresión

convencionalida

d

mostrar cierta actitud asociada con ese

slang o el grupo que

lo utiliza

cambio del registro

lingüístico para

provocar empatía

sin transgresión

convencionalida

d

reducción

sin marcas

sin transgresión mostrar cierta actitud asociada con ese sintáctico y pérdida de

carga

pragmática

pérdida de

carga

pragmática

pérdida de

carga

pragmática

la decisión de una traducción más convencional que natural hace que se pierda la funcionalidad

patada en el culo es una opción muy convencional

en la traducción no hay ninguna marca de pertenencia a un grupo social. Otra opción como qué te cuentas hubiera suplido esa carencia.

pérdida de carga

pragmática

la traducción de ain't sigue siendo un problema, pero buen equivalente acuñado el de parida

pérdida de carga pragmática

justificada por la restricción formal

pérdida de carga

se observa un intento de mantener la funcionalidad con 


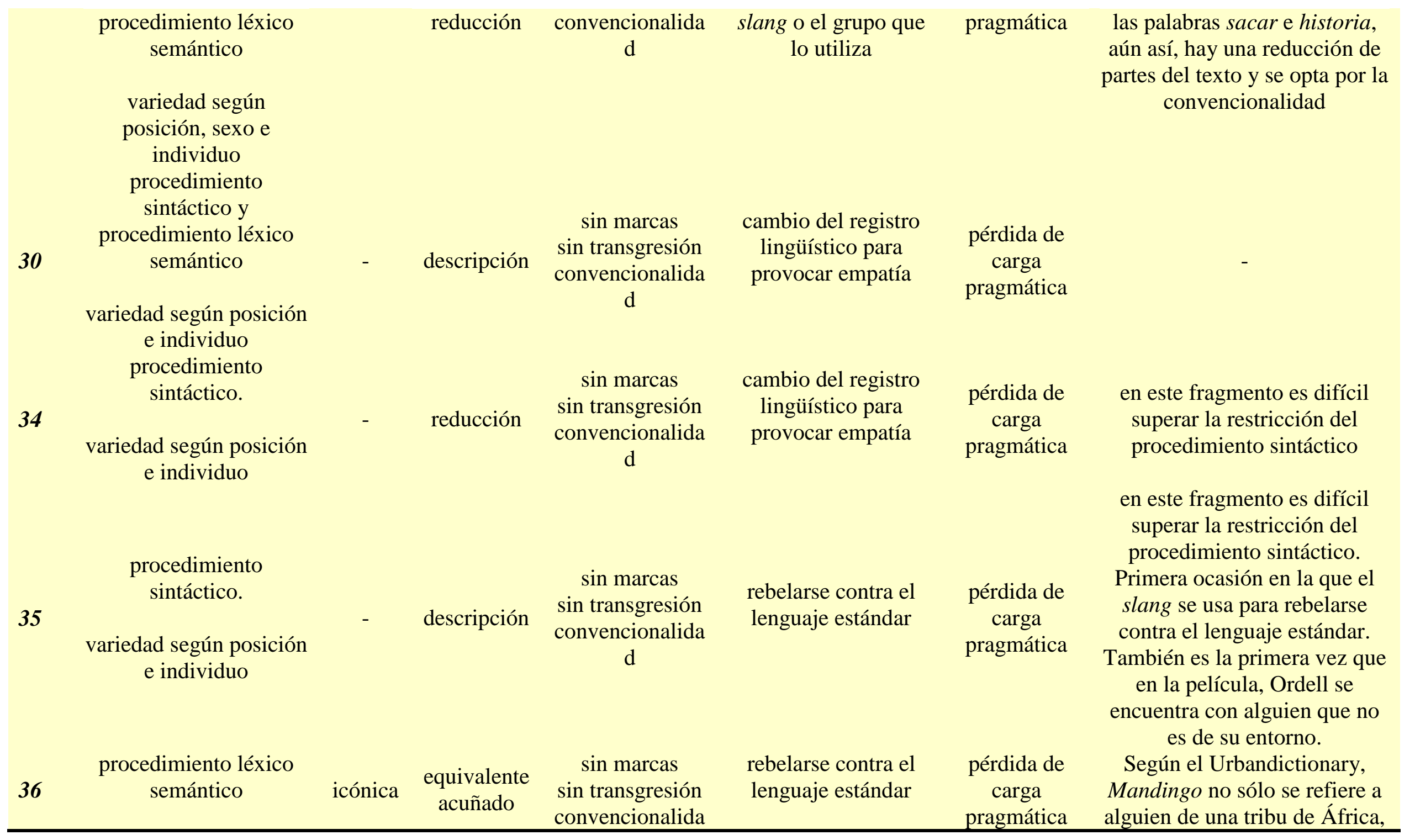


variedad según origen

procedimiento léxico

45 semántico

variedad según origen

Procedimiento léxico semántico

47

variedad según actitud, posición e individuo procedimiento sintáctico

51

variedad según

posición, actitud e individuo

procedimiento sintáctico y formal

variedad según posición, actitud e

d

sociocu equivalente sin transgresión

ltural acuñado convencionalida

d

sin marcas

sin transgresión

convencionalida

d

\section{sin marcas}

sin transgresión

convencionalida

d

reducción

reducción sin marcas sin transgresión convencionalida d marcar pertenencia a/identificación con

un grupo o establecer

las relaciones sociales dentro del grupo

mostrar cierta actitud asociada con ese slang o el grupo que lo utiliza

mostrar cierta actitud asociada con ese slang o el grupo que lo utiliza

marcar pertenencia a/identificación con un grupo o establecer las relaciones sociales dentro del grupo

sino también «African male who knows that he has a huge penis that can hit all night and keep a female comin back for more» ese aspecto se pierde en la traducción

pérdida de carga

pragmática

pérdida de

carga

pragmática

pérdida de

carga

pragmática

pérdida de carga

pragmática en la cultura meta el equivalente encontrado no funciona de la misma manera que en la cultura origen.

procedimiento para cumplir una función fática, se podía haber trasladado con elementos del LM que cumplan esa función

difícil mantener la funcionalidad con el procedimiento sintáctico

tres procedimientos sintácticos difíciles de trasladar 
individuo

procedimiento léxico

semántico

54

$$
\begin{aligned}
& \text { variedad según } \\
& \text { posición, origen e } \\
& \text { individuo }
\end{aligned}
$$

procedimiento léxico semántico

$$
\text { variedad según }
$$
posición, origen e individuo

procedimiento léxico semántico y formal

56

variedad según

posición, origen e

individuo

procedimiento léxico semántico

57

$$
\text { variedad según }
$$

posición, sexo, origen e

$$
\text { individuo }
$$

\section{con marcas}

equivalente acuñado

sin transgresión convencionalida

d

con marcas

equivalente acuñado

\section{sin transgresión} convencionalida

d

equivalente

acuñado

equivalente acuñado

con marcas

sin transgresión convencionalida d / naturalidad

equivalente

acuñado

con marcas

equivalente

acuñado

sin transgresión

convencionalida

d

reducción

con marcas marcar pertenencia a/identificación con un grupo o establecer las relaciones sociales dentro del grupo

marcar pertenencia a/identificación con un grupo o establecer las relaciones sociales dentro del grupo

pérdida de carga pragmática carga pragmática

en la cultura meta la palabra negro pocas veces cumple la función fática

mostrar cierta actitud asociada con ese slang o el grupo que lo utiliza pérdida de carga pragmática

cambio del registro lingüístico para provocar empatía semántico y formal sin transgresión
-

marcar pertenencia a/identificación con pérdida de carga

pragmática

pérdida de carga la palabra culo en la cultura meta no se usa como en la origen para designar a un todo, a la persona

en la cultura meta la palabra negro pocas veces cumple la función fática

expresión poco natural en la cultura meta

la traducción no resulta tan marcada por el slang y 


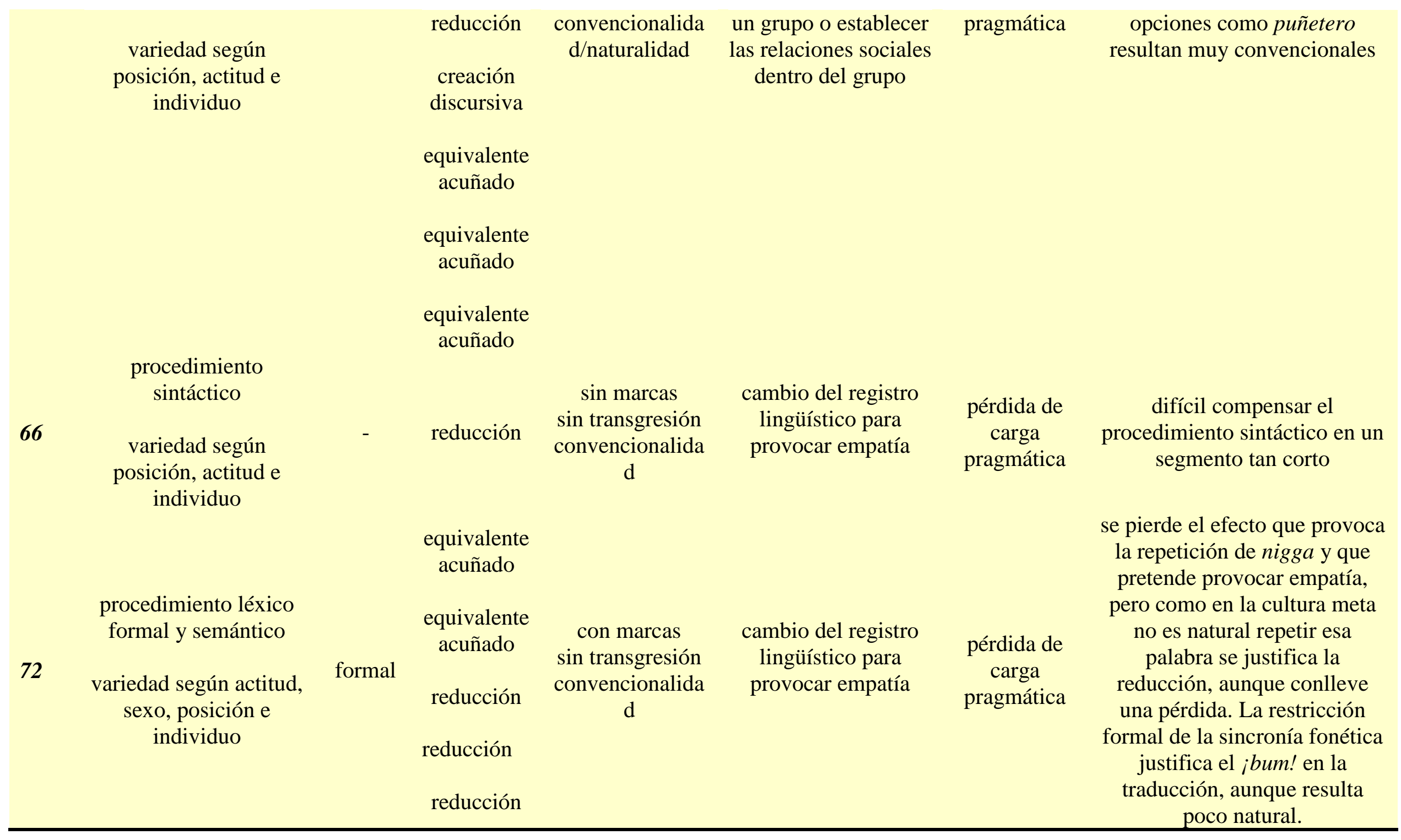


73

procedimiento léxico semántico

variedad según actitud, posición e individuo

procedimiento sintáctico y

procedimiento léxico

78

$$
\text { semántico }
$$

variedad según actitud, sexo, posición e individuo procedimiento sintáctico

80

variedad según actitud, posición e individuo procedimiento sintáctico y procedimiento léxico semántico

variedad según actitud, posición e individuo procedimiento sintáctico y

82

variedad según actitud, posición e individuo equivalente

equivalente procedimiento d

sin marcas acuñado

con marcas sin transgresión convencionalida d

reducción acuñado

reducción

reducción

sin marcas sin transgresión convencionalida d

reducción

omisión

reducción

reducción

reducción

cambio del registro

con marcas sin transgresión naturalidad

con marcas sin transgresión naturalidad

sin marcas sin transgresión convencionalida

reducción lingüístico para provocar empatía

cambio del registro lingüístico para provocar empatía

cambio del registro lingüístico para provocar empatía

marcar pertenencia a/identificación con

pérdida de

carga

pragmática

pérdida de carga

pragmática

pérdida de

carga

pragmática

pérdida de un grupo o establecer las relaciones sociales dentro del grupo

carga

pragmática

mostrar cierta actitud asociada con ese slang o el grupo que lo utiliza

pérdida de carga

pragmática

cambio del registro se pierde la funcionalidad por no poder trasladar el procedimiento sintáctico

es un segmento relativamente largo en el que hay poca carga de slang en el TM en comparación con el TO

es un procedimiento sintáctico que se repite a lo largo de la película y que presenta muchos problemas de traducción 
sintáctico

variedad según actitud, posición e individuo

procedimiento

sintáctico y

procedimiento léxico

$$
\text { semántico }
$$

variedad según actitud, posición, sexo e individuo

procedimiento léxico semántico

92

variedad según actitud, posición e individuo

procedimiento sintáctico

104

variedad según actitud, posición e individuo

procedimiento sintáctico y procedimiento léxico semántico

variedad según actitud, posición e individuo procedimiento léxico sin transgresión convencionalida d

reducción

reducción

equivalente acuñado

reducción

con marcas

sin transgresión convencionalida

d

sin marcas

reducción

sin transgresión

convencionalida

d

sin marcas

sin transgresión

convencionalida

d

lingüístico para
provocar empatía

formal modulación

reducción

reducción sin marcas

sin transgresión

convencionalida

d cambio del registro lingüístico para provocar empatía

carga

pragmática

pérdida de

carga

pragmática

cambio del registro lingüístico para

provocar empatía

marcar pertenencia a/identificación con

un grupo o establecer

las relaciones sociales dentro del grupo

cambio del registro lingüístico para provocar empatía pérdida de carga

pragmática

pérdida de

carga

pragmática

pérdida de

carga pragmática el equivalente acuñado jodido resulta una traducción

demasiado convencional, se ha convertido en lenguaje fílmico, ya que en la realidad no se usa como adjetivo antepuesto a un sustantivo.

en este caso, la modulación no ayuda a mantener la funcionalidad, se pierde la variedad lingüística y su función modulación

con marcas

mostrar cierta actitud

pérdida de 
semántico y formal

variedad según actitud, posición e individuo

\section{procedimiento sintáctico}

108

variedad según actitud, posición e individuo

procedimiento léxico

115

$$
\text { semántico }
$$

variedad según actitud

procedimiento léxico semántico y procedimiento sintáctico

variedad según actitud procedimiento léxico

118 semántico y formal

variedad según actitud

123

\section{sin transgresión \\ equivalente acuñado}

$$
\begin{gathered}
\text { asociada con ese } \\
\text { slang o el grupo que } \\
\text { lo utiliza }
\end{gathered}
$$

carga pragmática

traducción formal uno por

uno

generalizac ión

generalizac ión

reducción sin marcas sin transgresión convencionalida d

\section{sin marcas} sin transgresión convencio
$\mathrm{d}$

\section{sin marcas} sin transgresión convencionalida d

mostrar cierta actitud asociada con ese slang o el grupo que lo utiliza

mostrar cierta actitud asociada con ese slang o el grupo que lo utiliza

mostrar cierta actitud asociada con ese slang o el grupo que lo utiliza

mostrar cierta actitud slang o el grupo que lo utiliza transgresión convencionalida d asociada con ese pérdida de

carga

pragmática

pérdida de carga

pragmática

pérdida de carga

pragmática

pérdida de carga pragmática señales no es tan marcada como en el TO y la anteposición del adjetivo al sustantivo en el TM denota convencionalidad. Además, el equivalente culo por ass no cumple la misma función y se pierde en naturalidad.

pérdida de funcionalidad justificada por la restricción

formal. Además, se ve fácilmente compensada con otros segmentos de la misma escena. 
semántico

variedad según actitud

procedimiento léxico

124 semántico

variedad según actitud

procedimiento léxico semántico y

procedimiento sintáctico

128

variedad según

individuo, posición,

actitud y tema

procedimiento sintáctico

131 variedad según individuo, posición y actitud

134 acuñado

sin transgresión convencionalida d

lenguaje estándar

sin marcas

creación sin transgresión

discursiva convencionalida

d

rebelarse contra el

lenguaje estándar

modulación

equivalente

acuñado

con marcas

sin transgresión

convencionalida

d

reducción

formal reducción

sin marcas

sin transgresión

naturalidad

generalizac

ión sin marcas

sin transgresión mostrar cierta actitud asociada con ese slang o el grupo que lo utiliza

rebelarse contra el lenguaje estándar

cambio del registro lingüístico para pérdida de

carga

pragmática

carga
pragmática
pérdida de carga
pragmática

pérdida de

carga

pragmática

pérdida de

carga segmentos con uso de slang para rebelarse contra el

lenguaje estándar. Jackie Brown pretende rebelarse ante los policías y mostrar, al igual que ellos, una actitud

desafiante. Sin embargo, el uso de la palabra maldita resulta muy convencional e, incluso, extranjerizante.

pérdida considerable, en tanto que es una de las pocas escenas en las que el slang se usa para rebelarse contra el lenguaje estándar.

en este segmento es prioritario mantener la rima, algo que resulta en una traducción poco natural.

caso claro en el que se usa el slang para provocar empatía. 
procedimiento léxico semántico

variedad según

individuo, posición y actitud

procedimiento sintáctico

139

$$
\text { variedad según }
$$

individuo, posición y actitud

procedimiento léxico semántico

143

variedad según individuo y actitud

procedimiento léxico semántico

146

variedad según individuo, origen y actitud

procedimiento léxico semántico

148 variedad según
dividuo, posición y actitud convencionalida provocar empatía pragmática d

marcar pertenencia a/identificación con

sin marcas sin transgresión convencionalida d

un grupo o establecer

las relaciones sociales dentro del grupo

sin marcas sin transgresión convencionalida d

mostrar cierta actitud asociada con ese slang o el grupo que lo utiliza

pérdida de carga

pragmática

mostrar cierta actitud asociada con ese

sin marcas slang o el grupo que sin transgresión convencionalida d

$$
\text { lo utiliza y }
$$

cambio del registro

lingüístico para

provocar empatía

pérdida de

carga

pragmática

se pierde la intención de provocar empatía con la expresión good brother

mostrar cierta actitud asociada con ese

con marcas

formal reducción

slang o el grupo que

pérdida de

carga

pérdida debido a la restricción formal

naturalidad

lo utiliza

pragmática 
procedimiento sintáctico

152

variedad según

individuo, posición y

actitud

procedimiento

sintáctico

153

variedad según

individuo, posición y

actitud

procedimiento

sintáctico

154

variedad según

individuo, posición y actitud

procedimiento léxico semántico

156

variedad según

individuo, origen,

posición y actitud

procedimiento léxico semántico

159

variedad según

individuo, posición y actitud

162

procedimiento léxico sin marcas

sin transgresión

convencionalida

d

sin marcas

sin transgresión

convencionalida

d

sin marcas

sin transgresión

convencionalida

d

con marcas

equivalente

acuñado

sin transgresión

convencionalida

d

mostrar cierta actitud

asociada con ese

slang o el grupo que

lo utiliza

mostrar cierta actitud asociada con ese

slang o el grupo que

lo utiliza

mostrar cierta actitud

asociada con ese

slang o el grupo que

lo utiliza

mostrar cierta actitud

asociada con ese

slang o el grupo que

lo utiliza

sin transgresión

convencionalida

d pérdida de

carga

pragmática

pérdida de

carga

pragmática

se pierde la función fática de nigga y la manera en la que esa palabra deja ver ciertas actitudes del personaje

pérdida de carga

pragmática

sin marcas

mostrar cierta actitud

pérdida de 


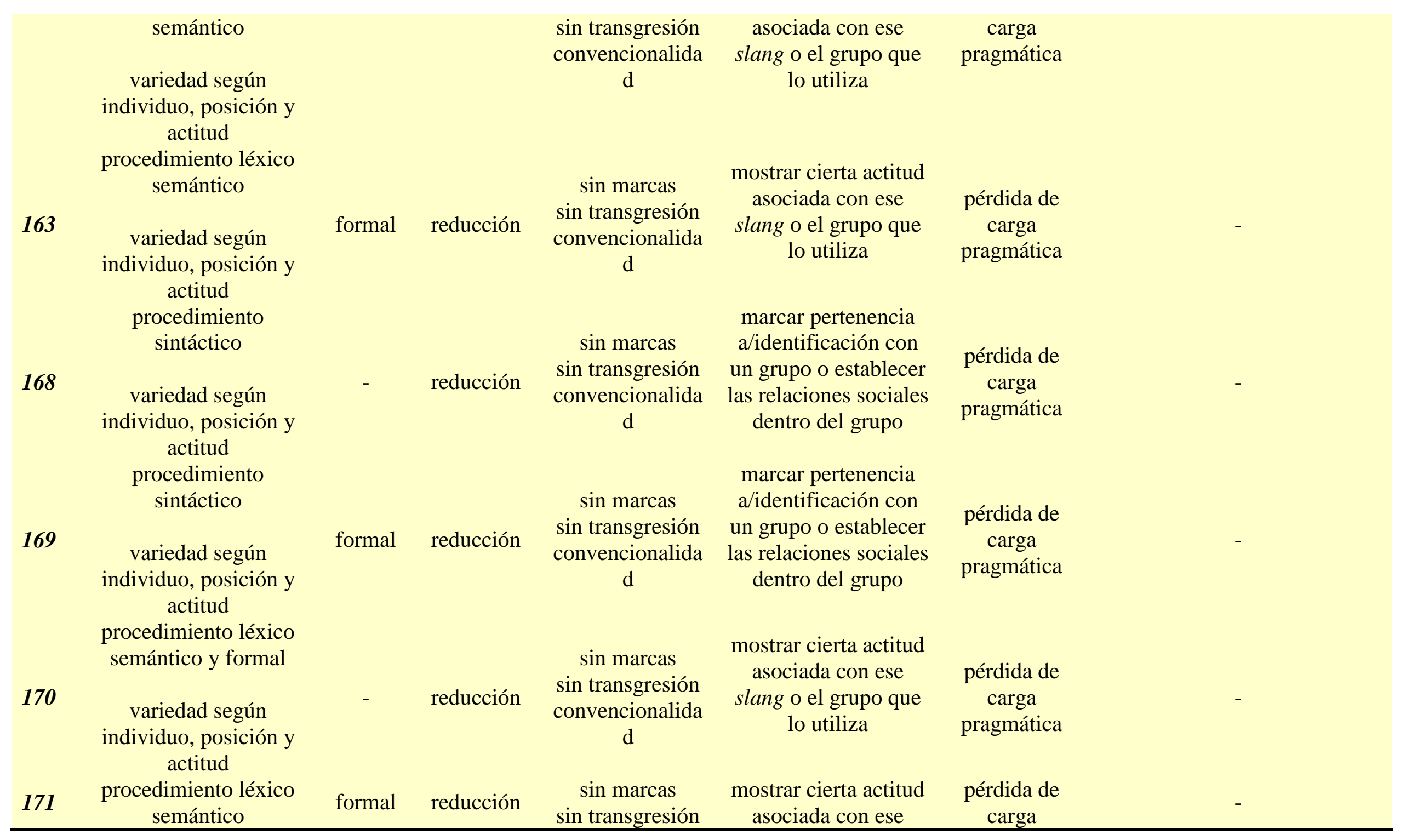


variedad según

individuo, posición y actitud

procedimiento sintáctico

172

variedad según

individuo, posición y actitud

procedimiento sintáctico

174

variedad según

individuo, posición y actitud

procedimiento sintáctico

175

variedad según individuo, posición y actitud

\section{procedimiento} sintáctico

176

variedad según individuo, posición y actitud convencionalida

slang o el grupo que lo utiliza

marcar pertenencia

sin marcas

sin transgresión

convencionalida

d

a/identificación con

un grupo o establecer

las relaciones sociales dentro del grupo

sin marcas

sin transgresión

convencionalida

d

mostrar cierta actitud asociada con ese

slang o el grupo que

lo utiliza

cambio del registro lingüístico para

reducción

sin marcas

sin transgresión convencionalida

d

pérdida de

carga

pragmática

pérdida de

carga

pragmática

pérdida de carga

pragmática

marcar pertenencia

sin marcas

sin transgresión

convencionalida

a/identificación con

un grupo o establecer

las relaciones sociales dentro del grupo pérdida de

carga

pragmática es una de las pocas veces en las que Max Cherry usa el slang para establecer relaciones sociales con la protagonista. Se pierde una funcionalidad muy importante de la escena, si bien hay que entender que el proceso sintáctico de esta muestra es 
procedimiento léxico

$$
\text { semántico }
$$

178

$$
\begin{aligned}
& \text { variedad según } \\
& \text { individuo, posición y }
\end{aligned}
$$
actitud

procedimiento léxico

$$
\text { semántico }
$$

180

$$
\begin{aligned}
& \text { variedad según } \\
& \text { individuo, posición y } \\
& \text { actitud }
\end{aligned}
$$

formal reducción sin marcas

sin transgresión convencionalida

d cambio del registro lingüístico para provocar empatía

d procedimiento léxico semántico

185

$$
\begin{gathered}
\text { variedad según } \\
\text { individuo }
\end{gathered}
$$
formal
equivalente acuñado

pérdida de carga

pragmática mostrar cierta actitud asociada con ese slang o el grupo que lo utiliza

\section{pérdida de carga pragmática}

mostrar cierta actitud

muy difícil de trasladar al TM desde el TCR 00:55:00 hasta esta muestra, hay muchos

casos de pérdida de

funcionalidad. Es posible que sea porque la conversación es entre Jackie y Max Cherry.

Jackie hace uso de slang, pero Max Cherry (cuando habla con ella, al menos) no. Dada la situación comunicativa y la relación entre los personajes, la pérdida de funcionalidad en esta escena no es tan relevante como en otras. asociada con ese slang o el grupo que lo utiliza pérdida de carga pragmática en la cultura meta, difícilmente se puede mostrar una actitud asociada a un grupo simplemente contestando al teléfono, esto es algo muy particular de la cultura origen que resulta difícilmente trasladable. Por eso, se aboga por la naturalidad y por un equivalente acuñado más 
procedimiento léxico semántico y formal

197

variedad según

individuo, posición y actitud

procedimiento léxico semántico

198

variedad según

individuo, posición y actitud

procedimiento

sintáctico

203

variedad según

individuo, posición y

actitud

procedimiento

sintáctico

206

variedad según

individuo, posición y

actitud marcar pertenencia a/identificación con

reducción

sin marcas

sin transgresión

convencionalida

d

un grupo o establecer

las relaciones sociales dentro del grupo

marcar pertenencia a/identificación con

sin marcas

sin transgresión

convencionalida

d

un grupo o establecer

las relaciones sociales dentro del grupo

marcar pertenencia

sin marcas sin transgresión convencionalida

reducción d a/identificación con un grupo o establecer las relaciones sociales dentro del grupo

marcar pertenencia a/identificación con

sin marcas

reducción

d

un grupo o establecer

las relaciones sociales dentro del grupo general

pragmática

pragmática

pragmática pérdida de

carga

pérdida de

carga

pérdida de

carga

se ve compensada por la

funcionalidad añadida de

segmentos anteriores de la misma escena.

es bastante habitual en la cultura origen que algunos grupos sociales relacionados con clases sociales bajas no usen la forma correcta de los verbos para la tercera persona del singular. Este

procedimiento sintáctico resulta difícilmente trasladable a la cultura origen sin que la traducción resulte demasiado familiarzante.

pérdida de

carga

pragmática 
procedimiento léxico semántico y formal

212

variedad según

individuo, posición y actitud

procedimiento léxico

$$
\text { semántico }
$$

215

$$
\begin{aligned}
& \text { variedad según } \\
& \text { individuo, tema, } \\
& \text { posición y actitud } \\
& \text { procedimiento }
\end{aligned}
$$$$
\text { sintáctico }
$$

variedad según

individuo, posición y

$$
\text { actitud }
$$

procedimiento léxico

semántico y

procedimiento

sintáctico

variedad según

individuo, posición y actitud

procedimiento

sintáctico y

229 procedimiento léxico semántico sin marcas

sin transgresión

convencionalida

d

generalizac

ión

sin marcas

sin transgresión

convencionalida d

sin marcas

sin transgresión

convencionalida

d

reducción

reducción

sin marcas sin transgresión convencionalida

d

reducción

equivalente acuñado

con marcas sin transgresión naturalidad mostrar cierta actitud

un grupo o establecer

las relaciones sociales

un grupo o establecer

las relaciones sociales un grupo o establecer las relaciones sociales

mostrar cierta actitud asociada con ese

slang o el grupo que

lo utiliza

marcar pertenencia a/identificación con dentro del grupo

marcar pertenencia a/identificación con dentro del grupo

marcar pertenencia a/identificación con dentro del grupo asociada con ese

\section{pérdida de}

carga

pragmática

pérdida de carga

pragmática

pérdida de

$$
\text { carga }
$$

pragmática

pérdida de carga

pragmática slang o el grupo que lo utiliza pérdida de

carga

pragmática no se observa en el TM ningún slang asociable al tema en cuestión y el segmento pierde su funcionalidad

ligera pérdida en la funcionalidad por la dificultad de mantener el procedimiento sintáctico. Sin embargo, el equivalente acuñado hace que 


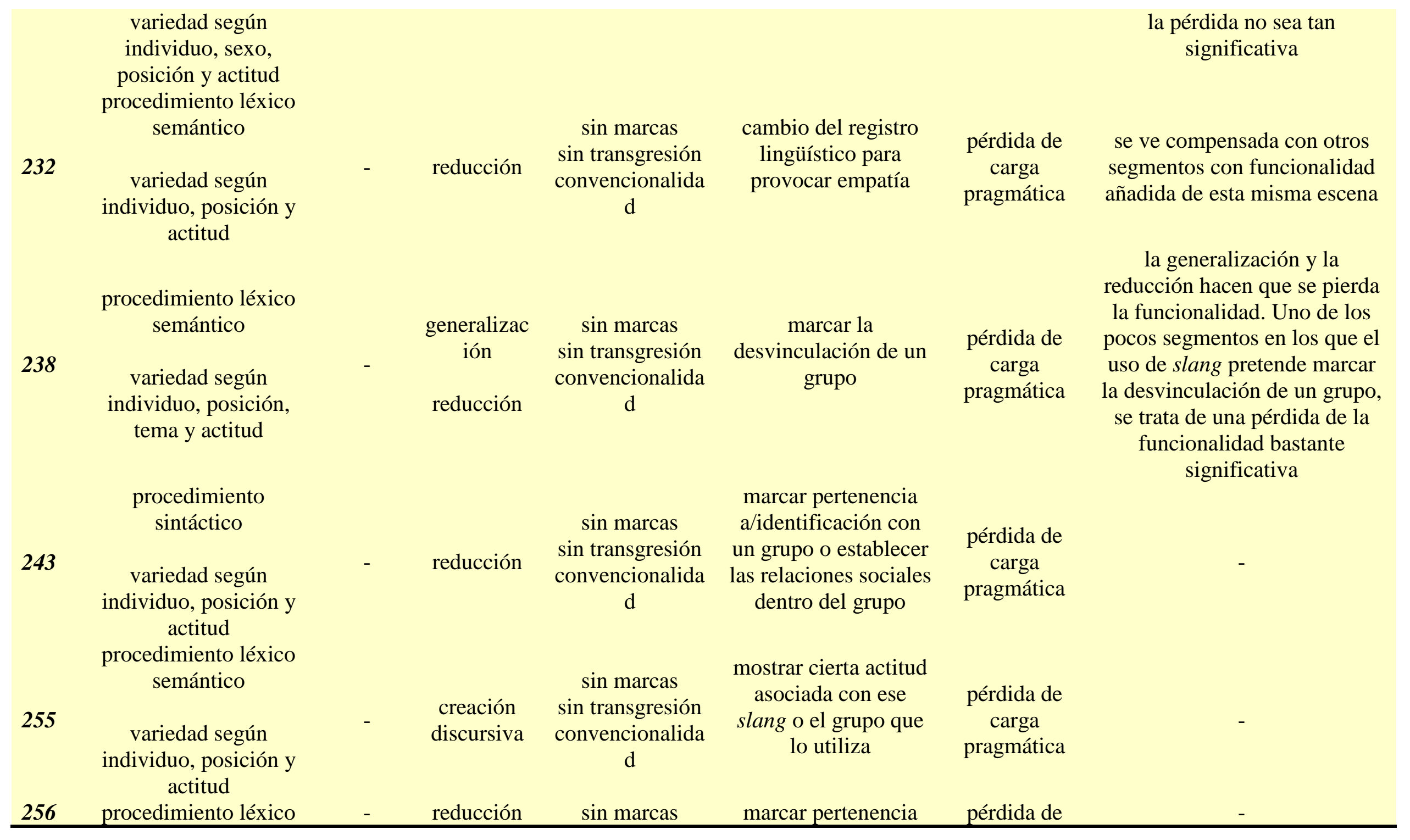




\begin{tabular}{|c|c|c|c|c|c|c|c|}
\hline \multicolumn{4}{|c|}{ semántico } & \multirow{2}{*}{$\begin{array}{c}\text { sin transgresión } \\
\text { convencionalida } \\
\text { d }\end{array}$} & \multirow{2}{*}{$\begin{array}{l}\text { a/identificación con } \\
\text { un grupo o establecer } \\
\text { las relaciones sociales } \\
\text { dentro del grupo }\end{array}$} & \multirow{2}{*}{$\begin{array}{c}\text { carga } \\
\text { pragmática }\end{array}$} & \multirow[b]{3}{*}{$\begin{array}{l}\text { pérdida considerable. El slang } \\
\text { de de esta muestra intenta } \\
\text { hacer ver que Jackie pretende } \\
\text { que piensen que no les va a } \\
\text { fallar, que como están dentro } \\
\text { del mismo grupo social no les } \\
\text { delatará a la policía }\end{array}$} \\
\hline & $\begin{array}{l}\text { variedad según } \\
\text { individuo, sexo, } \\
\text { posición y actitud }\end{array}$ & & & & & & \\
\hline 259 & $\begin{array}{l}\text { procedimiento léxico } \\
\text { semántico } \\
\text { variedad según } \\
\text { individuo, posición y } \\
\text { actitud }\end{array}$ & - & $\begin{array}{l}\text { creación } \\
\text { discursiva }\end{array}$ & $\begin{array}{c}\text { sin marcas } \\
\text { sin transgresión } \\
\text { convencionalida } \\
\text { d }\end{array}$ & $\begin{array}{l}\text { marcar pertenencia } \\
\text { a/identificación con } \\
\text { un grupo o establecer } \\
\text { las relaciones sociales } \\
\text { dentro del grupo }\end{array}$ & $\begin{array}{l}\text { pérdida de } \\
\text { carga } \\
\text { pragmática }\end{array}$ & \\
\hline 260 & $\begin{array}{c}\text { variedad según } \\
\text { individuo, posición y } \\
\text { actitud }\end{array}$ & - & reducción & $\begin{array}{c}\text { sin marcas } \\
\text { sin transgresión } \\
\text { convencionalida } \\
\text { d }\end{array}$ & $\begin{array}{l}\text { marcar pertenencia } \\
\text { a/identificación con } \\
\text { un grupo o establecer } \\
\text { las relaciones sociales } \\
\text { dentro del grupo }\end{array}$ & $\begin{array}{l}\text { pérdida de } \\
\text { carga } \\
\text { pragmática }\end{array}$ & 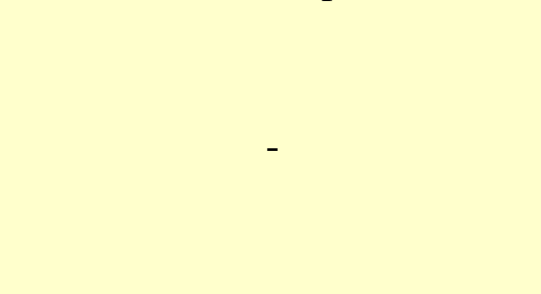 \\
\hline 265 & $\begin{array}{l}\text { variedad según } \\
\text { individuo, sexo, } \\
\text { posición y actitud }\end{array}$ & - & reducción & $\begin{array}{c}\text { sin marcas } \\
\text { sin transgresión } \\
\text { convencionalida } \\
\text { d }\end{array}$ & $\begin{array}{l}\text { marcar pertenencia } \\
\text { a/identificación con } \\
\text { un grupo o establecer } \\
\text { las relaciones sociales } \\
\text { dentro del grupo }\end{array}$ & $\begin{array}{l}\text { pérdida de } \\
\text { carga } \\
\text { pragmática }\end{array}$ & - \\
\hline 271 & $\begin{array}{l}\text { procedimiento } \\
\text { sintáctico y } \\
\text { procedimiento léxico } \\
\text { semántico } \\
\\
\text { variedad según } \\
\text { individuo, posición y }\end{array}$ & - & $\begin{array}{l}\text { generalizac } \\
\quad \text { ión } \\
\text { reducción }\end{array}$ & $\begin{array}{c}\text { sin marcas } \\
\text { sin transgresión } \\
\text { convencionalida } \\
\text { d }\end{array}$ & $\begin{array}{c}\text { marcar pertenencia } \\
\text { a/identificación con } \\
\text { un grupo o establecer } \\
\text { las relaciones sociales } \\
\text { dentro del grupo }\end{array}$ & $\begin{array}{l}\text { pérdida de } \\
\text { carga } \\
\text { pragmática }\end{array}$ & $\begin{array}{l}\text { se pierde la relación social que } \\
\text { se quiere establecer con kid }\end{array}$ \\
\hline
\end{tabular}




\begin{tabular}{|c|c|c|c|c|c|c|c|}
\hline 272 & $\begin{array}{c}\text { actitud } \\
\text { procedimiento } \\
\text { sintáctico } \\
\text { variedad según } \\
\text { individuo, posición y } \\
\text { actitud }\end{array}$ & - & reducción & $\begin{array}{c}\text { sin marcas } \\
\text { sin transgresión } \\
\text { convencionalida } \\
\text { d }\end{array}$ & $\begin{array}{l}\text { marcar pertenencia } \\
\text { a/identificación con } \\
\text { un grupo o establecer } \\
\text { las relaciones sociales } \\
\text { dentro del grupo }\end{array}$ & $\begin{array}{l}\text { pérdida de } \\
\text { carga } \\
\text { pragmática }\end{array}$ & - \\
\hline 275 & $\begin{array}{l}\text { procedimiento léxico } \\
\text { semántico y } \\
\text { procedimiento } \\
\text { sintáctico } \\
\\
\text { variedad según } \\
\text { individuo, posición y } \\
\text { actitud }\end{array}$ & - & $\begin{array}{l}\text { modulación } \\
\text { reducción } \\
\text { reducción }\end{array}$ & $\begin{array}{l}\text { con marcas } \\
\text { sin transgresión } \\
\text { naturalidad }\end{array}$ & $\begin{array}{l}\text { mostrar cierta actitud } \\
\text { asociada con ese } \\
\text { slang o el grupo que } \\
\text { lo utiliza }\end{array}$ & $\begin{array}{l}\text { pérdida de } \\
\text { carga } \\
\text { pragmática }\end{array}$ & $\begin{array}{l}\text { pérdida en el segmento, pero } \\
\text { no en la escena completa }\end{array}$ \\
\hline 278 & $\begin{array}{l}\text { procedimiento léxico } \\
\text { semántico } \\
\text { variedad según } \\
\text { individuo, posición y } \\
\text { actitud }\end{array}$ & formal & reducción & $\begin{array}{c}\text { sin marcas } \\
\text { sin transgresión } \\
\text { convencionalida } \\
\text { d }\end{array}$ & $\begin{array}{l}\text { marcar pertenencia } \\
\text { a/identificación con } \\
\text { un grupo o establecer } \\
\text { las relaciones sociales } \\
\text { dentro del grupo }\end{array}$ & $\begin{array}{l}\text { pérdida de } \\
\text { carga } \\
\text { pragmática }\end{array}$ & - \\
\hline 285 & $\begin{array}{c}\text { variedad según } \\
\text { individuo, posición y } \\
\text { actitud }\end{array}$ & - & reducción & $\begin{array}{c}\text { sin marcas } \\
\text { sin transgresión } \\
\text { convencionalida } \\
\text { d }\end{array}$ & $\begin{array}{l}\text { marcar pertenencia } \\
\text { a/identificación con } \\
\text { un grupo o establecer } \\
\text { las relaciones sociales } \\
\text { dentro del grupo }\end{array}$ & $\begin{array}{l}\text { pérdida de } \\
\text { carga } \\
\text { pragmática }\end{array}$ & $\begin{array}{c}\text { se compensa con la } \\
\text { funcionalidad añadida de la } \\
\text { muestra anterior }\end{array}$ \\
\hline 287 & $\begin{array}{l}\text { procedimiento léxico } \\
\text { semántico } \\
\text { variedad según }\end{array}$ & - & reducción & $\begin{array}{c}\text { sin marcas } \\
\text { sin transgresión } \\
\text { convencionalida } \\
\text { d }\end{array}$ & $\begin{array}{l}\text { mostrar cierta actitud } \\
\text { asociada con ese } \\
\text { slang o el grupo que } \\
\text { lo utiliza }\end{array}$ & $\begin{array}{l}\text { pérdida de } \\
\text { carga } \\
\text { pragmática }\end{array}$ & $\begin{array}{l}\text { pérdida poco significante, } \\
\text { porque la escena completa es } \\
\text { homofuncional, aunque, en } \\
\text { este segmento, sí que se pierde }\end{array}$ \\
\hline
\end{tabular}


individuo, posición y actitud

procedimiento léxico semántico

297 variedad según individuo, posición y actitud

procedimiento léxico semántico

298

variedad según

individuo, posición y actitud

procedimiento léxico semántico y formal

317

variedad según

individuo, posición y actitud

procedimiento léxico semántico

323

variedad según

individuo, posición y actitud

procedimiento léxico semántico

325

variedad según

individuo, posición y

formal reducción

sin marcas

sin transgresión

convencionalida

d

sin marcas
sin transgresión
convencionalida
d

d

reducción

equivalente

acunnado

sin marcas

sin transgresión

convencionalida

d

reducción

reducción

sin marcas

sin transgresión

convencionalida

d

sin marcas

sin transgresión

convencionalida

d mostrar cierta actitud asociada con ese

slang o el grupo que lo utiliza

mostrar cierta actitud asociada con ese slang o el grupo que lo utiliza

cambio del registro lingüístico para provocar empatía

mostrar cierta actitud asociada con ese slang o el grupo que lo utiliza

marcar pertenencia a/identificación con un grupo o establecer las relaciones sociales dentro del grupo cierta actitud desafiante que muestra el slang en el TO

pérdida de

carga

pragmática

poco significativa, ya que no se pierde la funcionalidad de la escena en general

pérdida de carga

pragmática

muy poco significativa

pérdida de carga

pragmática

pérdida de

carga

pragmática

se pierde la actitud asociada al slang

pérdida de

carga

se pierde la intención de pragmática mostrar un vínculo entre los personajes mediante el slang 


\begin{tabular}{|c|c|c|c|c|c|c|c|}
\hline \multicolumn{8}{|c|}{ actitud } \\
\hline 329 & $\begin{array}{l}\text { procedimiento léxico } \\
\text { semántico } \\
\text { variedad según } \\
\text { individuo, posición y } \\
\text { actitud }\end{array}$ & $\begin{array}{ll}- & -1 \\
\end{array}$ & $\begin{array}{l}\text { generalizac } \\
\text { ión } \\
\text { reducción }\end{array}$ & $\begin{array}{c}\text { sin marcas } \\
\text { sin transgresión } \\
\text { convencionalida } \\
\text { d }\end{array}$ & $\begin{array}{l}\text { mostrar cierta actitud } \\
\text { asociada con ese } \\
\text { slang o el grupo que } \\
\text { lo utiliza }\end{array}$ & $\begin{array}{l}\text { pérdida de } \\
\text { carga } \\
\text { pragmática }\end{array}$ & $\begin{array}{l}\text { se pierde la intención de } \\
\text { mostrar una actitud específica }\end{array}$ \\
\hline 331 & $\begin{array}{c}\text { procedimiento } \\
\text { sintáctico } \\
\text { variedad según } \\
\text { individuo, posición y } \\
\text { actitud }\end{array}$ & $\begin{array}{ll}- & -1 \\
-1\end{array}$ & reducción & $\begin{array}{c}\text { sin marcas } \\
\text { sin transgresión } \\
\text { convencionalida } \\
\text { d }\end{array}$ & $\begin{array}{c}\text { marcar pertenencia } \\
\text { a/identificación con } \\
\text { un grupo o establecer } \\
\text { las relaciones sociales } \\
\text { dentro del grupo }\end{array}$ & $\begin{array}{l}\text { pérdida de } \\
\text { carga } \\
\text { pragmática }\end{array}$ & $\begin{array}{c}\text { el procedimiento sintáctico es } \\
\text { difícilmente trasladable a la } \\
\text { LM }\end{array}$ \\
\hline 333 & $\begin{array}{c}\text { procedimiento } \\
\text { sintáctico y } \\
\text { procedimiento léxico } \\
\text { semántico y formal } \\
\\
\text { variedad según } \\
\text { individuo, posición y } \\
\text { actitud }\end{array}$ & formal & $\begin{array}{l}\text { reducción } \\
\text { reducción } \\
\text { equivalente } \\
\text { acuñado } \\
\text { reducción }\end{array}$ & $\begin{array}{l}\text { con marcas } \\
\text { sin transgresión } \\
\text { naturalidad }\end{array}$ & $\begin{array}{l}\text { cambio del registro } \\
\text { lingüístico para } \\
\text { provocar empatía }\end{array}$ & $\begin{array}{l}\text { pérdida de } \\
\text { carga } \\
\text { pragmática }\end{array}$ & - \\
\hline 352 & $\begin{array}{c}\text { procedimiento } \\
\text { sintáctico y } \\
\text { procedimiento léxico } \\
\text { semántico } \\
\text { variedad según } \\
\text { individuo, posición y } \\
\text { actitud }\end{array}$ & formal & $\begin{array}{l}\text { reducción } \\
\text { equivalente } \\
\text { acuñado }\end{array}$ & $\begin{array}{l}\text { con marcas } \\
\text { sin transgresión } \\
\text { naturalidad }\end{array}$ & $\begin{array}{c}\text { marcar pertenencia } \\
\text { a/identificación con } \\
\text { un grupo o establecer } \\
\text { las relaciones sociales } \\
\text { dentro del grupo }\end{array}$ & $\begin{array}{l}\text { pérdida de } \\
\text { carga } \\
\text { pragmática }\end{array}$ & $\begin{array}{l}\text { la dificultad de trasladar el } \\
\text { procedimiento sintáctico y la } \\
\text { restricción formal hacen que se } \\
\text { pierda la funcionalidad. Al ser } \\
\text { la única frase que Winston le } \\
\text { dice a Ordell en toda la } \\
\text { película, no se puede recuperar } \\
\text { la funcionalidad en otros }\end{array}$ \\
\hline
\end{tabular}


356

variedad según

individuo, posición y actitud

procedimiento léxico semántico

363

variedad según

individuo, posición y actitud

procedimiento

sintáctico y léxico semántico

366

variedad según

individuo, posición y actitud

procedimiento léxico semántico y

procedimiento reducción

creación

discursiva

con marcas

sin transgresión

naturalidad

mostrar cierta actitud asociada con ese

slang o el grupo que

lo utiliza

modulación

sin marcas

sin transgresión

reducción

convencionalida

d

sin marcas

sin transgresión

convencionalida

d

reducción

reducción

equivalente

acuñado

generalizac

ión

mostrar cierta actitud asociada con ese slang o el grupo que lo utiliza

marcar pertenencia a/identificación con un grupo o establecer las relaciones sociales dentro del grupo

marcar pertenencia a/identificación con

con marcas naturalidad

un grupo o establecer

las relaciones sociales dentro del grupo

marcar pertenencia a/identificación con segmentos

aunque la creación discursiva y la modulación aporten cierta actitud que se muestra en el TO hay cierta pérdida del juego de palabras hand in handcuf motherfucking hand, así como el procedimiento sintáctico carga

pragmática

pérdida de carga

pragmática sin transgresión

pérdida de carga

pragmática poco significativa, pero se compensa con el segmento siguiente

pérdida de carga convencionalida un grupo o establecer pragmática 
Estudio descriptivo de la traducción para el doblaje del slang en el largometraje Jackie Brown (Quentin Tarantino, 1997)

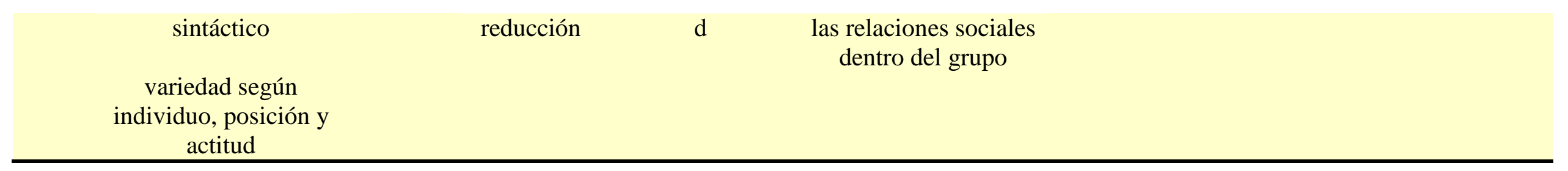

Tabla 7. Datos extraídos de las muestras en las que el TM presenta pérdida de carga pragmática 
Muestras en las que el TM presenta carga pragmática añadida:

\begin{tabular}{|c|c|c|c|c|c|c|c|}
\hline$\stackrel{\circ}{z}$ & $\begin{array}{l}0 \\
\vdots \\
\vdots \\
5 \\
0 \\
0 \\
0 \\
0 \\
\vdots \\
\vdots\end{array}$ & 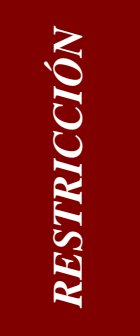 & 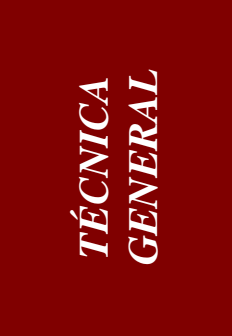 & 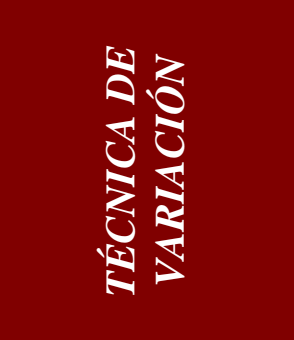 & 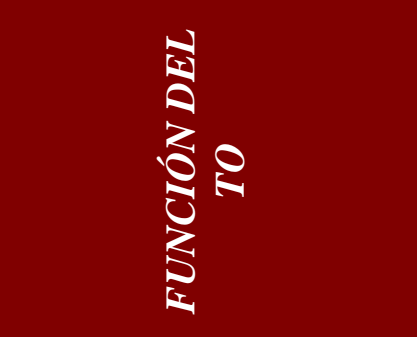 & 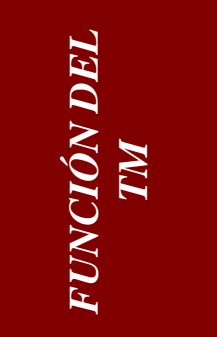 & 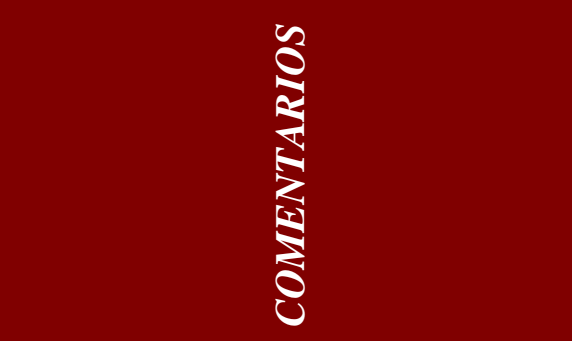 \\
\hline 38 & - & - & $\begin{array}{l}\text { particulariza } \\
\text { ción }\end{array}$ & $\begin{array}{l}\text { con marcas } \\
\text { sin transgresión } \\
\text { naturalidad }\end{array}$ & $\begin{array}{l}\text { cambio del registro } \\
\text { lingüístico para } \\
\text { provocar empatía }\end{array}$ & $\begin{array}{l}\text { carga } \\
\text { pragmática } \\
\text { añadida }\end{array}$ & $\begin{array}{l}\text { se traduce con slang un segmento } \\
\text { sin slang para compensar la } \\
\text { pérdida de funcionalidad de otros } \\
\text { segmentos. }\end{array}$ \\
\hline 40 & - & - & $\begin{array}{l}\text { particulariza } \\
\text { ción }\end{array}$ & $\begin{array}{l}\text { con marcas } \\
\text { sin transgresión } \\
\text { naturalidad }\end{array}$ & $\begin{array}{l}\text { marcar pertenencia } \\
\text { a/identificación con un } \\
\text { grupo o establecer las } \\
\text { relaciones sociales } \\
\text { dentro del grupo }\end{array}$ & $\begin{array}{l}\text { carga } \\
\text { pragmática } \\
\text { añadida }\end{array}$ & $\begin{array}{l}\text { se traduce con slang un segmento } \\
\text { sin slang para compensar la } \\
\text { pérdida de funcionalidad de otros } \\
\text { segmentos. }\end{array}$ \\
\hline 49 & - & - & ampliación & $\begin{array}{l}\text { con marcas } \\
\text { sin transgresión } \\
\text { naturalidad }\end{array}$ & - & $\begin{array}{l}\text { carga } \\
\text { pragmática } \\
\text { añadida }\end{array}$ & $\begin{array}{l}\text { compensa las pérdidas de } \\
\text { funcionalidad en otros segmentos } \\
\text { de esta misma escena }\end{array}$ \\
\hline 50 & $\begin{array}{l}\text { procedimiento sintáctico } \\
\text { variedad según actitud }\end{array}$ & - & modulación & $\begin{array}{l}\text { con marcas } \\
\text { sin transgresión } \\
\text { naturalidad }\end{array}$ & $\begin{array}{l}\text { cambio del registro } \\
\text { lingüístico para } \\
\text { provocar empatía }\end{array}$ & $\begin{array}{l}\text { carga } \\
\text { pragmática } \\
\text { añadida }\end{array}$ & $\begin{array}{c}\text { compensa las pérdidas de } \\
\text { funcionalidad en otros segmentos } \\
\text { de esta misma escena, añadiendo } \\
\text { un slang algo más marcado }\end{array}$ \\
\hline 71 & $\begin{array}{c}\text { procedimiento léxico } \\
\text { semántico }\end{array}$ & formal & $\begin{array}{c}\text { amplificació } \\
n\end{array}$ & $\begin{array}{l}\text { con marcas } \\
\text { sin transgresión } \\
\text { naturalidad }\end{array}$ & $\begin{array}{l}\text { marcar pertenencia } \\
\text { a/identificación con un } \\
\text { grupo o establecer las }\end{array}$ & $\begin{array}{l}\text { carga } \\
\text { pragmática } \\
\text { añadida }\end{array}$ & $\begin{array}{c}\text { la funcionalidad añadida } \\
\text { compensa otros segmentos de la } \\
\text { misma escena }\end{array}$ \\
\hline
\end{tabular}


76

97

variedad según sexo, posición e individuo

procedimiento léxico

$$
\text { formal }
$$

variedad según actitud, posición e individuo

procedimiento léxico semántico y formal

variedad según actitud, posición, sexo e individuo ampliación

equivalente acuñado

creación discursiva

ampliación

equivalente acuñado

reducción y amplificació

$\mathrm{n}$

con marcas formal ampliación sin transgresión naturalidad

con marcas sin transgresión naturalidad

sin marcas naturalidad particulariza

ción particulariza ción

relaciones sociales dentro del grupo

cambio del registro sin transgresión dentro del grupo

añadida
carga
pragmática
añadida
lingüístico para provocar empatía

marcar pertenencia a/identificación con un grupo o establecer las relaciones sociales

pragmática añadida añadida in transgresión naturalidad

$\begin{array}{cc}\begin{array}{c}\text { con marcas } \\ \text { naturalidad }\end{array} & \begin{array}{c}\text { lingüístico para } \\ \text { provocar empatía }\end{array} \\ & \text { marcar pertenencia } \\ \text { con marcas } & \text { a/identificación con un } \\ \text { grupo o establecer las } \\ \text { naturansgresión } & \text { relaciones sociales } \\ \text { naturad } & \text { dentro del grupo }\end{array}$

carga
pragmática
añadida

carga pragmática añadida

\section{carga} pragmática añadida la creación discursiva compensa otros segmentos

el TM, con el apelativo amarillos también pretende mostrar una desvinculación de cierto grupo social

aunque sea una de las primeras intervenciones del personaje, la ampliación no modifica la caracterización del mismo, porque en esta y otras escenas posteriores el discurso del personaje va muy acorde con el estilo de la traducción de este segmento.

el slang marcado en el TM intenta provocar empatía

muestra una actitud desafiante propia del grupo social que usa ese slang. Esto no se advierte en el TO 

semántico

variedad según tema

procedimiento léxico

142

variedad según individuo procedimiento léxico semántico

marcar pertenencia a/identificación con un

181 equivalente acuñado

amplificació

$$
\text { ción }
$$

modulación

particulariza

ción

modulación

creación

discursiva

particulariza

ción grupo o establecer las relaciones sociales dentro del grupo

marcar pertenencia

sin marcas sin transgresión naturalidad

con marcas sin transgresión naturalidad

con marcas a/identificación con un grupo o establecer las relaciones sociales dentro del grupo sgresión naturalidad

con marcas sin transgresión naturalidad con marcas sin transgresión naturalidad con marcas sin transgresión naturalidad

con marcas sin transgresión naturalidad carga pragmática añadida

carga

en el TM el slang es mucho más marcado, algo que hace que se advierta cierta empatía entre los personajes.

la amplificación de mierda se asocia con ciertas actitudes del grupo social que usa ese tipo de slang, algo que no se aprecia en el TO

la modulación permite una traducción muy natural que compense la pérdida de pragmática añadida

carga pragmática añadida

carga pragmática añadida

carga pragmática añadida

carga pragmática añadida funcionalidad de otros segmentos el TM pretende, con más fuerza que el TO, mostrar una actitud asociada con el slang

el TM añade la funcionalidad de querer establecer relaciones sociales mediante el slang

el TM añade la funcionalidad de querer establecer relaciones sociales mediante el slang el equivalente acuñado de cops sería polis, algo que se usa durante todo el largometraje. Con pasma se particulariza el término y se le añade la funcionalidad de mostrar cierta actitud asociada 
procedimiento léxico semántico

231

variedad según individuo, sexo, posición y actitud con marcas

sin transgresión

naturalidad

con marcas

sin transgresión

naturalidad

con marcas

creación $\quad$ sin transgresión

discursiva

particulariza

ción

naturalidad

con marcas

sin transgresión

naturalidad

creación

discursiva

con marcas

sin transgresión

naturalidad

creación

discursiva con marcas

creación

discursiva

sin transgresión

naturalidad

particulariza

ción

modulación

creación con marcas

sin transgresión naturalidad

con marcas

con el slang al segmento

carga

pragmática

añadida

carga

pragmática

añadida

carga

pragmática

añadida

carga

pragmática

añadida

marcar pertenencia

a/identificación con un

grupo o establecer las

relaciones sociales

dentro del grupo carga

pragmática

añadida

carga pragmática añadida

carga

pragmática

añadida

carga se observa una particularización

con el termino cargó que muestra

un slang más marcado

el slang otorga cierta actitud al

personaje que no se muestra en el

$$
\text { TO }
$$

el slang otorga cierta actitud al personaje que no se muestra en el TO

se annade la funcionalidad de establecer relaciones sociales dentro del grupo

la expresión hacerse la picha un lio aporta naturalidad y, si bien resulta un tanto familiarizante, pretende establecer las relaciones sociales dentro del grupo

en el TM se pretende mostrar una actitud asociable a cierto grupo social

\section{compensa otros segmentos}

se advierte una actitud desafiante 
discursiva sin transgresión naturalidad

con marcas

sin transgresión naturalidad

con marcas sin transgresión

naturalidad

con marcas

modulación

modulación

naturalidad

con marcas

ampliación

sin transgresión

naturalidad

con marcas

ampliación

sin transgresión

naturalidad

con marcas

creación

discursiva

\section{- $\quad$ modulación}

sin transgresión pragmática añadida

carga pragmática añadida

carga

pragmática añadida

carga pragmática añadida

carga pragmática añadida

carga pragmática añadida

carga pragmática que muestra la actitud del grupo social de forma más marcada en el TM que en el TO

el TM marca una actitud asociable al slang utilizado que no se marca en el TO. Compensa las reducciones que puede haber en la escena

el slang en el TM pretende crear un vínculo entre los personajes, además de identificarse con un grupo social concreto

una modulación muy pertinente para mantener la naturalidad y no caer en la estrategia extranjerizante de mentar a Dios para quejarse, algo muy propio de la cultura origen

se observa en el TM la intención de transmitir una actitud asociada con el slang. No es una adición de funcionalidad muy significativa, ya que el slang de la escena en general tiene esa

$$
\text { función }
$$

el TM muestra cierta actitud que no se observa en el TO. La adición, sin embargo, es poco significativa.

se observa una intención en el TM de mostrar empatía 


\begin{tabular}{|c|c|c|c|c|c|c|c|}
\hline 312 & - & formal & $\begin{array}{l}\text { creación } \\
\text { discursiva }\end{array}$ & $\begin{array}{c}\text { naturalidad } \\
\text { con marcas } \\
\text { sin transgresión } \\
\text { naturalidad }\end{array}$ & - & $\begin{array}{l}\text { añadida } \\
\text { carga } \\
\text { pragmática } \\
\text { añadida }\end{array}$ & $\begin{array}{c}\text { el TM está más marcado por una } \\
\text { actitud asociable al lenguaje } \\
\text { utilizado }\end{array}$ \\
\hline 314 & - & - & $\begin{array}{l}\text { creación } \\
\text { discursiva }\end{array}$ & $\begin{array}{l}\text { con marcas } \\
\text { sin transgresión } \\
\text { naturalidad }\end{array}$ & - & $\begin{array}{l}\text { carga } \\
\text { pragmática } \\
\text { añadida }\end{array}$ & $\begin{array}{c}\text { el TM muestra una actitud } \\
\text { asociada al slang que no muestra } \\
\text { el TO. }\end{array}$ \\
\hline 339 & - & - & $\begin{array}{l}\text { particulariza } \\
\text { ción }\end{array}$ & $\begin{array}{l}\text { con marcas } \\
\text { sin transgresión } \\
\text { naturalidad }\end{array}$ & - & $\begin{array}{l}\text { carga } \\
\text { pragmática } \\
\text { añadida }\end{array}$ & $\begin{array}{c}\text { se observa en el TM la intención } \\
\text { de transmitir una actitud asociada } \\
\text { al slang }\end{array}$ \\
\hline 346 & - & formal & $\begin{array}{l}\text { creación } \\
\text { discursiva }\end{array}$ & $\begin{array}{l}\text { con marcas } \\
\text { sin transgresión } \\
\text { naturalidad } \\
\text { con marcas }\end{array}$ & - & $\begin{array}{l}\text { carga } \\
\text { pragmática } \\
\text { añadida } \\
\text { carga }\end{array}$ & 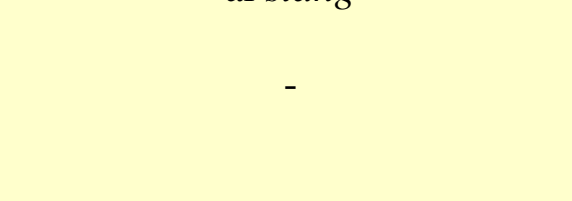 \\
\hline 364 & - & - & ampliación & $\begin{array}{l}\text { sin transgresión } \\
\text { naturalidad }\end{array}$ & - & $\begin{array}{l}\text { pragmática } \\
\text { añadida }\end{array}$ & poco significativa \\
\hline 367 & $\begin{array}{l}\text { procedimiento léxico } \\
\text { semántico y formal } \\
\text { variedad según individuo, } \\
\text { posición y actitud }\end{array}$ & - & $\begin{array}{l}\text { modulación } \\
\text { partuculariz } \\
\text { ación }\end{array}$ & $\begin{array}{l}\text { con marcas } \\
\text { sin transgresión } \\
\text { naturalidad }\end{array}$ & $\begin{array}{c}\text { mostrar cierta actitud } \\
\text { asociada con ese slang } \\
\text { o el grupo que lo utiliza }\end{array}$ & $\begin{array}{l}\text { carga } \\
\text { pragmática } \\
\text { añadida }\end{array}$ & $\begin{array}{c}\text { poco significativa, pero } \\
\text { compensa al segmento anterior }\end{array}$ \\
\hline
\end{tabular}

Tabla 8. Datos extraídos de las muestras en las que el TM presenta carga pragmática añadida 
Estudio descriptivo de la traducción para el doblaje del slang en el largometraje Jackie Brown (Quentin Tarantino, 1997)

\section{Anexo 4: CD-ROM con las versiones original y traducida del \\ largometraje y el trabajo presentado en formato digital}

